RAONI KULESZA

\title{
UMA CAMADA DE ADAPTAÇÃO PARA TRANSMISSÃO DE MÍDIAS DIGITAIS
}

Dissertação apresentada à Escola Politécnica da Universidade de São Paulo para obtenção do Título de Mestre em Engenharia Elétrica

São Paulo

2006 


\title{
RAONI KULESZA
}

\section{UMA CAMADA DE ADAPTAÇÃO PARA TRANSMISSÃO DE MÍDIAS DIGITAIS}

\author{
Dissertação apresentada à Escola \\ Politécnica da Universidade de São \\ Paulo para obtenção do Título de \\ Mestre em Engenharia Elétrica
}

Área de Concentração:

Sistemas Digitais

Orientador:

Profa. Dra. Graça Bressan 
"Tenho pensamentos que, se pudesse revelá-los e fazê-los viver, acrescentariam nova luminosidade às estrelas, nova beleza ao mundo e maior amor ao coração dos homens." (Fernando Pessoa) 
Para mainha, painho e meu "eterno" amigo Júlio César. 


\section{AGRADECIMENTOS}

Muitas pessoas ajudaram para a realização deste trabalho, assim gostaria de dizer, antes de tudo, um Muito Obrigado coletivo, para não esquecer de agradecer ninguém. No entanto, tenho alguns agradecimentos especiais.

À professora Graça Bressan, pela excelente orientação e parceria durante todas as fases deste trabalho (desde o início na aceitação de um menino nordestino recém chegado a São Paulo, até as fases finais quando teve bastante calma para esperar, discutir e revisar os textos de última hora) e ensinamentos (diretos e indiretos) sobre como proceder no desenvolvimento não apenas de um trabalho de pesquisa, mas também no decorrer da vida profissional e pessoal.

À professora Regina Silveira, uma pessoa especial, pelos ensinamentos, companhia e alegria sempre carinhosa no meu dia-a-dia (profissional e pessoal) e imenso entusiasmo e seriedade com que sempre tratou a pesquisa acadêmica, desenvolvimento de projetos e ensino que motivam qualquer pessoa e trabalho.

Ao professor Guido Lemos e sua "super” equipe do LAVID/UFPB pelos valiosos comentários na qualificação e durante reuniões de projetos, que ajudam constantemente na melhoria significativa dos rumos das minhas pesquisas na área de aplicações multimídia.

A todos os professores do DSC/UFCG que me permitiram um excelente curso na graduação, particularmente, Jacques Sauvé na área de redes e engenharia de software.

Ao professor Wilson Ruggiero pela oportunidade de trabalho no LARC que possibilitaram não apenas esse trabalho, mas o aperfeiçoamento da minha formação como pesquisador, profissional e pessoa.

Aos demais professores, amigos e colegas do LARC, em particular àqueles com quem trabalhei diretamente ou convivi lado a lado: Luiz Gustavo, Daniel Pires, Chris Meiler, Caue, Daniela, Marcelo Dutra, Gustavinho, Gustavão, Sérgio Rodrigo, Silvia, Patrícia, Júnior, Lúcio, Edivaldo e Ana Maria. Um agradecimento especial a Huguito pela companhia nas longas jornadas da noite e finais de semana, além das conversas sobre "universos paralelos" no almoço :) e para o Reinaldo, Samuel, Rony e Bruno pela imensa ajuda na reta final deste trabalho. 
Ao Andreas Schrader pelas dicas na implementação do mecanismo de adaptação em processos de transmissão.

Aos funcionários das dependências (biblioteca, CPG, secretaria, lanchonete, segurança) da EPUSP, que diariamente dão condições e muita simpatia que facilitam o desenrolar do trabalho cotidiano.

A todos os amigos da minha segunda família (Marconi, Erick, Gustavo, Gabriel, Pierre, Alexandre, Ericksson, Kiko, Helder e Bruno), que estão longe, mas ao mesmo tempo perto para qualquer apoio.

À minha super menina poderosa Amanda pela força, amor, carinho, paciência e ajuda (inicialmente à distância, mas sempre muito "pertinho" nos últimos seis meses).

Ao meu professor-irmão Uirá pelos ensinamentos, ajuda na área de orientação a aspectos e projeto de software e companheirismo durante toda a minha vida com um carinho e dedicação especial.

Ao meu cunhado-irmão Nandinho e grande amigo Daniel Uchoa pela companhia (normalmente, acompanhadas de discussões e muita cerveja), apoio e paciência para dividirem dias, noites e madrugadas comigo.

À minha irmã Maité que me incentivou a vir para a USP, me acolheu e sempre me faz acreditar que é possível seguir em frente e melhor.

Um agradecimento, mais especial ainda para: meu irmão Yuri, Yasmin, Roberta e a todos da família Kulesza (Vó Anita, Stan, Isabel, Nito, Luana, Bruno, Juliana, Gustavo e Rafaela) e Mitsunaga (Nê, Lica, Sérgio Wallace e Chayenne), que sempre estiveram presente de maneira indireta e direta, com seu carinho e suporte que não permitiram que eu desistisse dessa vocação.

E finalmente, ao meu pai Tek e a minha mãe Tereza, que sempre passaram para mim e meus irmãos o melhor dos seus corações. 


\section{RESUMO}

A convergência da Internet com outras redes (telefonia móvel e televisão digital), o surgimento da computação ubíqua e crescente demanda pela computação autônoma, tem favorecido a existência de um ambiente constantemente modificado e altamente dinâmico, caracterizado pelo tratamento e transporte de conteúdo multimídia, heterogeneidade nos recursos, tecnologias de redes e dispositivos de acesso. Este cenário tem exigido a existência de sistemas adaptativos, ou seja, que tenham a capacidade de se adaptar dinamicamente em resposta a mudanças no contexto em que estão inseridos. O projeto de software de sistemas adaptativos que visem atender de forma satisfatória evolução e mudança neste novo ambiente heterogêneo da Internet tem particular relevância e complexidade. Um dos principais desafios é realizar a implementação de comportamentos adaptativos sem entrelaçamento com outras funcionalidades da aplicação, que podem levar a dificuldade de legibilidade e prejudicar a manutenção do código. Este trabalho procura abordar este tema empregando programação orientada a aspectos na especificação e implementação de uma camada de adaptação que atua sobre aplicações multimídia em rede utilizando abordagens de adaptação baseados em servidor. Em particular, através do uso da linguagem AspectJ, é mostrado como promovemos a separação do interesse de adaptabilidade de forma modular para permitir que a camada de adaptação realize configuração estática e dinâmica de processos de transmissão de fluxos multimídia a partir de mecanismos de monitoração do seu ambiente de operação.

Palavras-chave: aplicações multimídia em rede, adaptação, projeto de sistemas adaptativos, programação orientados a aspectos, separação de interesses. 


\section{ABSTRACT}

The convergence of the Internet with other networks (e.g. Mobile Telecom and Digital Television Networks), the ubiquitous computing raising and the increasing demand on the autonomic computing has favored the existence of a constantly modified and highly dynamic environment. It is characterized by the treatment and transport of multimedia content and resources, network technologies and access devices heterogeneity. This scenario has demanded the existence of adaptive systems, which has the capacity to dynamically adapt based on the context where they are inserted. The software design for adaptive systems, which aim to deal on a satisfactory way the evolution and changes in this new heterogeneous Internet environment, has particular relevance and complexity. One of the main challenges is performing the development of adaptive behaviors without tangled and scattered code along other application functionalities, which could result in code legibly problems, affecting its maintenance. The main purpose of this work is the specification and development of an adaptation layer working in multimedia networked application and using server based adaptation approach, making use of aspect oriented programming. Specifically, through the adoption of the AspectJ language it was showed how the adaptability concern was well modularized by enabling the adaptation layer to perform static and dynamic configuration of the multimedia chains through the monitoring of its operational environment.

Keywords: multimedia networked application, adaptation, adaptive software design, aspect oriented programming, separation of concerns. 


\section{SUMÁRIO}

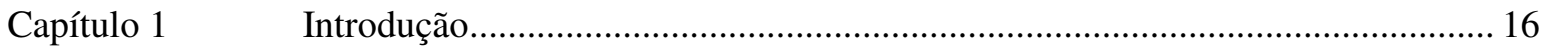

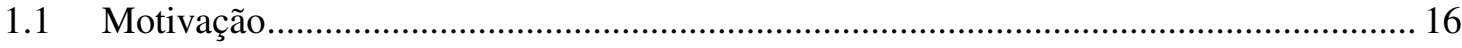

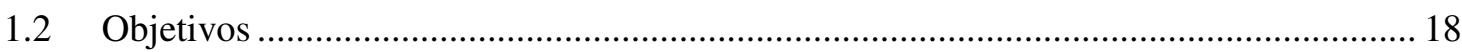

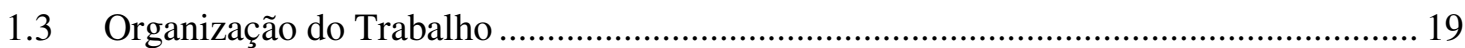

Capítulo 2 Aplicações Multimídia em Rede …...................................................................... 20

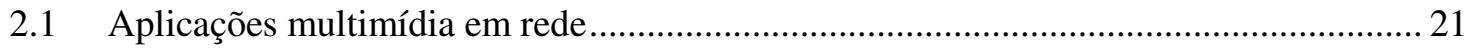

2.1.1 Aplicações Multimídia baseada em Servidores .............................................. 23

2.1.1.1 Aplicação de Transmissão de Vídeo Sob Demanda ........................ 24

2.1.1.2 Aplicação de Transmissão de Vídeo ao Vivo .................................. 25

2.2 Qualidade de Serviço em Aplicações Multimídia em Rede .............................................. 25

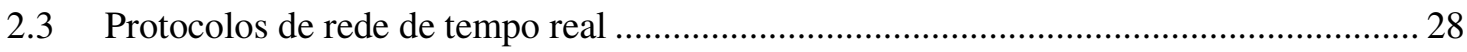

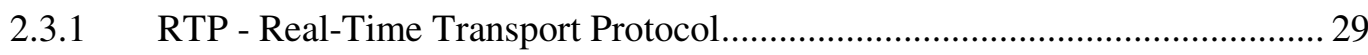

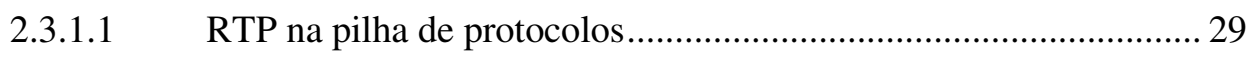

2.3.1.2 Uma nova abordagem para protocolos ......................................... 31

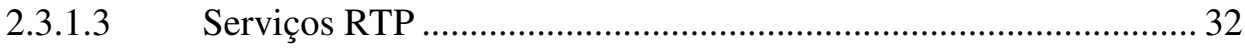

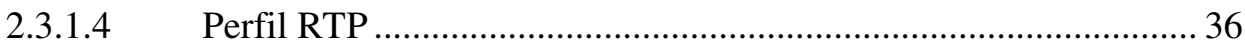

2.3.2 RTCP - Real-Time Control Protocol …………............................................. 36

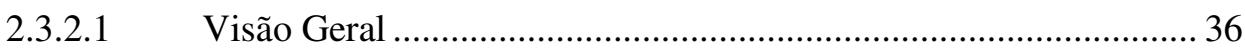

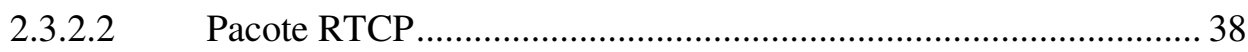

2.3.3 RTSP - Real-Time Streaming Protocol............................................................ 39

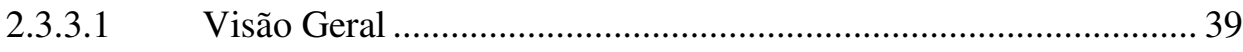

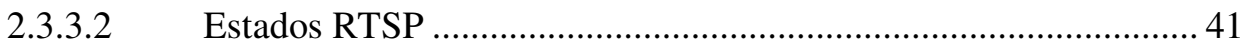

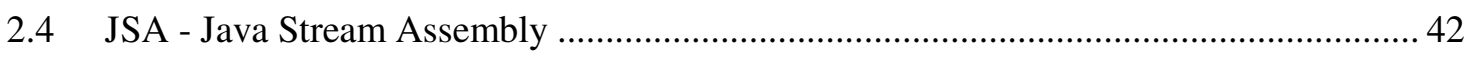

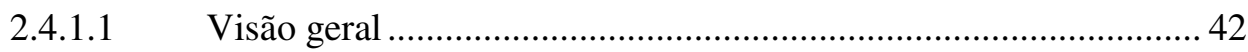

2.4.1.2 Arquitetura da JSA.................................................................... 44

2.4.1.3 Principais conceitos da JSA ........................................................... 46 
2.5 Requisitos Tecnológicos das Aplicações Multimídia em Rede

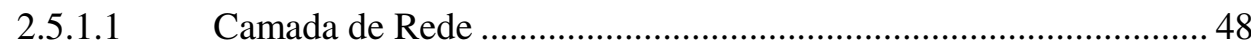

2.5.1.2 Camada de Transporte …........................................................... 49

2.5.1.3 Camada de Codificação e de Sincronização ..................................... 49

2.5.1.4 Camada de Integração de Aplicação................................................ 49

Capítulo $3 \quad$ Técnicas de Adaptação em Software ...................................................................... 50

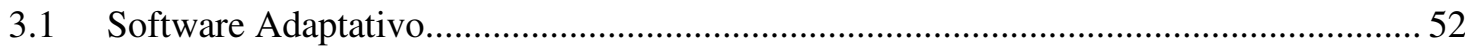

3.2 Técnicas de Projeto de Software Adaptativos ....................................................................... 55

3.2.1 Software Baseado em Componentes................................................................ 55

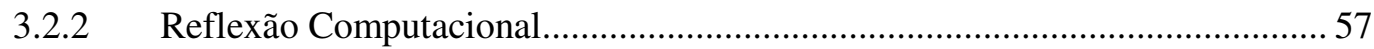

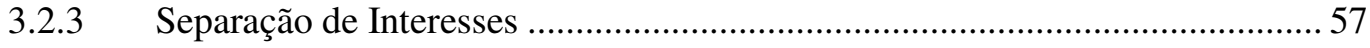

3.2.4 Outras técnicas para adaptação por composição.................................................59

3.3 Programação Orientada a Aspectos.................................................................................. 59

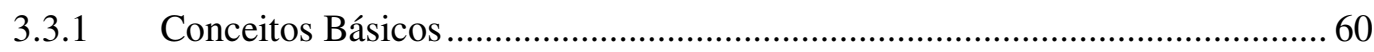

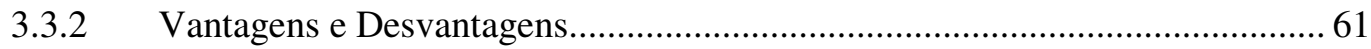

3.3.3 AspectJ

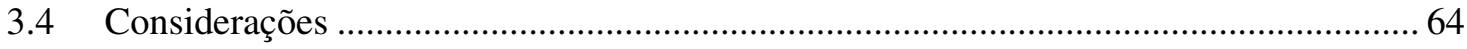

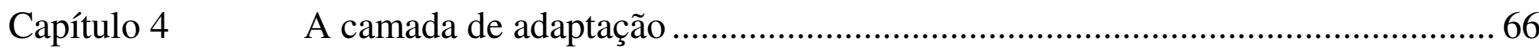

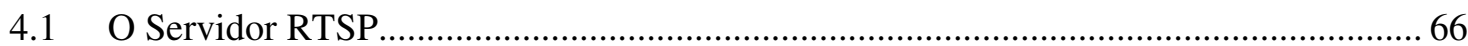

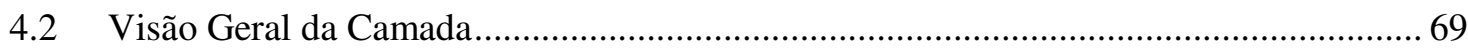

4.2.1 Módulo de Configuração ............................................................................ 71

4.2.2 Módulo de Monitoração................................................................................... 71

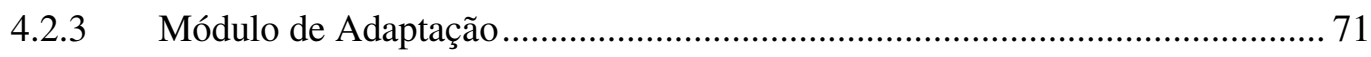

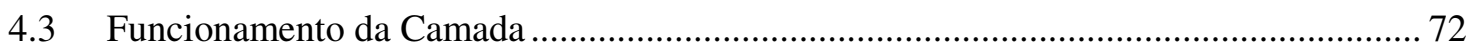

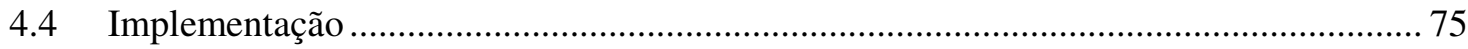

4.4.1 Módulo de adaptação ..................................................................................... 77

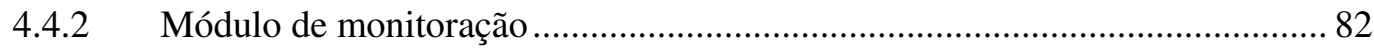

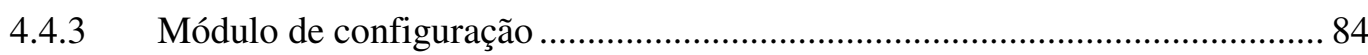




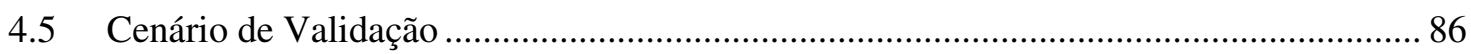

4.5.1 Mecanismo para monitoração do ambiente de execução.................................... 86

4.5.2 Mecanismo para monitoração das sessões ...................................................... 87

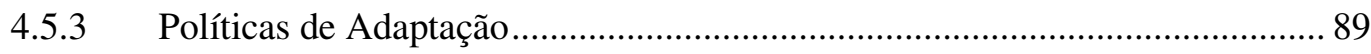

4.5.3.1 Mudança da taxa de transmissão com mudança de codificação .... 89

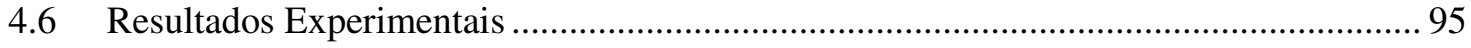

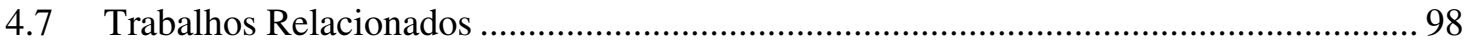

4.7.1 Uma Camada de Suporte à QoS para Aplicações Multimídia na Internet....... 98

4.7.2 DynaVideo - Um Serviço de Distribuição de Vídeo baseado em Configuração Dinâmica .99

4.7.3 APSL - Adaptation Proxy Specification Language .......................................... 99

4.7.4 Multimedia synchronization based on AOP .............................................. 100

4.7.5 ARE - Adaptative Runtime Enviroment ...................................................... 100

4.7.6 Adaptative QoS Mechanism for Multimedia Applications in Heterogeneous Environment. 101

4.7.7 Structuring Adaptive Applications using AspectJ ....................................... 101

4.8 Resumo comparativo com trabalhos relacionados ................................................... 102

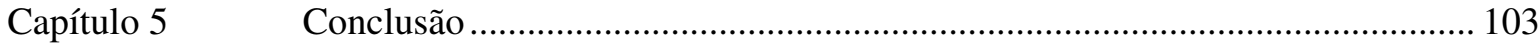

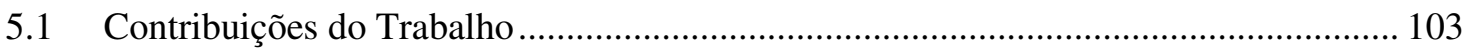

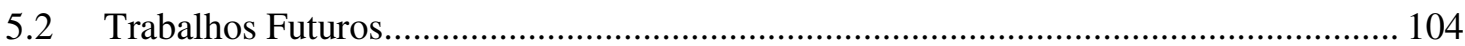

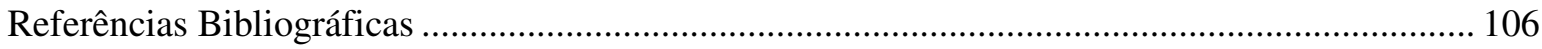

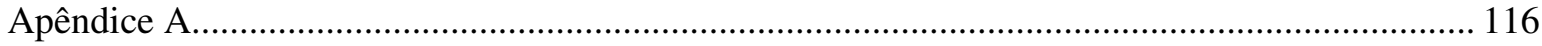

Modelo Analítico para Adaptação de Processos de Transmissão de Mídias .................................... 116

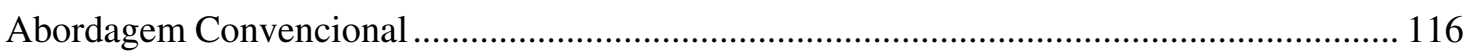

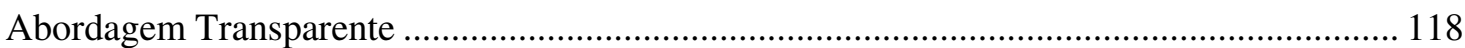




\section{LISTA DE FIGURAS}

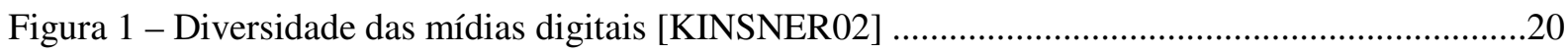

Figura 2 - Taxonomia de Aplicações Multimídia em Rede ..................................................................23

Figura 3 - a) Posição do RTP na pilha de protocolos. b) Encapsulamento RTP [TANEMBAUM_03]30

Figura 4 - Exemplo do uso de timestamps para minimizar o jitter …......................................................34

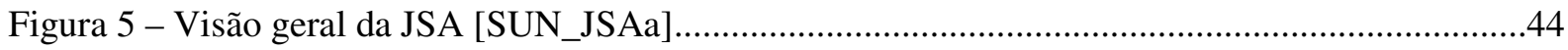

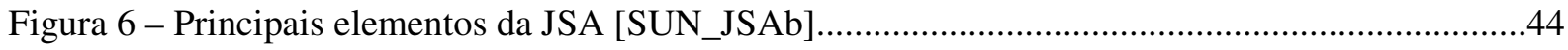

Figura 7 - Hierarquia de componentes do plano de dados da JSA [SUN_JSAa] ..................................47

Figura 8 - Modelo de camadas das aplicações multimídia baseado em servidores ................................48

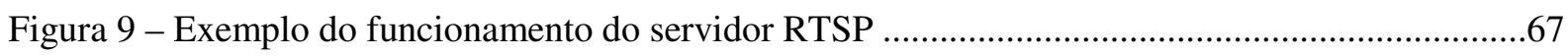

Figura 10 - Diagrama de classes do Servidor RTSP..........................................................................68

Figura 11 - Visão Geral da Camada de Adaptação................................................................................

Figura 12 - Cenário de configuração estática da Camada de Adaptação................................................74

Figura 13 - Cenário de configuração dinâmica da Camada de Adaptação.............................................75

Figura 14 - Projeto detalhado da camada de adaptação no servidor RTSP ..........................................76

Figura 15 - Detalhamento do Módulo de Monitoração ..........................................................................83

Figura 16 - Exemplo de Processos de Transmissão de Mídias Paralelos ...............................................90

Figura 17 - Modo Sequencial de Adaptação de Processo de Transmissão de Fluxos de Mídias ...........92

Figura 18 - Modo Transparente de Adaptação de Processo de Transmissão de Fluxos de Mídias .......93

Figura 19 - Transmissão com simulação de taxa de perdas e sem adaptação........................................97

Figura 20 - Transmissão com simulação de taxa de perdas e adaptação sequencial ..............................97

Figura 21 - Transmissão com simulação de taxa de perdas e adaptação transparente ...........................98

Figura 22 - Adaptação convencional de processos de transmissão de mídia através da construção

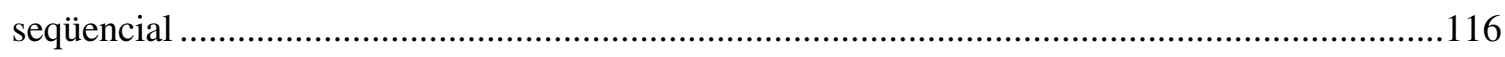

Figura 23 - Adaptação transparente de processos de transmissão de mídia através da construção simultânea. 


\section{LISTA DE TABELAS}

Tabela 1 - Características e requisitos de transporte das diversas mídias [LUNARDI01] ....................27

Tabela 2 - Tipos de payload para codificações de áudio .......................................................................36

Tabela 3 - Resumo comparativo dos esquemas de adaptação em aplicações multimídia em rede.........51

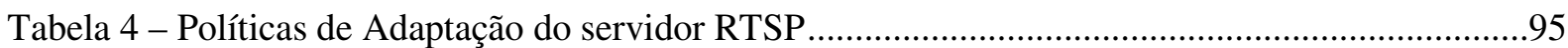

Tabela 5 - Resumo comparativo dos trabalhos relacionados.............................................................102 


\section{LISTA DE ABREVIATURAS}

$\begin{array}{ll}\text { AOP } & \text { Aspect Oriented Proggramming } \\ \text { API } & \text { Application Program Interface } \\ \text { APSL } & \text { Adaptation Proxy Specification Language } \\ \text { ATM } & \text { Asynchronous Transfer Mode } \\ \text { CLOS } & \text { Common Lisp Object System } \\ \text { CORBA } & \text { Common Object Request Broker Architeture } \\ \text { DCOM } & \text { Distributed Component Object Model } \\ \text { DiffServ } & \text { Differentiated services } \\ \text { DRM } & \text { Digital Rights Management } \\ \text { DSM-CC } & \text { Digital Storage Media - Command and Control } \\ \text { DSOO } & \text { Desenvolvimento de Software Orientado a Objetos } \\ \text { DTD } & \text { Data Type Definition } \\ \text { FTP } & \text { File Tranfer Protocol } \\ \text { HTML } & \text { Hypertext Markup Language } \\ \text { IETF } & \text { Internet Engineering Task Force } \\ \text { IP } & \text { Internet Protocol } \\ \text { IPTV } & \text { Internet Protocol Television } \\ \text { ISO } & \text { International Organization for Standardization } \\ \text { ITU } & \text { International Telecommunication Union } \\ \text { JMF } & \text { Java Media Framework } \\ \text { JNI } & \text { Java Native Interface } \\ \text { JSA } & \text { Java Stream Assembly } \\ \text { J2SE } & \text { Java 2 Platform Standard Edition } \\ \text { LDAP } & \text { Lightweight Directory Access Protocol } \\ \text { MPEG } & \text { Moving Picture Experts Group } \\ \text { MPLS } & \text { Multiprotocol Label Switching } \\ \text { PCIM } & \text { Policy Core Information Model } \\ \text { POA } & \text { Programação Orientada a Aspectos } \\ \text { QoS } & \text { Qualidade de Serviço } \\ \text { RFC } & \text { Request for Comments } \\ \text { RMI } & \text { Remote Method Invocation } \\ \text { RSVP } & \text { Resource Reservation Protocol } \\ \text { RTtrol Protocol }\end{array}$




$\begin{array}{ll}\text { RTP } & \text { Real-Time Protocol } \\ \text { RTSP } & \text { Real-Time Streaming Protocol } \\ \text { SDP } & \text { Session Description Protocol } \\ \text { SGML } & \text { Standard markup Language } \\ \text { SIP } & \text { Session Initiation Protocol } \\ \text { TCP } & \text { Transport Control Protocol } \\ \text { TS } & \text { Tranport Stream } \\ \text { UDP } & \text { User Datagram Protocol } \\ \text { VCR } & \text { Video Cassette Recorder } \\ \text { W3C } & \text { World Wide Web Consortium } \\ \text { XML } & \text { eXtensible Markup Language } \\ \text { XSD } & \text { W3C XML Schema }\end{array}$




\section{Capítulo 1}

\section{Introdução}

Desde o início das experiências do projeto ARPANET em 1969 as redes de comunicação de dados, particularmente a Internet, estão em constante mudança visando atender a demanda de uma gama crescente de novos serviços que são disponibilizados a cada dia. Os conteúdos estáticos estão dando lugar para conteúdos dinâmicos, imagens e fotos estão sendo substituídos por vídeos, textos são substituídos por música ou por voz e os serviços de vídeo e áudio com interação e melhor qualidade começam a se tornar viáveis [PERKINS03].

Esses serviços, conhecidos como aplicações multimídia em rede, possuem peculiaridades que os distinguem dos serviços tradicionais orientados a dados, dentre as principais estão: grande volume de dados, dependência temporal e necessidades de sincronização [STEINMETZ95]. Conseqüentemente, essas diferenças trazem novos requisitos, desafios e avanços na infra-estrutura de redes e engenharia de sistemas.

Podemos citar como principais avanços na infra-estrutura de redes e engenharia de sistemas nos últimos anos: (i) o aperfeiçoamento das técnicas de compressão de mídias,; (ii) melhorias das técnicas de transmissão digital no meio físico (fibra ótica); (iii) o custo decrescente de armazenamento e processamento nos sistemas finais; (iv) a disseminação de novas tecnologias com maior largura de banda para o usuário final; (v) a utilização de servidores de armazenamento intermediários; (vi) o emprego de novos protocolos orientados à qualidade de serviço [KUROSE03]; e (vii) a convergência da rede Internet com outras redes (telefonia móvel e televisão digital) que favorecem, através de maior mobilidade de acesso e presença, a computação móvel e ubíqua.

\subsection{Motivação}

Através do cenário descrito na seção anterior é possível identificar a existência de um ambiente constantemente modificado e altamente dinâmico, caracterizado pelo tratamento e 
transporte de conteúdo com várias mídias (áudio, vídeo e texto) e heterogeneidade nos recursos, tecnologias de redes e dispositivos de acesso, que estimula o desenvolvimento de sistemas de software com requisito de adaptabilidade. Particularmente, esse requisito tem sido apontado com um dos grandes desafios da computação ubíqua, uma área de interesse crescente atualmente e que demanda arquiteturas flexíveis e configuráveis para suportar um ambiente altamente heterogêneo [LYYTINEN02].

$\mathrm{O}$ requisito de adaptabilidade tem sido usado para referenciar sistemas de software adaptável e adaptativo. Frequentemente as palavras adaptável e adaptativo são usadas de forma intercambiável, entretanto, quando usadas em conjunto, elas podem apresentar diferentes significados [DANTAS04a]. Um sistema adaptável pode ser definido como: "um sistema que permite adaptar facilmente uma estrutura completa ou partes específicas devido a mudanças nos requisitos" [TEKINER97]. Já um sistema é dito adaptativo se é capaz de mudar seu comportamento automaticamente, durante sua execução, de acordo com mudanças no contexto do ambiente em que está situado [LIEBERHERR95].

Nesse contexto, adaptabilidade está totalmente relacionada à auto-adaptação, ou simplesmente software adaptativo, o qual modifica seu próprio comportamento em resposta às mudanças em seu ambiente de operação [PEYMAN99]. Para alcançar esse requisito, um dos grandes desafios atualmente é atender o requisito de adaptabilidade e concomitantemente prover manutenibilidade desses sistemas. Prover flexibilidade muitas vezes conduz a um código que é difícil de entender e isso conduz a uma manutenibilidade ruim, especialmente quando um comportamento adaptável deve mudar, ou um novo deve ser incluído. O tipo de manutenção que procura adicionar novas ou alterar funcionalidades já existentes num sistema de software é conhecida como manutenção adaptativa [LIENTZ78].

O projeto de sistemas adaptáveis e adaptativos que visem atender de forma satisfatória a evolução e mudança do software neste novo ambiente heterogêneo da Internet tem particular relevância, complexidade e existem muitos pontos que devem ser considerados no desenvolvimento dessa categoria de software. Este trabalho procura abordar esse tema através do estudo e aplicação de técnicas de projetos de sistemas adaptativos no contexto do 
desenvolvimento de uma aplicação multimídia de rede. Em particular, será dada ênfase especial para técnicas baseadas na abordagem de programação orientação a aspectos (POA).

Adicionalmente, o presente trabalho está inserido no contexto das atividades de pesquisa e desenvolvimento na área de aplicações multimídia do Laboratório de Arquitetura e Redes de Computadores (LARC) da Escola Politécnica da Universidade de São Paulo (EPUSP) e busca contribuir para o desenvolvimento de resultados que auxiliem atividades do grupo.

\subsection{Objetivos}

O principal objetivo deste trabalho é a especificação e desenvolvimento de uma camada de adaptação para aplicações multimídia baseada em servidores utilizando AspectJ [KICZALES01a], uma extensão orientada a aspectos da linguagem de programação Java [GOSLING00]. Esta camada atua sobre processos de transmissão de fluxos de mídias digitais de tempo real ${ }^{1}$, viabilizando a realização de mudanças dinâmicas para melhorar a entrega do conteúdo multimídia para o usuário final de acordo com a monitoração do seu ambiente de operação.

Atualmente, as principais abordagens para oferecer suporte ao desenvolvimento e implantação de aplicações, atendendo a requisitos de adaptabilidade, manutenção adaptativa e atendimento a requisitos não-funcionais ${ }^{2}$, utilizam técnicas como reflexão, arquiteturas baseada em notificação de eventos e meta-nível [TRIPATHI02, KON02, AGHA02, VENKATASUBRAMANIAN02]. Nestes casos, plataformas de software (middleware) acompanhadas de frameworks completos são utilizadas com o propósito de fornecer características de adaptação desde o nível do sistema operacional, até o nível do usuário. Essas plataformas são propostas para dar suporte ao desenvolvimento de aplicações (normalmente,

\footnotetext{
${ }^{1} \mathrm{O}$ termo tempo real nesta dissertação é utilizado para definir que o usuário recebe um fluxo contínuo quase instantaneamente, com um mínimo atraso - e que a duração do fluxo transmitido e recebido é exatamente a mesma.

${ }^{2}$ Requisitos não-funcionais abrangem requisitos de suporte à operação (e.g., processador e memória), requisitos de qualidade de serviço (QoS), tradicionalmente ligados à redes de computadores, e quaisquer recursos (e.g., streamers e codecs) ou qualidades (e.g., tolerância a falhas e segurança) não necessariamente ligadas às funções essenciais da aplicação.
} 
aplicações distribuídas) de um determinado domínio, implicando numa alta complexidade para a utilização, entendimento e manutenibilidade dessas soluções. Neste trabalho utilizamos técnicas de projeto baseadas em abordagens orientadas a aspectos para projetar e implementar uma camada de adaptação que possibilite a construção de sistemas adaptativos para transmissão de fluxos multimídia e, ao mesmo tempo, possibilite compreensão e manutenção de forma simplificada.

Para alcançar o objetivo proposto, foi necessário inicialmente um entendimento das principais aplicações multimídia em rede e estudo de técnicas de projeto de software adaptável no domínio de aplicações multimídia em rede. Após essas investigações, foi especificada e implementada uma camada de adaptação utilizando POA e AspecJ. A camada fornece serviços de adaptação para processos de transmissão de fluxos multimídia e pode ser configurada para atuar de diferentes formas a partir de políticas de monitoração e adaptação. Por fim, foram realizados testes para avaliar o funcionamento correto e desempenho das funcionalidades de adaptação do sistema.

\subsection{Organização do Trabalho}

O presente trabalho está organizado em cinco capítulos. Neste capítulo foram apresentados o contexto no qual se insere o trabalho, a motivação, os objetivos e a metodologia. O capítulo dois aborda alguns aspectos conceituais e desafios das aplicações multimídia em rede. No capítulo três são definidos os conceitos de adaptação no contexto de aplicações multimídia em rede e apresentadas as principais técnicas de projeto de software adaptativo estudadas, dando ênfase especial para a abordagem e tecnologia utilizada no trabalho, o paradigma de orientação a aspectos e a linguagem AspectJ. O capítulo quatro descreve a arquitetura, os principais módulos, a implementação e os cenários de validação para a camada proposta, bem como uma análise comparativa com trabalhos relacionados. O capítulo cinco conclui o trabalho, ressaltando as considerações finais, principais contribuições e perspectivas futuras. Em acréscimo, seguem as referências bibliográficas e um apêndice com detalhes sobre os mecanismos de adaptação utilizados. 


\section{Capítulo 2}

\section{Aplicações Multimídia em Rede}

O termo multimídia refere-se a uma diversidade de classes de mídias utilizadas para representar informação. A Figura 1 exibe exemplos de mídias classificadas em três grupos: (i) texto, (ii) imagens e (iii) áudio.

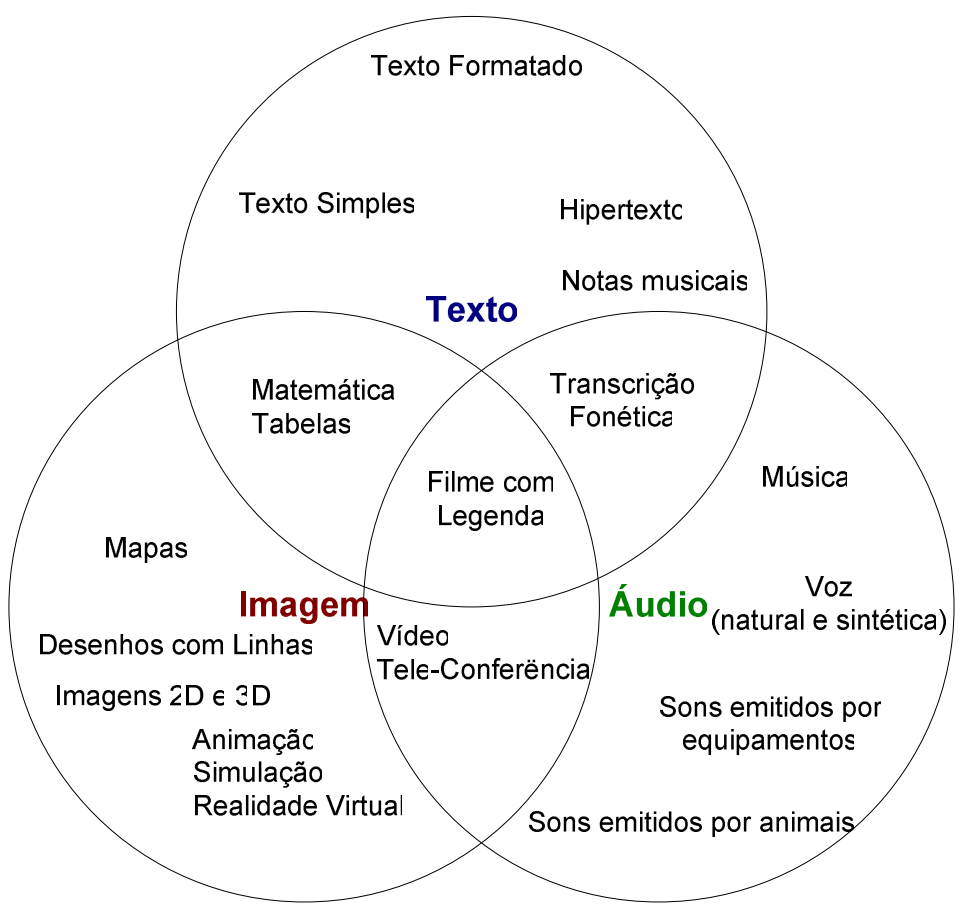

Figura 1 - Diversidade das mídias digitais [KINSNER02]

Como ilustrado na Figura 1, texto pode ser representado não apenas pelos símbolos dos alfabetos mais conhecidos, mas também por caracteres especiais, expressões matemáticas, transcrições fonéticas da voz, notas musicais e outras representações simbólicas mais recentes, como o hipertexto. Imagens normalmente são representações visuais definidas por uma forma (dimensões) e um conjunto de cores, através de um grupo de linhas, pontos de diversas cores, mapas, fotografias, etc. O termo vídeo baseia-se na exibição de uma sequiência de imagens num determinado intervalo de tempo, gerando a impressão de movimento ao observador. Podemos citar como exemplo de vídeos: desenhos animados, simulações, representação de objetos de 
realidade virtual, filmes, etc. A mídia áudio pode ser representada pela voz humana, sons emitidos por instrumentos musicais, sinais biológicos e etc.

Adicionalmente, as mídias também podem ser classificadas em outras duas categorias: (i) mídias contínuas e (ii) discretas. As mídias contínuas ou dependentes do tempo, frequentemente representadas por áudio e vídeo, são aquelas em que o tempo faz parte da semântica da apresentação, ou seja, seus significados dependem da ordem em que são apresentados. Por outro lado, mídias discretas não possuem esta relação no tempo e, tradicionalmente, utilizam texto, gráficos ou imagens estáticas.

Outros sentidos da percepção humana, tais como tato e olfato também podem ser considerados como multimídia, mas não fazem parte do escopo deste trabalho. Também trataremos exclusivamente de mídias digitais no domínio de sistemas computacionais, empregando o termo conteúdo multimídia ou mídia digital no restante do texto para representar esse conceito.

\subsection{Aplicações multimídia em rede}

Segundo [KUROSE03], aplicações multimídia em rede podem ser definidas como aplicações que transmitem e/ou recebem conteúdo multimídia (texto, imagem e áudio) através de uma rede de comunicação de dados. Isso implica que uma aplicação multimídia em rede necessita, além do sistema computacional (local) que exibe ou difunde o conteúdo, de um ou mais sistemas remotos interconectados através de uma rede de dados. Duas razões justificam a utilização de sistemas remotos: (i) quando a aplicação tem o objetivo genuinamente de comunicação (por exemplo, uma aplicação de vídeo conferência) ou quando existem (ii) motivos técnicos ou financeiros (por exemplo, uma aplicação de biblioteca multimídia digital) [FLUCKIGER95].

Neste ambiente, a ITU (International Telecommunication Union) define uma taxonomia [ITU_I211], amplamente utilizada pela comunidade científica e indústria, que divide em quatro categorias as aplicações multimídia em rede: 
- Serviços conversacionais: implicam em aplicações com interação entre usuários e presença simultânea dos mesmos. Assim, essa classe inclui aplicações interpessoais tais como: vídeo conferência e voz sobre IP.

- Serviços de mensagens: abrangem aplicações para troca de mensagens assíncronas entre usuários e utilizando entidades de armazenamento. Podemos citar como exemplo: correio eletrônico com mensagens de áudio ou vídeo.

- Serviços de recuperação: cobrem todos os tipos de aplicações que envolvem acesso a um servidor ${ }^{3}$ para consumo de conteúdo multimídia. Caracteristicamente, uma entidade cliente (representada por um usuário) envia um pedido para uma entidade servidora que realiza um processamento (por exemplo, autorização de acesso e busca) para iniciar a entrega do conteúdo multimídia. Vídeo sob demanda é um exemplo deste tipo de serviço.

- Serviços de distribuição: incluem serviços onde o conteúdo multimídia é distribuído através da iniciativa de um servidor. Esta classe ainda é subdividida em dois tipos: (i) sem controle de apresentação pelo usuário, que é caso das transmissões de fluxos contínuos (streaming) de vídeos ao vivo pela Internet; e (ii) com controle de apresentação pelo usuário, que é o caso da TV Digital Interativa.

Na figura abaixo ilustramos um resumo da relação entre uma rede de comunicação, as mídias e suas aplicações (serviços) multimídia.

\footnotetext{
${ }^{3} \mathrm{O}$ termo servidor empregado neste trabalho baseia-se do conceito de aplicação cliente-servidor de [HALL94], que define que uma arquitetura cliente/servidor é utilizada para dividir tarefas entre duas entidades. Basicamente, o cliente realiza uma requisição de tarefa(s) ao servidor, através de uma rede de comunicação, que então a(s) processa e retorna os resultados ao cliente.
} 


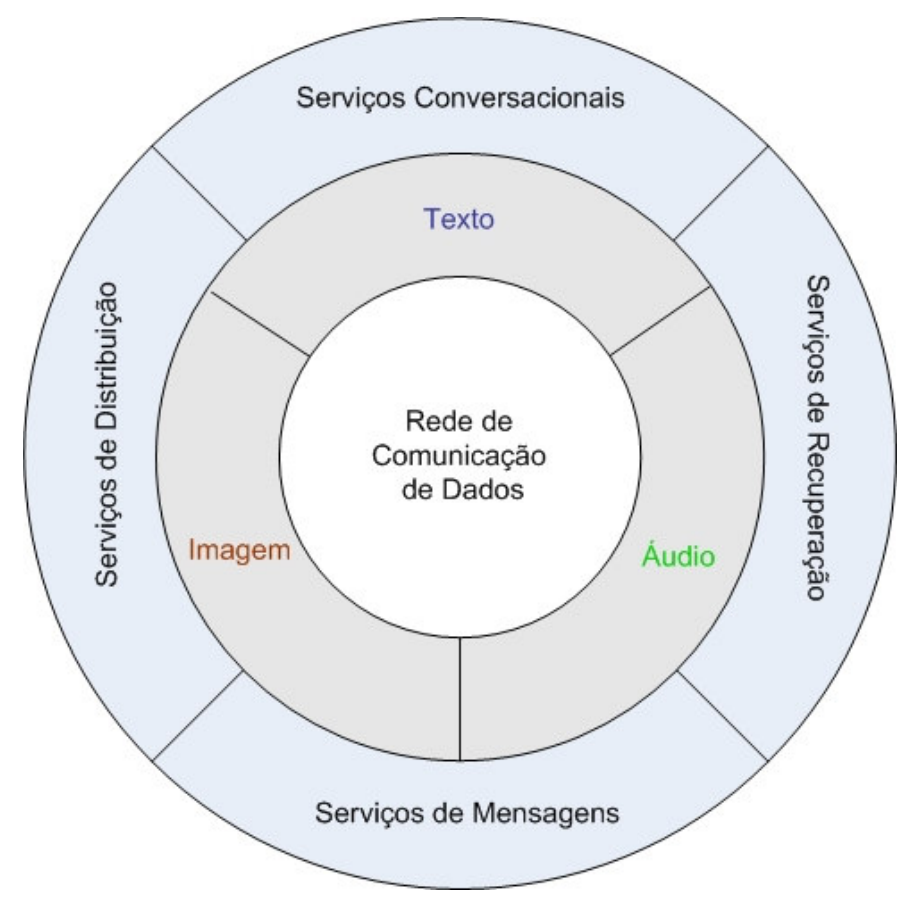

Figura 2 - Taxonomia de Aplicações Multimídia em Rede

\subsubsection{Aplicações Multimídia baseada em Servidores}

Aplicações multimídia baseada em servidores podem ser definidas como aplicações multimídia em rede cujo objetivo não é a comunicação entre usuários, mas a comunicação entre usuário-sistema [FLUCKIGER95]. Desde que este sistema seja apoiado por hardware e software específicos e possam servir a uma variedade de funções, eles são chamados de servidores. Dividimos esse tipo de sistema em duas classes:

- Servidores interativos: o sistema age como um conjunto de funcionalidades que o usuário acessa remotamente, tais como: busca, recuperação e armazenamento de conteúdo multimídia. Normalmente, também podem oferecer interatividade remota com mecanismos de controle de reprodução e permissões de acesso sobre o conteúdo, suporte a transações comerciais e etc. O fato mais importante é que em todos os casos a entidade que inicia a comunicação é o usuário. Exemplos desse tipo de sistema se enquadram em serviços de recuperação, de acordo com taxonomia apresentada na seção anterior.

- Servidores de distribuição: o sistema distribui diretamente informações para todo um conjunto de usuários ou apenas para um subconjunto selecionado, utilizando 
mecanismos de difusão. Os usuários podem ou não ter alguma forma individual de controle sobre a apresentação local. Os serviços de distribuição são exemplos desse tipo de sistema.

Como exemplo dessas duas classes de sistemas, pretendemos descrever com mais detalhes nas próximas seções duas aplicações que pretendemos utilizar como base para especificação e implementação da camada de adaptação: (i) vídeo sob demanda e (ii) vídeo ao vivo (transmissão de fluxo contínuo) que, respectivamente, utilizam servidores interativos e de distribuição.

\subsubsection{Aplicação de Transmissão de Vídeo Sob Demanda}

O ATM Fórum [ATMFORUM96] define este tipo de sistema da seguinte maneira: "Serviço assimétrico que envolve várias conexões, transferindo informações de vídeo digital, comprimido e codificado, de um servidor (tipicamente um servidor de vídeo), para um cliente (tipicamente um terminal de acesso multimídia ${ }^{4}$ ou um computador pessoal). No destino o vídeo é descomprimido, decodificado e apresentado em um monitor ou em algum outro equipamento equivalente".

Quando um vídeo sob demanda é transmitido, o grau de interatividade que o cliente pode ter varia desde a difusão tradicional, que não oferece nenhuma interação ao usuário (consumo passivo, onde não existe a possibilidade nenhuma intervenção na exibição do conteúdo), até sistemas totalmente interativos (consumo ativo, onde é possível ter acesso randômico à transmissão inteira e saltar para qualquer ponto desejado do conteúdo, semelhante as operações de um vídeo cassete).

Além dos requisitos normalmente exigidos da estrutura de rede das aplicações multimídia em rede (largura de banda, sincronismo de mídia, taxa de entrega constante, tempo de resposta mínimo e etc.), um dos grandes desafios no desenvolvimento desse tipo de serviço, devido ao grande volume de dados armazenados e processados de conteúdo, encontra-se na

\footnotetext{
${ }^{4} \mathrm{O}$ termo original utilizado na referência é set-top box.
} 
disponibilidade dos recursos (memória, CPU, barramentos, interface de rede, etc.) da(s) máquina(s) que atente às solicitações [MA02].

\subsubsection{Aplicação de Transmissão de Vídeo ao Vivo}

Uma aplicação de vídeo ao vivo ou transmissão fluxo contínuo de mídia, como o próprio nome explica, é um sistema de entrega de mídias contínuas através de um fluxo de bits que pode ser utilizado para transmissão de áudio, vídeo e dados a partir de uma fonte [KOZAMERNIK02]. Essa fonte poderia ser qualquer dispositivo que captura um evento (por exemplo, um microfone ou webcam) e no mesmo instante repassa seu conteúdo para um servidor transmitir para os clientes do serviço.

Diferente de um serviço sob demanda, numa aplicação de fluxo contínuo, a transmissão funciona mais ou menos como uma versão para a Internet de uma transmissão de TV ou rádio, os usuários podem ligar, desligar e mudar de canal, mas o conteúdo é visto a partir do ponto que a transmissão é enviada.

O fato de existir a necessidade de entrega em tempo real e a possibilidade de o usuário acessar uma transmissão de conteúdo multimídia em qualquer ponto da mesma (ao contrário do acesso a um arquivo de um serviço de vídeo sob-demanda) cria a necessidade do envio de segmentos de controle para viabilizar a sincronização do fluxo multimídia (que pode conter elementos de texto, áudio e vídeo), através de protocolos de transporte (por exemplo, RTP[RFC3550]) ou mecanismos de sinalização que definem sintaxe e semântica dos fluxos em que as mídias são multiplexadas (por exemplo, MPEG-2 System[MPEG00]).

\subsection{Qualidade de Serviço em Aplicações Multimídia em}

\section{Rede}

Em uma aplicação multimídia em rede existem, numa visão simples, dois grandes grupos de requisitos de qualidade de serviço: (1) requisitos de comunicação e (2) requisitos do sistema de processamento e transmissão propriamente dito. O primeiro é inerente à rede e aos equipamentos e tecnologias envolvidas entre a transmissão e recepção e diz respeito a características das camadas física, enlace, rede e transporte da arquitetura TCP/IP. O segundo é 
inerente à construção de um sistema na camada de aplicação com suporte a (i) tratamento (armazenamento, codificação e sincronização) do conteúdo multimídia e (ii) adaptação sensível ao contexto de um ambiente de rede fim-a-fim dinâmico e heterogêneo. Sem negar a importância dos outros requisitos, este trabalho concentra-se no problema da capacidade de adaptação descrita em (ii), particularmente num ambiente de rede como a Internet.

A Internet tem sido utilizada, desde seu surgimento, para transmissão confiável de dados sem garantias de atraso, variação de atraso ou largura de banda. Contudo, as diferenças das aplicações multimídia de rede que estão surgindo na Internet em relação às aplicações tradicionais orientadas a dados discretos (não dependentes do tempo), trazem novas características e requisitos de tráfego para a rede de comunicação, tais como: (i) maior capacidade de processamento e armazenamento (ii) disponibilidade de maior largura de banda (iii) menor atraso fim a fim (iv) baixa variação de atraso [KUROSE03]. Esse conjunto de requisitos e seus respectivos parâmetros são normalmente expressos pelo termo qualidade de serviço (QoS) [VOGEL95].

Além de requisitos impostos a rede de comunicação, o conceito de QoS também pode ser aplicado a um conjunto de requisitos impostos no nível de aplicação, onde exige-se que determinados parâmetros (denominados parâmetros de QoS) relativos à, por exemplo, aplicações de transmissão de fluxo contínuo, estejam dentro de limites bem definidos (valor máximo, valor mínimo). Os requisitos de QoS no nível de aplicação devem ser atendidos pelo ambiente de execução da aplicação, principalmente quando se trata de aplicações de natureza multimídia distribuída. Estes requisitos são representados pela quantidade de recursos (memória, CPU, dispositivos de áudio e vídeo etc.) disponíveis no sistema final, que devem ser alocados para as aplicações multimídia, podendo assim garantir qualidade para os usuários.

Neste trabalho, o termo QoS utilizado estará fazendo referência à Qualidade de Serviço da rede, mais especificamente relacionada com o tráfego dos dados como por exemplo, largura de banda disponível, taxa de transmissão necessária, taxa de perda de pacotes, variação de atraso e atraso fim-a-fim. A Tabela 1 resume os principais requisitos de Qualidade de Serviço de acordo com a mídia utilizada pela aplicação. 
Tabela 1 - Características e requisitos de transporte das diversas mídias [LUNARDI01]

\begin{tabular}{|c|c|c|c|c|}
\hline & Tráfego & $\begin{array}{l}\text { Vazão média } \\
\text { dos dados }\end{array}$ & $\begin{array}{l}\text { Tolerância } \\
\text { perdas }\end{array}$ & $\begin{array}{l}\text { Atraso máximo } \\
\text { e variação de }\end{array}$ \\
\hline Texto & Rajada & $\begin{array}{lr}\begin{array}{l}\text { Poucos } \\
\text { até }\end{array} & \text { Kbps } \\
\text { Mbps } & \text { alguns } \\
& \end{array}$ & Não tolerável & $\begin{array}{l}\text { Não constituem } \\
\text { problemas }\end{array}$ \\
\hline Imagem gráfica & Rajada & $\begin{array}{l}\text { Pode chegar a } \\
\text { dezenas de } \\
\text { Mbps }\end{array}$ & $\begin{array}{l}\text { Compromete } \quad \text { a } \\
\text { imagem final }\end{array}$ & $\begin{array}{l}\text { Não constituem } \\
\text { problemas }\end{array}$ \\
\hline Áudio & $\begin{array}{l}\text { Tráfego } \\
\text { contínuo com } \\
\text { taxa constante. } \\
\text { Introduzindo } \\
\text { silêncio tráfego } \\
\text { em rajadas e } \\
\text { utilizando } \\
\text { técnicas de } \\
\text { compactação } \\
\text { tráfego com taxa } \\
\text { variável }\end{array}$ & $\begin{array}{ll}\text { Depende } & \text { da } \\
\text { qualidade } & \text { do } \\
\text { sinal, } & \text { da } \\
\text { codificação } & \\
\text { utilizada. } & \end{array}$ & $\begin{array}{l}\text { Pode ser alta, não } \\
\text { causando } \\
\text { problemas. }\end{array}$ & $\begin{array}{l}\text { Crítico em } \\
\text { aplicações que } \\
\text { exigem } \\
\begin{array}{ll}\text { comunicação } \\
\text { interativa em } \\
\text { tempo real }\end{array}\end{array}$ \\
\hline Vídeo & $\begin{array}{l}\text { Tráfego } \\
\text { contínuo com } \\
\text { taxa constante. } \\
\text { Introduzindo } \\
\text { técnicas de } \\
\text { compactação se } \\
\text { caracteriza por } \\
\text { um tráfego com } \\
\text { taxas variáveis }\end{array}$ & $\begin{array}{ll}\text { Varia com a } \\
\text { qualidade do } \\
\text { sinal e } & \text { os } \\
\text { algoritmos } & \text { de } \\
\text { codificação } & \\
\text { utilizados } & \end{array}$ & $\begin{array}{l}\text { Tolerável, mas com } \\
\text { restrições. }\end{array}$ & $\begin{array}{lr}\text { Deve } & \text { ser } \\
\text { compensada } & \mathrm{e} \\
\text { obedecer aos } & \\
\text { requisitos da } \\
\text { mídia de áudio }\end{array}$ \\
\hline
\end{tabular}

Ao longo dos últimos anos, muitas pesquisas têm sido realizadas em torno de QoS para arquitetura de redes IP. Podemos citar como exemplos: (i) o modelo de Serviços Integrados (IntServ), o qual estende os serviços básicos IP com reserva de recursos por meio do protocolo RSVP - Resource reSerVation Protocol [BRADEN97]; (ii) o modelo de Serviços Diferenciados (DiffServ), no qual os pacotes que trafegam por um domínio que implementa esta noção recebem tratamento diferenciado de acordo com sua necessidade [BLAKE98] e; (iii) recentemente o MPLS (Multiprotocol Label Switching), que combinado com DiffServ, 
possibilita realizar a alocação de recursos destinados a um determinado fluxo (com roteamento explícito) e conferir o devido tratamento a cada classe de serviço [FINEBERG03].

Todavia, protocolos no nível da camada de aplicação (que é o foco deste trabalho) também têm sido desenvolvidos para assegurar serviços multimídia com QoS em ambientes sem reserva de recursos; em especial os protocolos: (i) Real Time Transport Protocol (RTP) - para transporte de dados; e (ii) Real Time Control Protocol (RTCP) - para controlar informações de feedback dos recebedores dos dados[RFC3550]. Esses dois protocolos são utilizados na camada de adaptação proposta e serão explicados na próxima seção.

\subsection{Protocolos de rede de tempo real}

O núcleo da rede Internet tem capacidade para transmitir algumas centenas de milhões de bits por segundo, porém taxas de transmissão desta ordem são apenas alcançadas na conexão entre os grandes roteadores dos provedores de serviço de Internet (do inglês, Internet Service Provider). A rede de acesso, que interliga o usuário ao provedor, ainda representa o grande gargalo da rede, limitando fortemente a taxa de transmissão na qual o cliente (usuário final) pode se comunicar. No entanto, esta configuração está começando a mudar, com operadoras de telefonia e de TV a cabo oferecendo conexões banda larga a preços cada vez mais razoáveis.

Este crescimento exponencial dos chamados serviços banda larga, aliado ao aperfeiçoamento das técnicas de compressão de mídias estão mudando significativamente a experiência do usuário, tornando possível o que se chama comunicação rica de dados, enriquecendo o leque de possibilidades no oferecimento de serviços.

Entretanto, esses serviços, conhecidos como aplicações multimídia em rede, possuem peculiaridades que os distinguem dos serviços tradicionais orientados a dados, dentre as principais estão: grande volume de dados, dependência temporal e necessidades de sincronização (ver capítulo 1). Na prática, aplicações multimídia em rede são fluxos contínuos de áudio, vídeo e dados e, consequentemente, são sensíveis a atrasos fim a fim, e também à variação deste atraso, possuindo sérias limitações quanto ao tempo de entrega de seus dados, o que as define como aplicações em tempo real. Acontece que a Internet presta um serviço de 
melhor esforço para conseguir transportar todos os datagramas do remetente ao transmissor o mais rápido possível. Portanto, o serviço de melhor esforço não é capaz de dar garantias sobre o atraso fim a fim, tampouco sobre a variação deste atraso, o que a torna inadequada para aplicações multimídia [PERKINS03].

Nesse contexto, os protocolos discutidos nesta seção trabalham em conjunto e utilizam estratégias para melhoria do melhor esforço oferecido pela camada de rede IP sem a necessidade de modificações estruturais na arquitetura da rede da Internet, sendo necessárias apenas mudanças na camada de aplicação.

\subsubsection{RTP - Real-Time Transport Protocol}

O Real-Time Transport Protocol (RTP) oferece funções de transporte fim a fim adequadas para aplicações em tempo real, sobre serviços de rede ponto-a-ponto (unicast) ou ponto-multiponto (multicast). Estes serviços incluem uma estrutura de dados padronizada para a identificação do tipo dos dados (payload), numeração seqüencial, marcas de tempo (timestamping) e monitoração das sessões de transmissão. O RTP é definido na [RFC3550] (substitui RFC 1889, que se tornou obsoleta).

\subsubsection{RTP na pilha de protocolos}

A posição do RTP na pilha de protocolos TCP/IP é um pouco confusa. Para possibilitar reutilização, o RTP normalmente é inserido no contexto da camada de aplicação, servindo de suporte para aplicações multimídia e utilizando os serviços oferecidos pela interface de soquete para acessar o protocolo de camada de transporte do sistema operacional, normalmente o protocolo UDP. A Figura 3 ilustra este arranjo. 


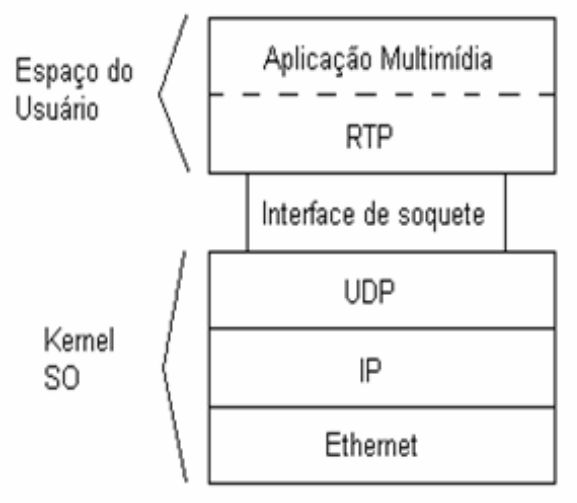

a)

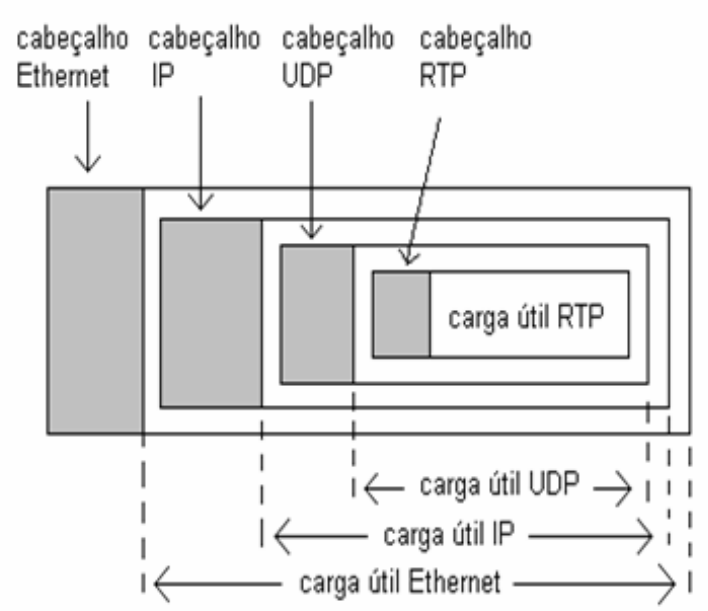

b)

Figura 3 - a) Posição do RTP na pilha de protocolos. b) Encapsulamento RTP

[TANEMBAUM_03]

A função básica do RTP é encapsular diversos fluxos em tempo real sobre um único fluxo de pacotes UDP (ou TCP). Assim, os vários fluxos constituintes de uma aplicação multimídia são armazenados no RTP, que efetua então uma multiplexação nos fluxos, identificando suas fontes, e os codifica em pacotes RTP, identificando o tipo de dado em seu conteúdo. Além disso, o RTP tem a função de acrescentar números de seqüências em cada pacote, para possibilitar reordenação dos pacotes recebidos no lado do receptor, e acrescenta ainda marcas de tempo capazes de indicar o momento de execução de cada pacote no seu destino, além do preenchimento de outros campos de cabeçalho discutidos ao longo desta seção. Estes pacotes RTP são então enviados através da interface de soquete para as demais camadas da pilha TCP. O encapsulamento RTP descrito acima está mostrado na Figura 3 (a).

Em conseqüência dessa estrutura, fica difícil afirmar a qual camada o protocolo RTP pertence. De um lado, ele opera no espaço do usuário, sendo vinculado ao programa aplicativo, e assim parece ser um protocolo de aplicação. Por outro lado, ele é um protocolo com o objetivo de ser genérico e independente das aplicações, apenas fornecendo recursos de transporte, e assim também se assemelha a um protocolo da camada de transporte.

Segundo [TANEMBAUM_03], podemos afirmar que o protocolo RTP é um protocolo de transporte implementado na camada de aplicação, sendo assim uma subcamada de transporte. 


\subsubsection{Uma nova abordagem para protocolos}

Toda esta confusão deve-se ao fato de o RTP pertencer a uma nova geração de protocolos [RFC3550] seguindo os princípios de enquadramento em nível de aplicação e processamento de camada integrada, proposta por [CLARK90]. Isto significa que o RTP tem a intenção de ser flexível para prover a informação necessária a uma aplicação em particular, e será frequentemente integrado dentro do processamento da aplicação, ao invés de ser implementado como uma camada separada.

O RTP não pretende ser um protocolo completo, mas um framework para a construção de protocolos de aplicação [RFC3550]. Ele especifica aquelas funções que se esperam comum a todas as aplicações para as quais o RTP seja apropriado e permite modificações e/ou adições aos seus cabeçalhos quando necessário.

Portanto, além das funções comuns especificadas em [RFC3550], uma especificação completa do RTP para uma aplicação particular precisa de mais duas definições:

- especificação de perfil, o qual define um conjunto de tipos de codificação de carga útil (payload). Um perfil pode também definir extensões ou modificações do RTP que são específicas para uma classe particular de aplicações. Tipicamente, uma aplicação irá operar sob apenas um perfil;

- especificação do formato da carga útil (payload), o qual define como um payload particular, tal como uma codificação de áudio ou vídeo, deve ser carregado pelo RTP.

O RTP foi desenvolvido levando em consideração dois fortes critérios de projeto. $\mathrm{O}$ primeiro deles é que a aplicação é o elemento melhor capacitado para tomar decisões acerca do transporte dos dados. Para tanto, a aplicação deve receber informações completas sobre o comportamento da rede, para então decidir a melhor abordagem para reagir a problemas; por exemplo, reenviar uma nova cópia igual de uma mensagem que foi perdida, ou uma cópia de menor qualidade, ou nem mesmo enviá-la, caso os dados perdidos tenham caráter transiente. O segundo é o de que a confiabilidade de uma transmissão deve ser conferida pelos elementos das 
pontas, de tal forma que a transmissão seja bem sucedida mesmo quando sujeita a trafegar numa rede que não é confiável.

Dentro deste contexto, o RTP é geralmente usado em conjunto com o protocolo UDP. Porém, não existem limitações quanto à escolha do protocolo de transporte, uma vez que o RTP foi desenvolvido de tal forma que é compatível com outros protocolos de rede e transporte. No entanto, pela simplicidade e mecanismos básicos de checagem de erros e multiplexação de serviços, o UDP evidencia os problemas apresentados pela rede de uma forma transparente, além de ser mais apropriado para aplicações em tempo real [PERKINS03].

\subsubsection{Serviços RTP}

O RTP apenas expande os serviços da camada de transporte e faz uso da multiplexação (através do uso de portas lógicas) e da checagem de pacote oferecida por essa camada. Sendo assim, ele não garante entrega temporizada ou provê qualquer garantia de QoS, embora preste serviços de baixo nível para que outra entidade o faça. Portanto, o RTP não garante entrega ou ordenação, não possui controle de fluxo, nenhuma confirmação e nenhum mecanismo de retransmissão. Também não há reserva de recursos.

O RTP presta serviços de baixo nível para que tudo isto seja possível, mas não é propriamente ele quem realiza todas essas funções. Ele apenas tem o propósito de ser um arcabouço para a construção de outros protocolos de camada de aplicação, apenas prestando serviços simples para que tudo isto seja possível.

Os três principais serviços que o RTP oferece são: (i) número de seqüência dos pacotes; e (ii) marca de tempo de amostra; e (iii) identificação de tipo de payload. Explicamos a seguir cada um destes serviços principais.

Cada pacote em um fluxo RTP recebe um número de seqüência maior em uma unidade que seu antecessor. Isto permite a reordenação dos pacotes no destino por parte de alguma outra entidade que utilize os serviços do RTP, haja vista que, por exemplo, o UDP, não garante a chegada ordenada dos pacotes transmitidos. Além disso, acompanhando esta numeração, o destino consegue descobrir a falta de algum pacote, o que indica que algum pacote foi perdido pela rede IP. Pode-se também identificar dentro do fluxo um pacote defeituoso (com erro de 
transmissão). Apesar de essas características permitirem o uso de mecanismos de retransmissão, normalmente são usadas técnicas que implementam interpolação ou predições de pacotes perdidos ou correção de erros em avanço (do inglês, FEC - Forward Error Correction) para pacotes defeituosos, de forma a evitar quebra na continuidade do fluxo. Em se tratando de aplicações em tempo real, um pacote estimado ou recuperado é sempre melhor que um pacote atrasado.

Além de possibilitar a reordenação de pacotes e detecção de perdas, o número de seqüência pode também identificar duplicatas, ou seja, pacotes iguais transmitidos mais de uma vez. Esta estratégia de replicação de pacotes no transmissor pode ser adotada como uma tentativa de minimizar perdas de pacotes ou erros de transmissão. Caso esta estratégia seja utilizada, duplicatas devem ser eliminadas pela aplicação, e o número de seqüência possibilita esta ação.

Um outro serviço de baixo nível bastante importante prestado pelo RTP é a marca de tempo (timestamping). A origem associa uma marca de tempo com a primeira amostra em cada pacote. Estes valores absolutos não trazem nenhuma informação de controle, mas como a origem associa uma marca de tempo com a primeira amostra em cada pacote, a diferença entre os timestamps dos pacotes que chegam pode ser utilizada pela aplicação como forma de estimativa de variação de atraso (jitter) e sincronização.

O mecanismo de timestamping também permite ao destino realizar alguma bufferização, reproduzindo cada amostra depois de determinado intervalo de tempo, contados desde o início do fluxo, independente de quando chegou o pacote contendo cada amostra.

Na Figura 4 é ilustrado como um atraso intencional na reprodução no lado do cliente, produzido pela utilização de um buffer, pode recuperar a taxa de apresentação constante originalmente atingida pelo codificador no transmissor, em troca da perda de instantaneidade em relação ao início de reprodução.

De início, alguma confusão com os conceitos de número de seqüência e timestamp pode ocorrer. Apesar de, a princípio, estes conceitos parecerem semelhantes, eles são bastante distintos. O timestamp relaciona os pacotes com os instantes em que eles foram gerados. 
Diferentemente, o número de seqüência os relaciona entre si. Em uma aplicação de vídeo, por exemplo, dois pacotes pertencentes à mesma imagem têm timestamps iguais, mas números de seqüência distintos. Já em uma aplicação de áudio, a distinção entre o período de silêncio e a perda de pacotes é resolvida comparando-se as marcas temporais e os respectivos números de sequiência.

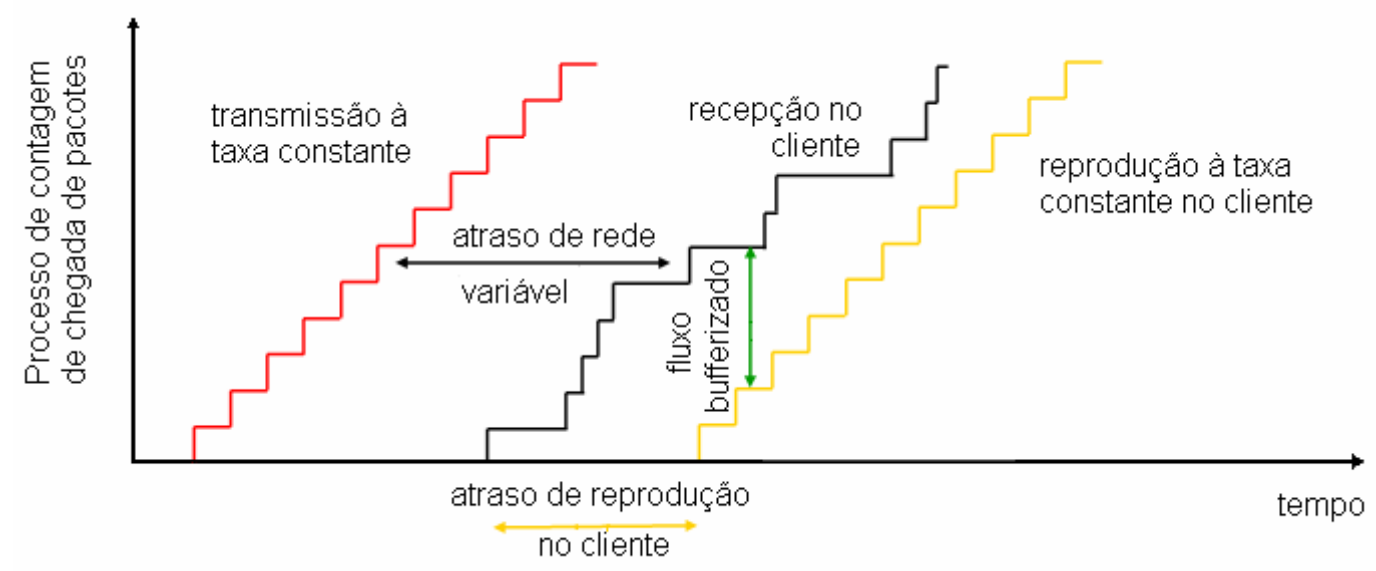

Figura 4 - Exemplo do uso de timestamps para minimizar o jitter

Por fim, o RTP fornece ainda outro serviço de baixo nível extremamente importante: a identificação do conteúdo dentro da carga útil do pacote. Cada carga útil pode conter várias amostras do sinal de informação de uma aplicação multimídia. Estas amostras podem ser codificadas da forma desejada pela aplicação. Assim, através de um campo de cabeçalho (Payload Type) o RTP permite à origem especificar a codificação utilizada. Entretanto, é importante ressaltar que o RTP não especifica a maneira de realizar essa codificação. Ele apenas realiza um mapeamento de um identificador com o algoritmo de codificação específico. Como cada pacote possui um campo para esta finalidade, a codificação pode mudar durante a transmissão, não sendo necessário a interrupção do fluxo para tal. Para permitir interoperabilidade entre formatos de codificação de várias aplicações, RTP define vários perfis, que são brevemente discutidos adiante.

Abaixo uma breve descrição principais campos do cabeçalho RTP. Para maiores detalhes, consultar [RFC3550].

- versão: identifica versão do RTP (atualmente, versão 2). 
- padding: é usado para preencher o pacote RTP com bytes adicionais, que não fazem parte do payload. Usado por algoritmos de codificação que exigem pacote com comprimento fixo.

- extension: indica presença de um cabeçalho de extensão. Cabeçalho de extensão não definido. Válvula de escape para exigências imprevistas.

- CSRC Count: Informa quantas origens de contribuição CSRC estão presentes.

- marker: marcador específico da aplicação. Sua interpretação depende do perfil. Pode ser utilizado para marcar começo de quadro de vídeo, palavra, etc.

- payload Type: informa algoritmo de codificação utilizado. Codificação pode mudar durante transmissão.

- sequence number: incrementado em cada pacote RTP enviado. É usado para detectar pacotes perdidos.

- timestamp: é produzido pela origem do fluxo para anotar quando a primeira amostra no pacote foi realizada;

- SSRC: identifica a fonte de sincronismo, informando a que fluxo o pacote pertence. Usado para multiplexar e demultiplexar vários fluxos de dados em um único fluxo de dados UDP.

- CSRC List: identifica as fontes que contribuem para o payload contido no pacote (no caso do uso de mixers), usando o SSRC Identifier de cada fonte participante.

- header Extension: permite implementação individual de experimentos com funções que independem do formato do payload, e que necessitam transportar informações adicionais junto com o cabeçalho RTP.

Dessa forma, outros protocolos ou mesmo a própria aplicação, podem fazer uso dos serviços de baixo nível implementados pelo RTP para facilitar a entrega, para detecção de faltas, segurança, monitoramento, reconstrução, mixagem (identificando de fontes variadas) e sincronização de fluxos multimídia. 


\subsubsection{Perfil RTP}

$\mathrm{Na}$ especificação do RTP [RFC3550] existem campos genéricos para aplicações multimídia em rede, mas uma aplicação normalmente precisa especificar estes campos de acordo com suas necessidades peculiares. Assim, uma aplicação que faz uso do protocolo RTP requer uma especificação de seu perfil; isto é, um documento que contenha a definição dos tipos de payload transportados, com o mapeamento para os formatos correspondentes dentro de um pacote RTP. Um perfil (profile) pode também conter extensões ou modificações do RTP específicas desta classe particular de aplicações. Um exemplo de profile para áudio e vídeo se encontra em [RFC3551], onde interpretações de campos genéricos do RTP são definidas para que preencham necessidades de aplicações de áudio e videoconferência com controle mínimo, ou seja, sem controle de sessão e grupos de usuários.

Alguns dos algoritmos de codificação de áudio e vídeo mais conhecidos são mostrados na Tabela 2. Esta Tabela exemplifica o mapeamento existente entre o número do identificador do campo de cabeçalho Payload Type e o tipo de codificação empregado.

Tabela 2 - Tipos de payload para codificações de áudio

\begin{tabular}{|c|c|c|}
\hline $\begin{array}{c}\text { Número do Identificador } \\
\text { de Conteúdo }\end{array}$ & Tipo de Codificação & $\begin{array}{c}\text { Taxa de bits } \\
\text { (kbps) }\end{array}$ \\
\hline 0 & PCM u-law & 64 \\
\hline 3 & GSM & 13 \\
\hline 7 & LPC & 2,4 \\
\hline 26 & Motion J-PEG & - \\
\hline 31 & H.261 & - \\
\hline 33 & MPEG2 video & - \\
\hline
\end{tabular}

\subsubsection{RTCP - Real-Time Control Protocol}

\subsubsection{Visão Geral}

O RTCP (Real-Time Control Protocol) é um protocolo utilizado em conjunto com o RTP para monitorar a qualidade do serviço oferecido, e também fornecendo informações sobre os participantes de uma sessão RTP. Ele opera simultaneamente com o RTP, sendo definido na mesma RFC [RFC3550].

O RTCP utiliza os mesmos mecanismos de entrega dos pacotes de dados RTP, e assim a rede deve permitir multiplexação para que se faça distinção entre pacotes de dados e controle. 
Esta multiplexação é implementada pelo protocolo de transporte, por meio da reserva de portas distintas para pacotes RTP e RTCP. Se o RTP opera na porta n, o RTCP irá operar na porta n+1. Embora RTCP seja considerado como um protocolo executado sobre o RTP, na verdade ele é apenas um tipo especial de pacote RTP.

O RTCP se baseia na transmissão periódica de pacotes de controle para todos os participantes de uma sessão RTP. Estas informações de controle podem incluir dados que identificam os participantes (como nome, endereço de e-mail, localidade geográfica) ou mapeiam suas fontes de fluxo individuais. No entanto, as informações mais relevantes obtidas por este protocolo dizem respeito a parâmetros de qualidade de serviço. Os pacotes RTCP contêm dados sobre atraso, jitter, perda de pacotes e outros, que, ao serem enviados para os respectivos destinos, fornecem subsídios que permitem que uma dada aplicação tome decisões acerca da codificação e do envio dos fluxos, permitindo assim melhorar o desempenho da transmissão.

Este envio de pacotes de controle periodicamente a todos os participantes da sessão constitui um problema quanto à escalabilidade quando tratamos de redes com grande número de participantes. Como todos os participantes recebem e enviam relatórios RTCP (reports), o número de componentes do grupo é conhecido; assim, cada um deles pode controlar a taxa com que enviam estes reports. Isto é empregado para limitar a largura de banda ocupada pelo RTCP a um valor razoável, normalmente não mais que 5\% da sessão; caso contrário, o tráfego de controle poderia crescer a um ponto que prejudicasse o desempenho do RTP. Esta reserva de banda por sua vez deve ser compartilhada por todos os participantes.

É estipulado que $25 \%$ dessa reserva seja destinada aos transmissores das mídias, uma vez que as informações por eles enviadas é essencial à tomada de decisão por parte dos receptores, que dividem o restante da reserva entre si. Mesmo no caso de sessões pequenas, a taxa mais rápida com que um participante consegue enviar relatórios RTCP é de um relatório a cada cinco segundos. A taxa de envio é tornada aleatória por um fator de 0,5 a 1,5 para evitar sincronização indesejada entre relatórios. O valor médio é obtido pelo participante a partir dos 
pacotes RTCP que ele deseja enviar e a partir do número de transmissores e receptores constantes nos pacotes RTCP que ele recebe [RFC3550].

\subsubsection{Pacote RTCP}

Cada pacote RTCP tem uma estrutura padrão, comum a todos os pacotes, seguido de elementos estruturados que variam de acordo com o tipo de pacote. Há cinco campos comuns a todos os tipos de pacotes:

- version: identifica a versão do RTP (o valor deste campo é o mesmo tanto nos pacotes RTP como nos pacotes RTCP).

- padding: análogo ao campo padding no cabeçalho RTP.

- item count: contém a quantidade de alguns itens, variando com o tipo de pacote: num pacote SR, trata-se do número de blocos contendo reports, enquanto num pacote SDES, contém o número de transmissores especificados no pacote.

- packet type: contém uma constante que identifica os diversos tipos de pacote.

- length: comprimento do pacote, quantificado em palavras de 32 bits, excluindo o cabeçalho e o padding.

Além disso, são cinco os possíveis diferentes tipos de pacotes:

- SR (Sender Report): estatísticas de transmissão e recepção dos participantes que são transmissores ativos;

- RR (Receiver Report): estatísticas de recepção dos participantes que não são transmissores ativos;

- SDES (Source Description Items): descrição de parâmetros da fonte, incluindo o CNAME (Canonical Name);

- $\boldsymbol{B Y E}$ : indica fim da participação;

- $\boldsymbol{A P P}$ : funções específicas de uma aplicação.

Os pacotes RTCP são geralmente transmitidos na forma de grupos, formando pacotes compostos, que são enviados como um único pacote de uma camada inferior (como o UDP, por exemplo). Estes pacotes são divididos em Report Block e todo pacote RTCP deve conter pelo 
menos um Report Block, para maximizar a resolução das estatísticas, e um pacote de SDES contendo um CNAME, para que novos receptores identifiquem as fontes o mais rápido possível. Os demais tipos de pacotes podem ou não estar contidos, e podem estar em qualquer ordem, com a única restrição de que o pacote de BYE (quando houver) seja o último pacote enviado. Para detalhes dos campos específicos para cada tipo de pacote, consultar [RFC3550].

\subsubsection{RTSP - Real-Time Streaming Protocol}

\subsubsection{Visão Geral}

O RTSP é um protocolo da camada de aplicação para controle sobre a entrega de dados com propriedades de tempo real [RFC2326]. Normalmente, este protocolo é utilizado para acessar conteúdos do tipo áudio e vídeo que estejam tanto armazenados em um servidor de vídeo sob demanda, mas também pode ser utilizados para fontes de mídia ao vivo. O protocolo tem capacidade de controlar diversas sessões simultâneas de dados, provendo habilidade para escolha do canal de entrega como UDP unicast, UDP multicast ou mesmo TCP. Além disso, possibilita a utilização conjunta com mecanismos de entrega baseados em RTP.

O RTSP não é tipicamente utilizado para transportar o conteúdo propriamente dito, apesar de ser possível intercalar o fluxo de dados com o fluxo de controle.

Segundo a norma que define o RTSP, não existe a noção de conexão RTSP, no entanto é mantida uma sessão rotulada por um identificador (identifier). Essa sessão não é vinculada a uma conexão de camada de transporte como o TCP. Na verdade, durante uma sessão RTSP, um cliente RTSP pode abrir e fechar diversas conexões de transporte com o servidor para fazer RTSP requests.

Os fluxos de áudio e vídeo controlados pelo RTSP podem utilizar o RTP para o transporte, porém o RTSP não depende desse mecanismo para transportar mídia contínua. É possível fazer uma analogia de funcionamento do RTSP com o HTTP/1.1 [RFC2068]. O protocolo foi criado intencionalmente para ter similaridade de sintaxe e operação, e, portanto, pode se utilizar de alguns mecanismos de extensão do próprio HTTP. Apesar disso, existem várias diferenças entre os dois protocolos. Podemos citar: (1) o RTSP introduz novos métodos; 
(2) um servidor RTSP precisa manter o estado (sessão), ao contrário do que acontece com o HTTP/1.1 que é stateless, ou seja, não mantém o estado da sessão; e (3) os dados são transportados separadamente por um protocolo diferente.

As principais operações suportadas pelo protocolo são:

- retirada de mídia do servidor: o cliente faz uma requisição de apresentação (presentation description) via HTTP ou outro método. Se a apresentação for multicast, a presentation description conterá os endereços multicast e portas que serão utilizados para o transporte da mídia. No caso de uma transmissão unicast, o cliente deve prover o endereço de destino por questões de segurança.

- convidar um servidor para a conferência: um servidor de mídia pode ser convidado a entrar em uma conferência, seja para exibir uma mídia ou mesmo para gravar o que esta sendo exibido. A norma indica esta forma de uso como um uso aplicações de ensino distribuído, onde os alunos podem colaborar interagindo com a mídia.

- adição de mídia a uma apresentação já existente: principalmente no caso de transmissões ao vivo, é interessante que o servidor possa avisar o cliente caso alguma nova mídia se faça disponível.

A norma [RFC2326] define diversas propriedades que mostram a versatilidade do protocolo:

- extensível: novos métodos e parâmetros podem ser facilmente adicionados.

- fácil de processar: protocolo baseado em texto. Pode ser facilmente processado por parsers HTTP ou MIME.

- seguro: RTSP utiliza os mecanismos já existentes de segurança. Podem ser utilizados mecanismos de autenticação e até mesmo mecanismos de camada de transporte.

- independente de transporte: podem ser usados vários protocolos, desde UDP até mesmo o TCP. 
- multi servidor: as mídias podem estar em servidores diferentes. O cliente estabelece diversas sessões concorrentes com os diferentes servidores e a sincronização da mídia ocorre na camada de transporte.

- controle de dispositivos de gravação: o protocolo é capaz de controlar dispositivos de exibição tanto quanto de gravação, ou mesmo que possam alternar os dois modos (ex.: VCR).

- descrição de apresentação neutra: o protocolo não especifica uma descrição de apresentação ou formato padrão. Pode utilizar SDP (Session Description Protocol) [RFC2327], XML (eXtensible Markup Language), etc., apenas obriga a existência um endereço RTSP.

- negociação de transporte: o cliente pode negociar o método de transporte antes da recepção da mídia.

- negociação de capacidade: em certos casos, algumas propriedades para manipulação dos fluxos podem estar desabilitadas. Nesse caso, o cliente deve ter conhecimento dessas limitações para que sua aplicação funcione corretamente.

\subsubsection{Estados RTSP}

Como a transmissão de conteúdo acontece de forma separada do controle, o servidor deve manter estados de sessão (session states) para conseguir manter relação entre os requests RTSP e a transmissão da mídia em si. Dentre os principais estados, temos:

- SETUP: faz com que o servidor aloque recursos e crie a sessão RTSP.

- PLAY: inicia a transferência da mídia.

- PAUSE: pára a transmissão temporariamente, sem liberar os recursos.

- REDIRECT: indica que a sessão deve mudar para um novo servidor ou local.

- PING: previne timeout no servidor para uma determinada sessão.

- TEARDOWN: destrói a sessão e libera os recursos alocados. 
O formato das mensagens do RTSP segue o mesmo padrão do HTTP/1.1. Dessa forma, é possível reutilizar muito do que já existe implementado para Web e adaptar os sistemas legados para suportarem o RTSP.

\subsection{JSA - Java Stream Assembly}

\subsubsection{Visão geral}

A Java Stream Assembly (JSA) [SUN_JSAa] é um esforço da comunidade JCP (Java Community Process) [SUN_JCP], através da JSR (Java Specification Request) 158, para definir uma API Java de manipulação em tempo real de componentes de hardware e/ou software utilizados para criação, controle, monitoração e entrega de fluxos de mídia multiplexados. Adicionalmente, API JSA também define interfaces com outros componentes/sistemas (controle de acesso de usuários, registro, contabilidade, persistência de dados, gerenciamento de propriedade intelectual e etc.) que compõem um processo típico de entrega de conteúdo multimídia. O principal objetivo é fornecer para aplicações multimídia em rede (por exemplo, servidores de vídeo) uma interface de software unificada e padronizada para gerenciamento de fluxos de mídias, independente das funcionalidades serem implementadas em software ou hardware e também do formato de mídia, protocolos de controle e transporte empregados.

A API JSA pode ser vista como um conjunto de abstrações, através de classes e interfaces na linguagem de programação Java, para facilitar o desenvolvimento de aplicações para entrega de serviços multimídia ao vivo (fluxo contínuo e difusão), sob demanda e interativos (IPTV, WebTV e TV Digital Interativa). Através do uso da API os desenvolvedores de software também podem escrever aplicações para gerenciar sistema de manipulação de fluxos de mídia ou componentes que suportem a API (uma placa de codificação de vídeo, por exemplo). A API é implementada utilizando a linguagem Java e baseada com componentes, porém, permite a implementação de componentes em linguagem $\mathrm{C}$ e $\mathrm{C}++$ e que podem ser integrados com a API através da tecnologia JNI (Java Native Interface) [SUN_JNI].

O escopo da JSA se restringe a criação, gerenciamento e processamento de fluxos de mídias multiplexados. Podemos citar como algumas funções típicas dessa manipulação: (i) 
combinação de fluxos áudio, vídeo e dados para criar um fluxo multimídia único; (ii) inserção de novos dados em um fluxo de multimídia; (iii) combinação de fluxo multimídia único para criar um de fluxo multimídia combinado; (iv) remoção de um programa do fluxo multimídia combinado. Adicionalmente, dois requisitos devem ser atendidos pela JSA para um processamento adequado de fluxos multimídia: (1) processar e transportar grande volume de dados contendo fluxos de mídias entre componentes e (2) esses dados devem ser processados em tempo real pelos componentes.

Resumidamente, a escopo da API JSA pode ser dividida em 3 (três) camadas (Figura 5):

- camada cliente - nesta camada as aplicações são responsáveis por configurar, gerenciar e monitorar os elementos da API JSA através de um nível de abstração de alto nível e com escopo mais específico para uma determinada aplicação. Os desenvolvedores que trabalham nesta camada são os desenvolvedores de aplicações.

- camada integração - as aplicações em Java ou C/C++ nesta camada conectam e gerenciam os fluxos de mídias entre componentes e provêem um modelo de eventos de publicação / inscrição para suportar o monitoramento em tempo de execução das atividades do sistema. Os desenvolvedores que trabalham nesta camada são os desenvolvedores de componentes.

- camada recursos - as aplicações em Java ou C/C++ nesta camada controlam os elementos de baixo nível de implementação, que podem ser componentes de software e/ou hardware e fornecem funcionalidades que representam fontes de saída (sources), entrada (sinks) ou processamento (processors) dos fluxos multimídia. Os elementos de recursos são controlados pelas suas abstrações na camada integração. Os desenvolvedores que trabalham nesta camada são os desenvolvedores de componentes. 


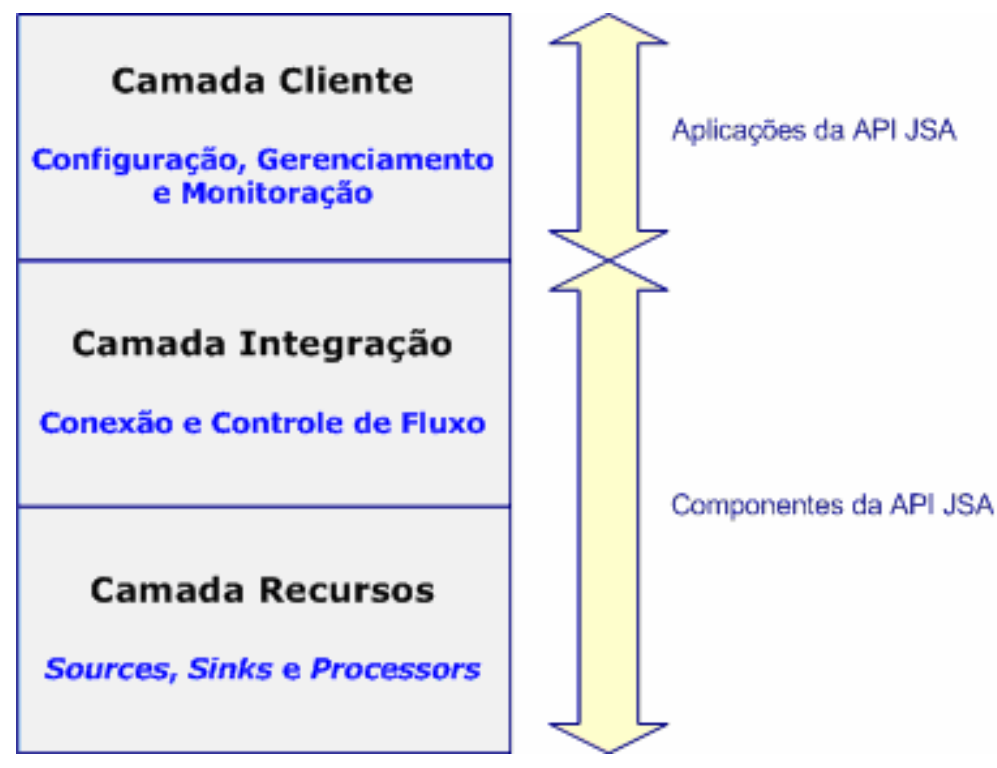

Figura 5 - Visão geral da JSA [SUN_JSAa]

\subsubsection{Arquitetura da JSA}

A arquitetura da JSA pode ser dividida em vários módulos ou subsistemas (Figura 6). O módulo A, que é resumidamente descrito pela Figura 5, representa a núcleo da API e é o mais importante, pois, contém todos os elementos principais que devem obrigatoriamente estar presentes em qualquer aplicação ou uso da API. Os demais módulos representam interfaces que a API opcionalmente deve possuir, dependendo do serviço ou aplicação em que é utilizada. A seguir são descritos cada módulo:

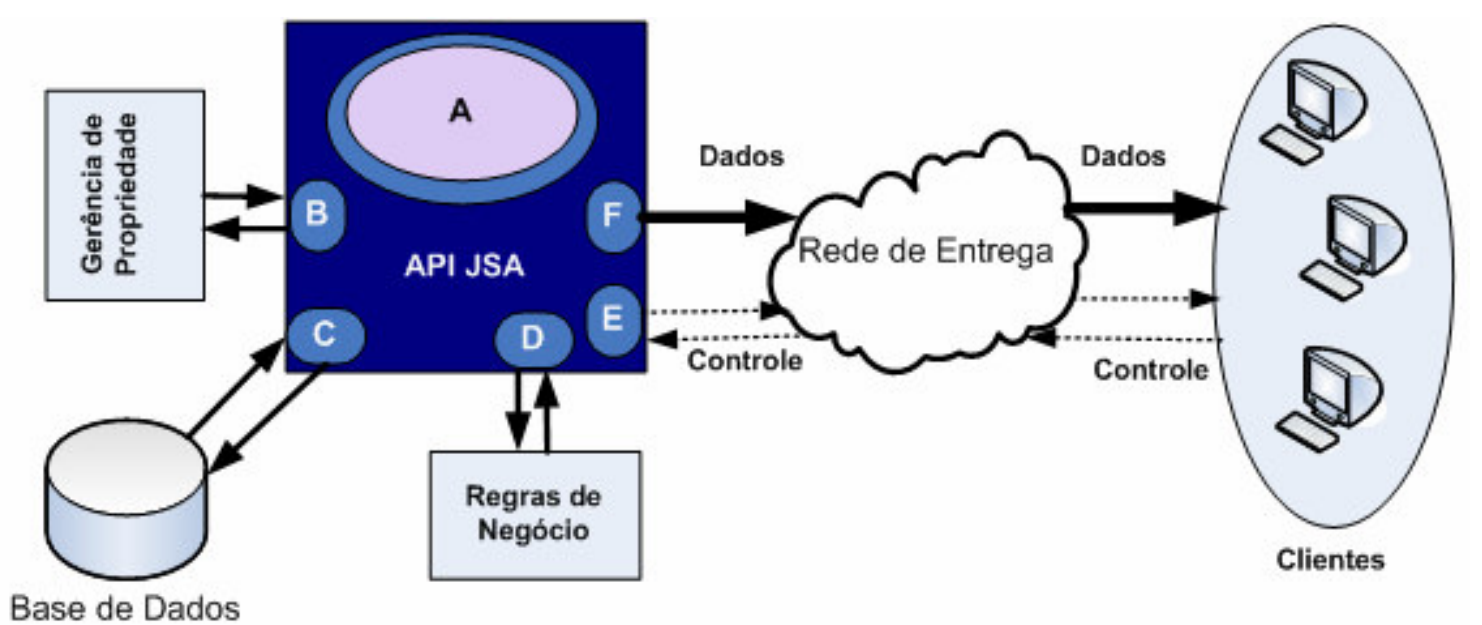

Figura 6 - Principais elementos da JSA [SUN_JSAb]

- Módulo A - este módulo deve representar as entidades que implementam tanto elementos de baixo nível de implementação - arquivos, portas, buffers, threads, 
soquetes, drivers, estrutura de dados, como também elementos de alto nível de implementação - elemento de rede, conteúdo e fluxos multimídia, sessões, usuários, grupos, protocolos de redes e etc. Esses elementos que representam recursos devem possuir abstrações em software que permitem a definição de um modelo de monitoração, controle e configuração (Figura 5). Os conteúdos multimídia recuperados de base de dados também possuem representações através de abstrações desse módulo.

- Módulo B - representa a interface com sistemas de gerência de propriedade (do inglês, Asset ou Digital Right Management) para um serviço de distribuição multimídia.

- Módulo C - representa a interface com sistemas de persistência de todo tipo de informação que pode ser utilizada pela API: informações de monitoramento, configuração, registro de atividades do sistema, metadados dos conteúdos multimídias disponibilizados, usuários, políticas de segurança e etc. Pode utilizar, por exemplo, sistemas de arquivos, serviços de diretórios ou banco de dados relacionais para armazenar as informações.

- Módulo D - representa a interface com sistemas que implementem regras de negócio do serviço de distribuição multimídia, por exemplo, bilhetagem, registro de atividades de sessões de transmissão (registro), políticas de adaptação e etc.

- Modulo E - representa a interface com sistemas de monitoração de eventos e/ou mensagens provindas de sessões de transmissões abertas pelo Módulo F ou da infraestrutura da rede. Pode utilizar, por exemplo, RTSP e DSM-CC para controle de sessões e integração com sistemas de monitoramento.

- Módulo F - representa a interface com sistemas de transmissão de dados multimídia, normalmente representados por interfaces de rede (Ethernet, ASI) e implementações de pilhas de protocolo de rede e transporte (IP, RTP, UDP, MPEG2 TS e etc). 


\subsubsection{Principais conceitos da JSA}

A API JSA divide suas abstrações em 3 (três) categorias principais: (a) dados, (b) controle e (c) auxiliares. A primeira contém todos os componentes que processam ou representam dados que API manipula. A segunda é composta por componentes que permitem o gerenciamento (monitoração e controle) dos processos de manipulação dos fluxos de mídias (montagem, transmissão e etc.). A terceira possui componentes que implementam mecanismos de suporte geral para a API, como resolução de nomes e descobrimento, localização e gerenciamento de recursos, entre outros.

As principais abstrações do plano de dados são: Stream, StreamSet, Ports e JSAComponent. Estes componentes em conjunto são capazes de representar toda a cadeia de processos típica da manipulação de um fluxo de mídias. Stream e Streamset representam um fluxo com uma ou mais mídias ou um conjunto de fluxos, respectivamente. Ports representam pontos de entrada ou saída de um fluxo de mídia em um determinado componente. Um componente pode ser um dispositivo físico (hardware) ou dispositivo lógico (software) de vários processos rodando em um multiplexador, ou seja, uma porta não corresponde necessariamente a uma interface física. As portas são classificadas em SourcePort e SinkPort, sendo que estes termos representam a relação da porta com o fluxo de mídia (Stream ou Streamset) e não com o componente. Dessa forma, a porta associada com o componente que origina o fluxo de mídia é do tipo SourcePort, e conseqüentemente, a porta associada com o componente que termina o fluxo de mídia é uma SinkPort. JSAComponent representa a interface para os componentes base da JSA e também provê os métodos para associar abstrações do plano de controle e permitir o gerenciamento dos componentes. Existem 2 (dois) subtipos de JSAComponent: EndPoint e StreamProcessor. EndPoint representam componentes de fontes de saída (Sources), possuindo apenas SourcePorts, ou entrada (Sinks), possuindo apenas SinkPorts de fluxos de mídias. StreamProcessor são componentes que conectam Sources e Sinks, possuindo uma ou mais SourcePort e uma ou mais SinkPort, e executam alguma operação. A operação executada por um StreamProcessor pode ser 
simplesmente conectar um EndPoint Source a um EndPoint Sink. Entretanto, normalmente, a operação envolve alguma manipulação do fluxo de mídia, como por exemplo, adicionar ou descartar fluxos específicos. Abaixo uma visão parcial da hierarquia de componentes do plano de dados da JSA:

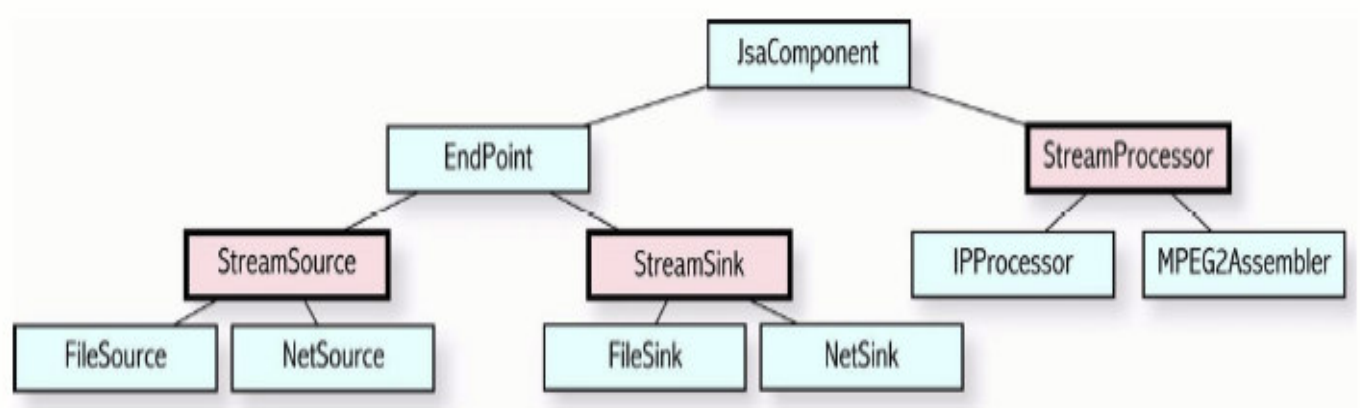

Figura 7 - Hierarquia de componentes do plano de dados da JSA [SUN_JSAa]

O plano de controle da JSA trabalha com 4 (quatro) principais abstrações: Session, ControlNode, Control e Controlposition. A classe Session representa uma sessão na JSA. As sessões são usadas para associar fluxos de mídias a uma entidade única possa realizar um gerenciamento centralizado e uniforme sobre os mesmos. A interface controlNode representa um ponto de conexão de um JSAComponent, provendo métodos para construir e conectar Ports, obter as interfaces de controle (Control) e fornecer as interfaces que vão notificar eventos (EventListeners). Um fluxo de mídia pode ser controlado por uma ou mais implementações de controle e apesar da estrutura da JSA possibilitar outras formas de controle, atualmente, a implementação base da JSA define dois aspectos de controle através de 2 (duas) interfaces: (i) Control: um controle básico que especifica o que fazer com o fluxo de mídia (iniciar, pausar, parar, etc). É basicamente o controle equivalente as funções básicas de um vídeo cassete; (ii) ControlPosition: um controle de posição que especifica onde, no fluxo de mídia, o controle deve ser executado. A posição pode ser representada pelo tempo, uma determinada amostra da mídia (um quadro de vídeo, por exemplo), pacotes e etc. 


\subsection{Requisitos Tecnológicos das Aplicações Multimídia}

\section{em Rede}

Adaptando o modelo de representação em camadas utilizada por [SCHWALB03], podemos descrever os principais aspectos envolvidos nas aplicações multimídia baseado em servidores em 4 (quatro) partes (Erro! Fonte de referência não encontrada.): camada de integração de aplicação, camada de sincronização e codificação, camada de transporte, camada de rede.

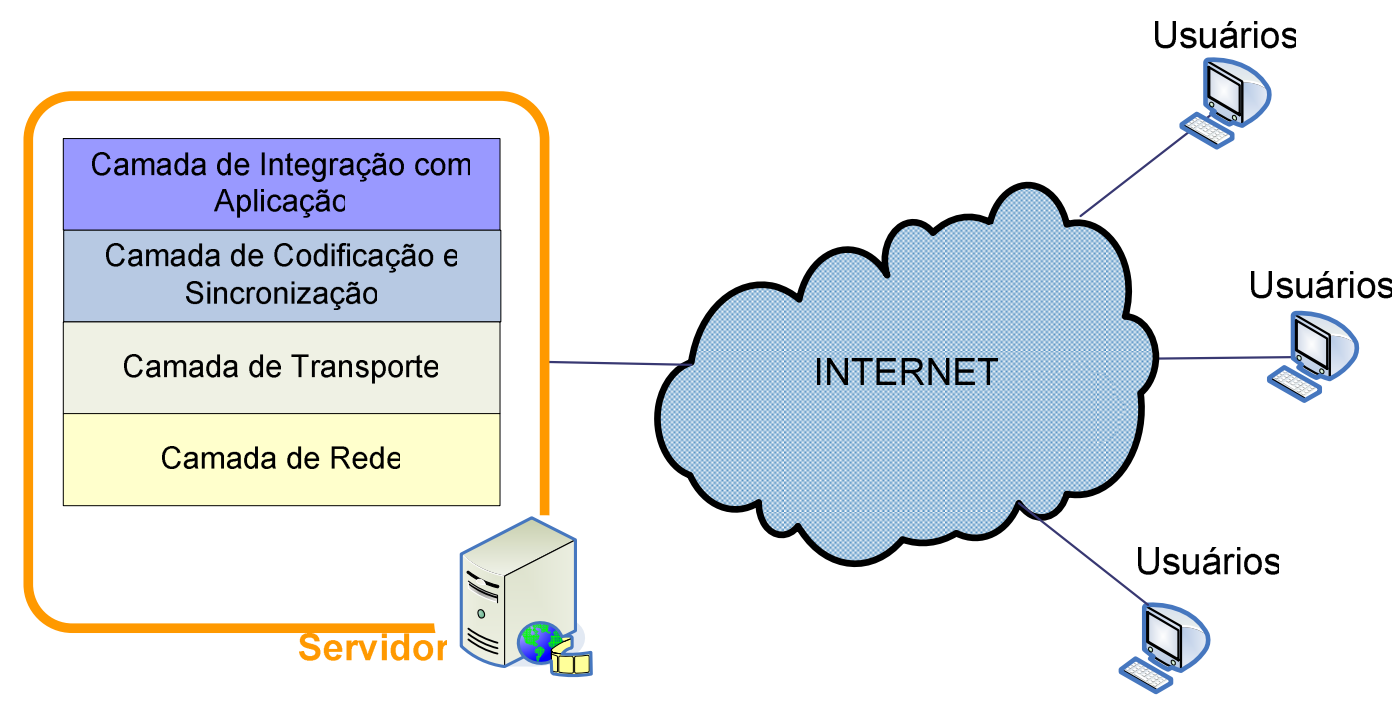

Figura 8 - Modelo de camadas das aplicações multimídia baseado em servidores

Nas próximas subseções são descritos resumidamente a função geral de cada uma dessas camadas e citar os padrões, protocolos e tecnologias utilizadas no contexto deste trabalho. O objetivo não é detalhar cada camada, mas relacionar o trabalho proposto com os requisitos tecnológicos das aplicações multimídia em rede. Aspectos adicionais podem ser encontrados nas referências citadas.

\subsubsection{Camada de Rede}

Representa a tecnologia da rede de comunicação de dados utilizada para transferência remota das informações. No escopo do nosso trabalho, utilizaremos redes IP e protocolos de rede que permitam modos de transmissão ponto-a-ponto (unicast) e ponto-multiponto 
(multicast). Mecanismos como RSVP [BRADEN97] e DiffServ [BLAKE98] também podem ser empregados nessa camada.

\subsubsection{Camada de Transporte}

Esta camada tem como objetivo encapsular os dados entregues pela camada de codificação através de protocolos de transporte que permitem a entrega fim-a-fim do conteúdo da rede de comunicação de dados. Nossa proposta utiliza os protocolos UDP e RTP (seção 2.3.1) em conjunto. A possibilidade de inclusão ou substituição de protocolos de transporte para redes de alta velocidade também devem ser considerados.

\subsubsection{Camada de Codificação e de Sincronização}

Esta camada tem o papel de codificação de acordo com o formato do conteúdo utilizado, aqui também pode ser tratada a sincronização que permite a coordenação e o relacionamento entre os vários tipos de mídias (por exemplo, áudio, vídeo e texto). No trabalho foram utilizadas as especificações do grupo MPEG, através do uso dos padrões de codificação MPEG-1, MPEG-2 [MPEG94] e MPEG-4 [MPEG] e, opcionalmente, o padrão MPEG-2Sistema [MPEG00] para sincronização.

\subsubsection{Camada de Integração de Aplicação}

Esta camada, através de um conjunto definido de abstrações e tecnologias de programação e protocolos de controle de sessão, provê acesso e controle aos recursos da rede de comunicação (por exemplo, soquetes) e conteúdo dos fluxos multimídia (por exemplo, leitura, descrição e localização de cada fluxo) para o usuário (administrador, distribuidor de mídia ou outro sistema de software) ou desenvolvedor do sistema. Particularmente, são utilizadas a plataforma de desenvolvimento Java 2 Standard Edition [SUN_J2SE] e API JSA (seção 2.4) para implementação de um servidor RTSP (seção 2.3.3) básico e a linguagem orientada a aspectos AspectJ e a linguagem declarativa XML [BRAY04] para implementação da camada que provê mecanismos que possibilitam que o servidor RTSP se transforme num software adaptativo. 


\section{Capítulo 3}

\section{Técnicas de Adaptação em Software}

Na seção 2.2 foram mencionados vários mecanismos de QoS fim-a-fim que buscam melhorar a atual arquitetura de natureza de melhor esforço da Internet, onde podemos destacar: (i) extensão do modelo da Internet incorporando reserva de recursos; (ii) oferecimento de serviços diferenciados; e (iii) provimento de novos protocolos e novas arquiteturas de comunicação. Entretanto, apesar desses esforços, ainda existem vários problemas que contribuem para que os requisitos de QoS das aplicações multimídia de rede não sejam oferecidos de forma satisfatória. Em [LUNARDI01], são citados como exemplos:

- heterogeneidade dos sistemas finais fazendo com que uma mesma aplicação se comporte de maneira diferente dependendo da máquina onde é executada;

- oferecimento de reserva de recurso "tudo ou nada", no qual, ou os recursos necessários para uma aplicação são oferecidos, ou nada é oferecido;

- probabilidade de reservas não serem suportadas em grandes partes da Internet ainda que por algum tempo;

- reserva de recursos ser cara em termos de troca de mensagens e possuir tarifação agregada.

Uma possibilidade para a aplicação, frente às deficiências consideradas, é ajustar seu funcionamento às condições variáveis que a rede de comunicação de dados oferece, adaptandose, assim, ao que lhe é oferecido. Essas aplicações adaptativas são chamadas "network-aware", justamente pelo fato de adaptarem seu funcionamento às variações de desempenho do ambiente de rede [GROSS98].

Em [WANG99], as aplicações adaptativas são dividas em três categorias de acordo com localização dos seus mecanismos de adaptação: (i) baseadas no servidor, (ii) baseadas no receptor e; (iii) baseadas na rede. Na primeira o servidor controla a transmissão do fluxo multimídia de acordo com condições da rede e o mecanismo de adaptação consiste na escolha 
de configurações das propriedades de codificação da mídia (por exemplo, fator de qualidade, taxa de quadros, configuração de tipos de quadros usados) para obter uma taxa de transmissão de acordo com as condições monitoradas. Na segunda abordagem as decisões de adaptação cabem ao receptor, numa condição em que o servidor deve replicar uma mesma mídia com diferentes taxas de codificação ou utilizar codificação hierárquica (mecanismo que divide um fluxo de mídia vídeo em várias camadas, permitindo que o mesmo atinja os receptores com diferentes taxas de transmissão) correspondentes a exigências de qualidade de serviço diferentes. Assim, o receptor pode escolher o conteúdo, ou parte dele, mais adequada às suas capacidades ou estado. A abordagem baseada na rede consiste em adaptações de mídias integradas em nós intermediários entre o transmissor e receptor, a fim de adequar o conteúdo multimídia de acordo com capacidades da rede, software e hardware. A tabela abaixo exibe um resumo comparativo entre as três abordagens.

Tabela 3 - Resumo comparativo dos esquemas de adaptação em aplicações multimídia em rede

\begin{tabular}{|c|c|c|c|}
\hline & Baseada no transmissor & Baseado no receptor & Baseado na rede \\
\hline Vantagens & $\begin{array}{l}\text { A adaptação é centralizada } \\
\text { facilitando gerenciamento } \\
\text { e implementação. Não } \\
\text { exige que cliente } \\
\text { implemente mecanismos } \\
\text { de adaptação. Atende } \\
\text { melhor adaptação que } \\
\text { beneficiam grupos. }\end{array}$ & $\begin{array}{l}\text { Como é o usuário que } \\
\text { implementa a } \\
\text { adaptação, permite a } \\
\text { uma decisão de } \\
\text { adaptação mais correta } \\
\text { e sem afetar outros } \\
\text { usuários }\end{array}$ & $\begin{array}{lr}\text { Abordagem } & \text { menos } \\
\text { intrusiva, } & \text { pois, } \\
\text { permanece } & \\
\text { transparente } & \text { para } \\
\text { transmissores } & \text { e } \\
\text { receptores. } & \end{array}$ \\
\hline Desvantagens & 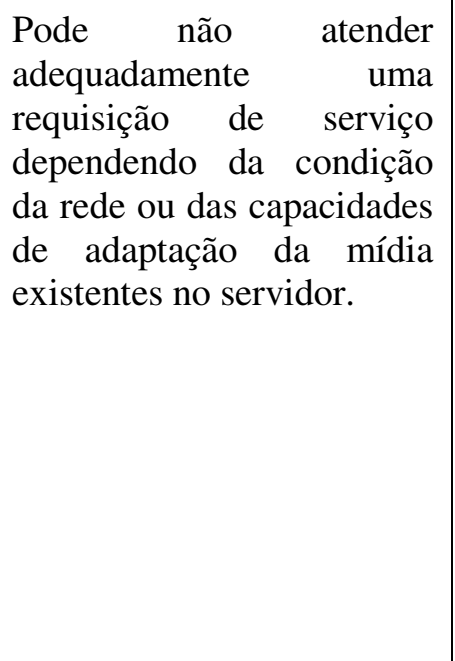 & $\begin{array}{l}\text { Exige que o servidor } \\
\text { armazene diferentes } \\
\text { versões para cada } \\
\text { mídia exigindo } \\
\text { grandes recursos de } \\
\text { armazenamento. } \\
\text { Diversidade de } \\
\text { adaptações depende do } \\
\text { servidor. Pode não ser } \\
\text { aplicada para terminais } \\
\text { receptores com } \\
\text { recursos limitados, } \\
\text { pois, exige a existência } \\
\text { do mecanismo de } \\
\text { adaptacão. }\end{array}$ & $\begin{array}{l}\text { Dificuldade } \\
\text { implementação } \\
\text { coordenação, pois, } \\
\text { depende da instalação } \\
\text { e gerenciamento de } \\
\text { servidores espalhados } \\
\text { pela rede. Como pode } \\
\text { receber conteúdo de } \\
\text { vários servidores e } \\
\text { tipos de conteúdo, a } \\
\text { implementação de } \\
\text { mecanismos para } \\
\text { atender todos os casos } \\
\text { pode ser tornar } \\
\text { complexa. }\end{array}$ \\
\hline
\end{tabular}


Neste trabalho, foram abordados esquemas de adaptação baseado no servidor. Abaixo descrevemos alguns cenários de adaptação que uma aplicação multimídia em rede baseada em servidores pode oferecer:

- escalabilidade e alocação dinâmica de recursos mínimos e adequados para o funcionamento da aplicação de acordo com requisitos exigidos e o ambiente de rede e execução presente. Por exemplo, ajuste da taxa de transmissão de acordo com a exigência mínima do tipo de fluxo multimídia transmitido e monitoração do nível de congestionamento da rede e da carga do sistema computacional de sua operação.

- atendimento das necessidades de diferentes usuários ao mesmo tempo. Por exemplo, pode-se exigir uma configuração de transmissão de vídeo de alta definição e modo de transmissão seguro e multiponto para um grupo de usuários e outra com requisitos totalmente diferentes (vídeo de baixa definição e modo transmissão ponto-a-ponto) para outro grupo de usuários.

- adequação do sistema para a integração de novas tecnologias e requisitos. Por exemplo, utilização de novos protocolos de transporte e mecanismos de garantia de QoS. Este exemplo tem particular importância na área de pesquisa de aplicações multimídia, já que mudanças devem ser constantemente suportadas para realização de estudos e novos experimentos.

Devido aos cenários descritos, diversas técnicas e abordagens devem ser consideradas no âmbito da adaptação no nível da aplicação. Nas próximas seções, descreveremos técnicas de projeto de software que foram desenvolvidas com o intuito de favorecer implantação desses requisitos de adaptação através da extensão de técnicas de projeto orientados a objeto.

\subsection{Software Adaptativo}

O interesse por sistemas com requisitos de adaptabilidade tem crescido muito nos últimos anos e atualmente uma variedade de técnicas permitem que o software adapte-se dinamicamente de acordo com seu ambiente de execução. De acordo com [MCKINLEY04], 
duas revoluções na área de computação são consideradas principais responsáveis pelo crescimento dessa abordagem de desenvolvimento. A primeira é o surgimento da computação ubíqua [WEISER93] que promete mudar a forma tradicional de como, quando e onde o ser humano interage com os computadores. A segunda é a crescente demanda pela computação autônoma [KEPHART03] (autonomic computing) que se constitui no desenvolvimento de sistemas que são autoconfiguráveis; auto-otimizados; automonitorados; e autoprotegidos, precisando de instruções mínimas e de alto nível (lógica de negócio).

O termo adaptabilidade tem sido usado para referenciar sistemas de software adaptável e adaptativo. Frequentemente as palavras adaptável e adaptativo são usadas de forma intercambiável, entretanto, quando usadas em conjunto, elas podem apresentar diferentes significados [DANTAS04a]. Um sistema adaptável pode ser definido como: "um sistema que permite adaptar facilmente uma estrutura completa ou partes específicas devido a mudanças nos requisitos". [TEKINER97]. Já um sistema é dito adaptativo se é capaz de mudar seu comportamento automaticamente, durante sua execução, de acordo com mudanças no contexto do ambiente em que está situado [LIEBERHERR95].

Em [MCKINLEY04], é definida uma classificação para técnicas de adaptação em software em duas abordagens gerais: (i) adaptação baseada em parâmetros (parameter adaptation) e (ii) adaptação por composição (compositional adaptation).

A adaptação baseada em parâmetros consiste na modificação de variáveis do sistema que determinam o seu comportamento. O protocolo TCP é usualmente citado como exemplo de implementação dessa abordagem. O TCP ajusta seu comportamento de acordo com as condições da rede através do seu mecanismo de controle de congestionamento e fluxo, tratando assim erros de transmissão e ajuste de taxas de envio e recebimento de dados. Entretanto, o protocolo não permite que novos algoritmos ou componentes possam ser incorporados depois do projeto original, tornando assim seus parâmetros de adaptação limitados e inerentemente falhos para muitas situações. Em outras palavras, ele permite que se ajuste parâmetros ou direcione uma aplicação para utilizar diversas estratégias originalmente existentes, mas não permite a adição de novas estratégias de funcionamento. 
A abordagem de adaptação por composição, por outro lado, permite a troca de algoritmos ou componentes estruturais de um sistema de modo que o funcionamento geral do sistema se adeque da melhor forma ao atual ambiente de execução. Diferente da adaptação baseada em parâmetros, uma aplicação pode adotar novos algoritmos para endereçar problemas que não foram previstos durante sua construção. Essa flexibilidade permite irmos além da seleção e arranjo de variável de um programa ou seleção de novas estratégias, permitindo uma recomposição dinâmica do software em tempo de execução - por exemplo, adicionar ou retirar componentes de um sistema com memória limitada ou adicionar um novo protocolo de transporte para um sistema já em operação.

No contexto desse trabalho, adaptabilidade está totalmente relacionado a auto-adaptação, ou simplesmente software adaptativo ou com adaptação por composição, o qual é capaz de modificar seu próprio comportamento em resposta às mudanças em seu ambiente de operação [PEYMAN99]. Existem muitos pontos que devem ser observados no desenvolvimento dessa categoria de software [DANTAS04a]:

- as condições que provocam uma adaptação e quão frequentemente devem ser verificadas;

- a habilidade de introduzir novos comportamentos e adaptação a uma aplicação em tempo de execução;

- o tipo de autonomia que será suportado (se adaptação totalmente automática ou com intervenção humana);

- o custo-benefício de uma adaptação e;

- o gênero da informação que será coletada para realizar decisões de adaptação;

- garantir que a realização de uma operação de adaptação não vai alterar a consistência do funcionamento da aplicação.

Contudo, além de considerar todos esses pontos, um grande desafio que o desenvolvedor encontra atualmente é atender concomitantemente adaptabilidade e manutenibilidade em sistemas adaptativos. Prover flexibilidade na arquitetura de um software muitas vezes conduz a 
um código que é difícil de entender e isso conduz a uma manutenibilidade ruim, especialmente quando um comportamento adaptável deve mudar, ou um novo deve ser incluído. O tipo de manutenção que procura adicionar novas ou alterar funcionalidades já existentes num sistema de software é conhecida como manutenção adaptativa [LIENTZ78].

Nas seções seguintes, são discutidas as principais técnicas atuais de projeto para desenvolvimento software adaptativo e que também procuram atender o requisito de manutenção adaptativa.

\subsection{Técnicas de Projeto de Software Adaptativos}

A idéia de adaptação por composição existe desde o início da computação [MCKINLEY04, LOUGHRAN05]. A indústria e a comunidade científica desde a década 70 [DIJKSTRA82, PARNAS72] procuram elaborar técnicas de construir programas de forma modular para tornar o código mais compreensível e assim, diminuir a complexidade, facilitar a manutenção e possibilidades de evolução. Devido à alta complexidade e crescente necessidade para construir e testar este tipo de software, mais de três décadas depois, a capacidade de adaptação de um software continua como ponto central de estudo na engenharia de software.

Novas ferramentas e técnicas têm surgido para tentar ajudar a facilitar a resolver essa questão. Nas próximas seções pretendemos fazer uma revisão dos principais conceitos e tecnologias envolvidos na área de adaptação por composição de sistemas orientados a objeto. Várias destas técnicas estendem o modelo convencional de orientação a objetos.

\subsubsection{Software Baseado em Componentes}

Outra tecnologia que suporta adaptação por composição é a técnica de projeto de software baseado em componentes. Componentes de software são unidades de software da qual se conhece apenas as interfaces, especificadas na forma de contratos, e as dependências de contexto. Um componente pode fazer parte de outros componentes, e pode ser disponibilizado independentemente, bem como utilizado em composições por terceiros. [SZYPERSKY02]. 
De acordo com [BARROS05], na primeira fase do desenvolvimento baseado em componentes, a preocupação básica concentrou-se em mecanismos de definição de interfaces (de programação e comunicação) e de encapsulamento de componentes de maneira a permitir que eles fossem interligados e configurados para atender os requisitos funcionais das aplicações de interesse (CORBA, Java/RMI, DCOM/.NET). Na fase atual, onde a tecnologia básica de componentes apresenta-se mais madura (por exemplo, Enterprise Java Beans, Corba Component Model, Web Services) a preocupação concentra-se em caracterizar os diversos aspectos não-funcionais (ou operacionais), por exemplo, desempenho e disponibilidade, que podem ser associados aos serviços ou componentes. Esta caracterização fornece os fundamentos necessários para o estabelecimento de responsabilidades individuais e mútuas destes componentes, e estabelecer a infra-estrutura de suporte, visando a garantia de propriedades do serviço oferecido como um todo.

O projeto baseado em componentes suporta dois tipos de composição: estática e dinâmica. Na composição estática, um desenvolvedor pode combinar vários componentes em tempo de compilação para produzir uma aplicação. Na composição dinâmica, o desenvolvedor pode adicionar, remover ou reconfigurar componentes de uma aplicação em tempo de execução. Para prover adaptação dinâmica, a infra-estrutura de suporte (normalmente representada por um framework) deve suportar ligação dinâmica (dynamic binding ou late binding), que permite que o acoplamento entre componentes compatíveis em tempo de execução através de interfaces bem definidas através de contratos. Adicionalmente, para permitir a consistência com outras aplicações, um framework baseado em componentes também deve suportar a coexistência de múltiplas versões de componentes. Por permitir a composição de software através de componentes de diferentes fornecedores, o projeto baseado em componentes promove a reutilização de software. Além disso, mecanismos para manter uma estrutura de um componente depois da sua implantação inicial, quando combinada com ligação dinâmica, facilitam a adaptação por composição [MCKINLEY04]. 


\subsubsection{Reflexão Computacional}

A técnica de Reflexão Computacional [MAES87] vem sendo amplamente reconhecida com um mecanismo poderoso de implementação de sistemas que demandem mudanças dinâmicas na sua estrutura e comportamento. Um sistema reflexivo mantém estruturas para representar a si próprio. No modelo de objetos, reflexão pode ser usada para interceptação e modificação do comportamento de operações básicas, tais como, criação de classes/objetos e invocação de métodos.

A arquitetura de um sistema reflexivo [SCHMIDT01] é formada por dois componentes principais: o meta-nível e o nível base. O meta-nível define, através dos meta-objetos, a própria representação da estrutura e comportamento do sistema. Os meta-objetos representam informações do sistema, tais como, estrutura de tipos e mecanismos de chamadas de funções. Já o nível base define a própria aplicação lógica do sistema; na sua implementação são utilizados os meta-objetos. Se um meta-objeto á alterado estática ou dinamicamente (através de um protocolo meta-objeto), a parte de implementação no nível base que utiliza os serviços ou informações deste meta-objeto também sofre alterações no que diz respeito a sua funcionalidade. O protocolo meta-objeto funciona como uma interface externa do meta-nível, através da qual aplicações podem especificar modificações para os meta-objetos.

A implementação de computação reflexiva pode vir através do suporte nativo em linguagem de programação, por exemplo, Common Lisp Object System (CLOS), Python ou várias variações da linguagem Java - ou através de plataformas de middleware. A reflexão computacional também pode ser combinada com a Programação Orientada a Aspectos [MCKINLEY04]

\subsubsection{Separação de Interesses}

Separação de interesses é um princípio bem estabelecido da engenharia de software que diz que, para se dominar a complexidade do desenvolvimento de software, deve-se separar as suas preocupações de forma a se concentrar em apenas uma por vez [GHEZZI91]. A primeira pessoa a usar o termo "separação de interesses" (separation of concerns) foi Dijkstra em seu 
livro "A Discipline of Programming" [DIJKSTRA76], onde ele diz que a característica principal do pensamento inteligente é ser capaz de estudar em profundidade um aspecto de determinado problema isoladamente, para o bem de sua própria consistência, mas sabendo o tempo todo que outros aspectos estão esperando sua vez, pois a mente humana é tão limitada que não consegue lidar com todos eles simultaneamente sem ficar confusa.

Um interesse (concern) é alguma parte do problema que se deseja tratar como uma unidade conceitual única [TARR99]. Um interesse pode ser um requisito, uma funcionalidade ou uma propriedade do sistema. Nos paradigmas atualmente dominantes, como o funcional, o de procedimentos e o de objetos ${ }^{5}$, interesses são modularizados por meio de diferentes abstrações providas por linguagens, métodos e ferramentas. As abstrações básicas do desenvolvimento de software orientado a objetos (DSOO) são classes, objetos, métodos e atributos. No entanto, essas abstrações podem não ser suficientes para separar alguns interesses especiais existentes em muitos sistemas complexos e que precisam ser compostos diferentemente e ainda ser coordenados. Esses interesses são chamados de interesses transversais, uma vez que, inerentemente, atravessam os componentes responsáveis pela modularização de outros interesses, ou seja, interesses transversais atravessam e permeiam vários objetos e ficam espalhados pela estrutura de classes do sistema. Sem meios apropriados para sua separação e modularização, os interesses transversais tendem a ficar espalhados e misturados a outros interesses. As consequiências naturais são: (i) a redução da facilidade de entendimento, (ii)o aumento da dificuldade de evolução e (iii)a diminuição da reusabilidade dos artefatos de software.

Em termos gerais, a separação de interesses possibilita o desenvolvimento separado do comportamento funcional de uma aplicação, isto é, da lógica de negócio, do código que implementa os interesses transversais, normalmente não inerente ao domínio da aplicação, tais como, Qualidade de Serviço (Qos), tolerância a falhas, tratamento de exceções, persistência,

\footnotetext{
${ }^{5}$ Esses paradigmas têm em comum o fato de se basearem na decomposição funcional como ponto principal de um projeto de software, onde cada interesse a ser implementado é encapsulado em um módulo apropriado.
} 
distribuição, sincronização e segurança. Atualmente, a principal implementação dessa abordagem é a técnica de desenvolvimento de software baseada em Programação Orientada a Aspectos (POA) [MCKINLEY04, LOUGHRAN05], que pretendemos usar no nosso trabalho e será detalhada numa seção posterior deste capítulo.

\subsubsection{Outras técnicas para adaptação por composição}

Além das três principais técnicas citadas anteriormente que suportam adaptação por composição, muitos outros fatores têm contribuído para o crescimento dessa área da engenharia de software. Talvez, a mais importante seja a crescente importância e emprego de middleware para computação distribuída [MCKINLEY04]. Um middleware provê uma camada que oculta detalhes da infra-estrutura da plataforma de execução de aplicações, mas que o desenvolvedor pode utilizar para implementar implícita ou explicitamente (dependendo de como o middleware expõe suas interfaces) comportamentos adaptativos. De fato, muitas técnicas de adaptação por composição podem ser empregadas em todas as camadas de um middleware. Outras técnicas importantes para um projeto de software adaptativo que permitem adaptação por composição e não serão detalhas são: padrões de arquitetura e projeto (architectural patterns e design patterns), agentes móveis, programação generativa (generative programming), programação intencional (intentional programming), programação orientada a assunto (subjetc orientedprogramming), programação adaptativa (intentional programming) e filtros de composição (composition filters). Maiores informações e discussões sobre a maioria dessas técnicas podem ser encontradas em [CZARNECKI00].

\subsection{Programação Orientada a Aspectos}

Como descrito nas seções anteriores, atualmente, é possível encontrar diversas abordagens que tratam o desenvolvimento de software com técnicas de projeto de software adaptativo. Porém, como já citado, a adaptabilidade adiciona certa complexidade ao desenvolvimento de aplicações. Um dos problemas é que a implementação de comportamentos adaptativos em muitos casos se entrelaça com outros interesses da aplicação (tais como, 
apresentação, negócio, qualidade de serviço, segurança e persistência) levando a problemas de modularização que podem prejudicar o entendimento e a manutenibilidade do código tanto dos interesses de adaptação da aplicação quanto dos demais [MCKINLEY04]. Em outras palavras, o requisito de adaptabilidade representa normalmente um interesse transversal de um sistema.

Abordagens que se baseiam no paradigma orientado a objeto utilizando técnicas, tais como, frameworks, padrões arquiteturais e de projeto são exemplos de abordagens que não permitem separação de interesses dos requisitos de adaptabilidade [LOUGHRAN05]. Por outro lado, as "arquiteturas reflexivas" ou "meta-arquiteturas" [BUSCHMANN96, YODER98] normalmente oferecem separação de interesses transversais de forma adequada, mas exigem o entendimento de protocolos meta-objeto que são complexos, de domínio de aplicação restrito e de difícil aprendizado [KICZALES97] .

A programação orientada a aspectos atualmente é vista como uma evolução das técnicas citadas anteriormente e procura facilitar a resolução de problemas relacionados à modularização do código de interesses transversais, dando assim suporte a implementação de requisitos de adaptação encontrado em determinadas aplicações.

\subsubsection{Conceitos Básicos}

O termo "Programação Orientada a Aspectos" foi introduzido no ano de 1996 no Centro de Pesquisas da Xerox de Palo Alto (PARC). No ano de 1997, foi apresentado aquele que é considerado o artigo seminal de POA: "Aspect-Oriented Programming”[KICZALES97]. Neste artigo, as propriedades que precisam ser implementadas em um sistema são divididas em dois tipos:

- componentes: elementos que podem ser facilmente modularizados através do processo tradicional de decomposição funcional;

- aspectos: o oposto do anterior, ou seja, elementos que representam propriedades que precisam ser satisfeitas em vários componentes de um sistema, como configuração de alguma característica do sistema que envolve vários componentes, ou que não fazem parte .dos requisitos funcionais dos componentes, por exemplo, monitoração. 
Assim, o objetivo de POA é promover a especificação separada de interesses nãotransversais (os componentes) e transversais (os aspectos) de sistemas de modo bastante simples, e ainda compô-los de entre si da maneira apropriada de forma a construir o sistema desejado.

De acordo com [CHAVES04], um sistema construído com POA é composto de: (i) uma linguagem de componentes; (ii) uma (ou mais) linguagem(ns) de aspectos; (iii) código de programas de componentes; (iv) código de programas de aspectos; e (v) um compilador de aspectos (ou combinador de aspectos, do inglês: aspect weaver), que é capaz de combinar o código dos programas de componentes e de aspectos de forma a gerar um programa final [PIVETA01].

A linguagem e o código dos programas de componentes (podem ser inclusive, sistemas legados) normalmente são representados por linguagens de programação que segue um dos paradigmas de software dominante, tais como: Java, C++, Pascal, C, SmallTalk, Lisp, C\# e etc.

Já para a linguagem e o compilador de aspectos, normalmente são usadas soluções associadas e que utilizam uma abordagem específica ou genérica de acordo com o escopo da sua aplicação. Nos trabalhos iniciais do grupo de programação orientada a aspectos do Xerox PARC foram desenvolvidas diferentes linguagens para a especificação e composição de aspectos para domínios e interesses específicos, por exemplo, concorrência, sincronização de objetos e estratégias de transferência de dados entre ambientes remotos. Atualmente, o grupo vem desenvolvendo uma linguagem de aspectos de propósito geral AspectJ, que será utilizada em nosso trabalho e explicada resumidamente na seção 3.3.3, através de exemplos de código de um

programa de aspectos. É importante também lembrar que existem outras linguagens e ferramentas atuais, tanto genéricas quanto específicas, em uso e desenvolvimento para POA na comunidade científica e industrial, porém, não abordaremos tais soluções neste trabalho.

\subsubsection{Vantagens e Desvantagens}

A principal vantagem do uso de POA é que a separação de interesses permite a facilidade para o processo de criação, entendimento, evolução e futura manutenção do software. 
Isso é possível devido os interesses transversais não aparecem no código dos componentes, ficando corretamente encapsulados nos aspectos. Os componentes e aspectos ficam mais legíveis individualmente, além da forma como eles se compõem. Além disso, na programação orientada a aspectos o reuso de código é sensivelmente mais efetivo [CHAVES04], uma vez que o componente torna-se reutilizável em uma maior variedade de situações, devido a inexistência de dependências relacionadas a requisitos implementados por aspectos, que normalmente representam requisitos secundários e não relacionados com a lógica de negócio da aplicação.

Entre as desvantagens da adoção de POA, podemos citar: (i) dificuldade inicial de aprendizado de um novo paradigma (por exemplo, familiaridade com os novos conceitos e construções de uma linguagem de aspectos); (ii) baixa maturidade dos ambientes de desenvolvimento que pode levar a problemas como tempo de compilação (ou combinação entre componentes e aspectos), tamanho e desempenho na execução do código final gerado na compilação; e (ii) problemas relacionados a composição de aspectos inerentes da orientação a aspectos (por exemplo, aspectos que se compõem podem ser incompatíveis e aspectos que implementam propriedades que possuem precedência entre si). Com exceção do item (i), a maioria dos problemas já são satisfatoriamente resolvidos com a evolução das ferramentas disponíveis atualmente.

\subsubsection{AspectJ}

AspectJ [ASPECTJ05] [KICZALES01a] [KICZALES01b] é a linguagem orientada a aspectos mais conhecida atualmente e utilizada por várias soluções de software da indústria, como por exemplo, o servidor de aplicação JBoss [JBOSS_AOP]. Inicialmente criada no XEROX PARC, hoje é mantida pelo projeto de código aberto Eclipse [ECLIPSE].

A opção pelo uso da linguagem de aspectos e compilador da AspectJ baseou-se no argumento que ela é uma extensão orientada a aspectos da linguagem de programação Java [GOSLING00], o que permite o uso do paradigma POA de forma eficiente em aplicações Java puramente orientadas a objetos. Com AspectJ os aspectos e seus elementos são combinados com o código Java (o programa de componentes) através da utilização de um compilador especial 
(ou combinador), chamado de weaver. O resultado final desse processo é um código Java comum (bytecode), que torna possível a execução da aplicação com aspectos totalmente portável em qualquer ambiente de execução da plataforma Java.

Além da modularização das funcionalidades que implementam interesses transversais, AspectJ torna possível o desenvolvimento independentes dessas partes do sistema, através da associação entre aspectos e componentes de uma forma que apenas o aspecto referencia o componente. É possível, por exemplo, que os aspectos que implementam requisitos nãofuncionais detectem eventos ou afetem o comportamento de componentes que implementam requisitos funcionais, sem esses não terem conhecimento daqueles.

Como uma extensão da linguagem Java, AspectJ acrescenta alguns novos conceitos e construções associadas. Esses conceitos e construções são: aspecto, ponto de junção (join point), um ponto bem definido da execução dinâmica de um programa em Java, pointcut, advice e declaração intertipos (inter-type declaration), que serão explicados adiante.

Aspecto representa a unidade de modularidade para interesses transversais em AspectJ. Eles efetivamente podem alterar componentes sobre os quais atuam, encapsulando uma funcionalidade de natureza estática (estrutural) e/ou dinâmica (comportamental) que entrecorta outras classes do programa. Um aspecto é similar a uma classe Java e, além de conter métodos, atributos e relacionamento com outros aspectos, é definido em termos de pointcuts, advices e declarações inter-tipos. Instancias de um aspecto podem ser associados a um objeto, mas também com outros elementos de tempo de execução da linguagem Java. A instancia é automaticamente criada quando o alvo da associação (elemento de tempo de execução) é ativado. Os aspectos podem ser flexivelmente incluídos e/ou excluídos do contexto de componentes de produção, assim como serem utilizados apenas na fase de desenvolvimento.

Pointcuts definem uma coleção de pontos de junção, que são elementos que especificam como as classes e os aspectos estão relacionados. Além disso, descrevem e dão nome a conjuntos de pontos de junção. As definições de pointcuts são especificadas utilizando designadores (pré-definidos na linguagem ou elaborado pelo programador a partir dos 
existentes) que podem representar: chamada de métodos, execução de métodos, criação de objeto, atribuição de referencia, lançamento de exceção e etc. Os pointcuts podem ser combinados utilizando operados lógicos, além da possibilidade de utilizar curingas (do inglês, wild cards) para construções mais avançadas.

Advice é um mecanismo análogo a um método onde se define qual é o trecho de código que deve ser executado quando um pointcut é atingido. AspectJ suporta advices dos tipos before, after e around, que determinam o tempo que o seu código é executado. Os advices before e after definem uma execução antes e depois, respectivamente, de um pointcut. Já o advice around, além de definir a execução de um código quando um pointcut é atingido, ele permite o controle sobre a computação de cada ponto de junção definido (por exemplo, a substituição total de uma execução de um método).

Adicionalmente, um aspecto pode introduzir métodos, atributos, relacionamento entre interfaces e classes usando a construção chamada de declaração intertipos. De forma simplificada, podemos ver pointcuts e advices como a representação da parte dinâmica da linguagem AspectJ. Já as construções de declaração de inter-tipos, permite a mudança na estrutura estática de um programa, por exemplo, adicionando campos e/ou métodos a classes alterando o relacionamento entre classes.

Um programa que utiliza AspectJ pode ser dividido em duas partes: a parte do código do programa de componentes que inclui classes, interfaces e outras construções da linguagem Java para implementar a funcionalidade básica da aplicação, e a parte do código do programa de aspectos que inclui os aspectos para implementar os interesses transversais da aplicação. $\mathrm{O}$ weaver da AspectJ, que é responsável por fazer a composição entre o código base e o código de aspectos, é chamado de "ajc".

\subsection{Considerações}

De forma segura, podemos crer que a programação orientada a aspectos em conjunto com AspectJ tem méritos suficientes para se estabelecer como um ferramenta auxiliar no 
desenvolvimento de software orientado a objetos, particularmente Java, melhorando as potencialidades de abstração, encapsulamento e reuso desse paradigma.

Além disso, fica bastante clara a importância da sua aplicação no projeto e desenvolvimento de software adaptativo, onde normalmente os requisitos de adaptabilidade são representados por interesses transversais.

No próximo capítulo será apresentado o uso de POA e AspectJ para o projeto e desenvolvimento de uma camada de adaptação, que permite a construção de aplicações multimídia em rede adaptativas. 


\section{Capítulo 4}

\section{A camada de adaptação}

Como vimos no capítulo 2 e 3, as aplicações multimídia de rede sofrem de certos problemas que dificultam o trabalho dos desenvolvedores que constroem software nesse domínio. Visando oferecer uma solução adequada às necessidades de adaptação levantadas, descrevemos neste capítulo uma camada de software desenvolvida com técnicas de projeto adaptativo e a linguagem de programação orientada a aspectos AspectJ. O objetivo principal é oferecer um suporte genérico para mecanismos de adaptação na transmissão de fluxos multimídia. Inicialmente, é apresentada uma aplicação de transmissão sem adaptação, depois a especificação e implementação de uma camada de adaptação e os respectivos mecanismos de monitoração e adaptação desenvolvidos. Nas últimas três seções são apresentados os resultados experimentais do sistema proposto e uma análise comparativa com trabalhos relacionados.

\subsection{O Servidor RTSP}

Para validar a camada de adaptação proposta neste trabalho, desenvolvemos um servidor RTSP (Real Time Streaming Protocol) com a tecnologia Java e que utiliza a API JSA (capítulo 2) para realizar o gerenciamento das transmissões dos fluxos de mídias.

Um servidor RTSP é uma aplicação capaz de permitir a interação cliente-servidor para transmissão de fluxos de mídia ao vivo e sob demanda. Essa interatividade possibilita uma configuração mais flexível (através da troca de parâmetros no estabelecimento de sessões) entre o servidor e o cliente e também maior controle do usuário (cliente) sobre a reprodução da mídia. A versão do servidor RTSP desenvolvida é simples, com suporte aos comandos básicos da especificação RTSP, tais como: OPTIONS, DESCRIBE, SETUP, PAUSE, PLAY, REDIRECT e TEARDOWN. Optamos pelo uso do RTSP, pois é um protocolo bastante utilizado para o estabelecimento de conexões de transmissão multimídia. Todavia, devido o projeto estar estruturado de modo adaptável, nada impede que a aplicação seja reestruturada para empregar o 
outro protocolo para estabelecimento de sessões (por exemplo, o SIP, Session Initiation Protocol). A figura abaixo exibe um exemplo de estabelecimento de sessão entre o servidor e um cliente RTSP

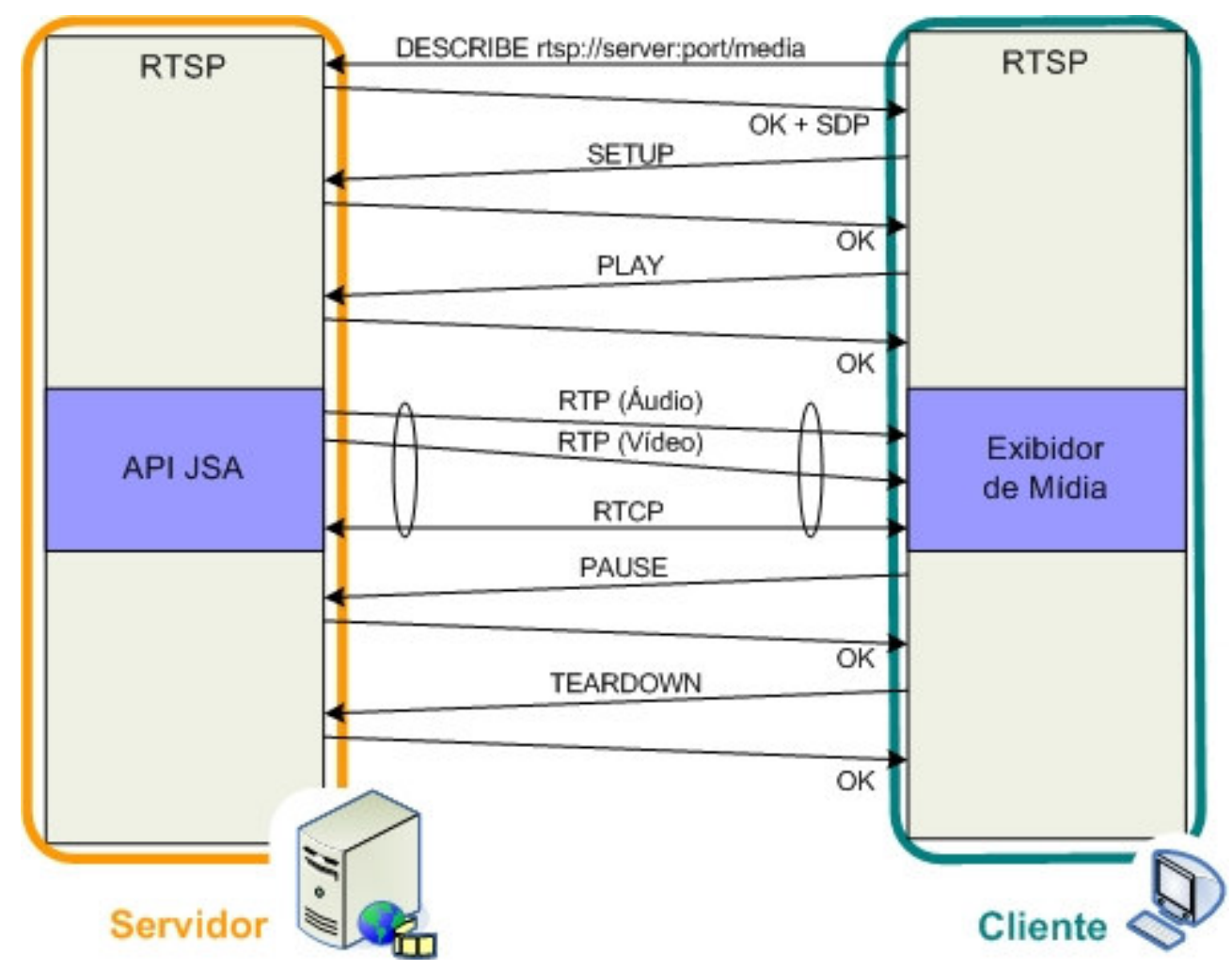

Figura 9 - Exemplo do funcionamento do servidor RTSP

De forma resumida ilustramos a estrutura do servidor RTSP no diagrama UML da Figura 10, através de dois pacotes principais: "rtsp" e "jsa". O pacote "rstp" é representado por 5 (cinco) classes principais, sendo elas: (i) RTSPServer, centraliza o acesso ao servidor, através da implementação da recepção de requisições (utiliza classe serverSocket da API padrão Java), além de encapsular e delegar tarefas para os demais componentes do servidor; (ii) RTSPMessage, responsável pela interface de envio e construção das mensagens de resposta às requisições (através da classe ClienteSocket da API Java padrão); (iii) RTSPHandler, thread que realiza a interpretação das requisições concorrentemente; (iv) RTSPBase, armazena as principais propriedades, estados e sintaxe de comandos do servidor; e finalmente (v) RTSPSession, classe que guarda o estado de cada sessão aberta pelo servidor e realiza a interface sobre as ações numa sessão de transmissão multimídia. 


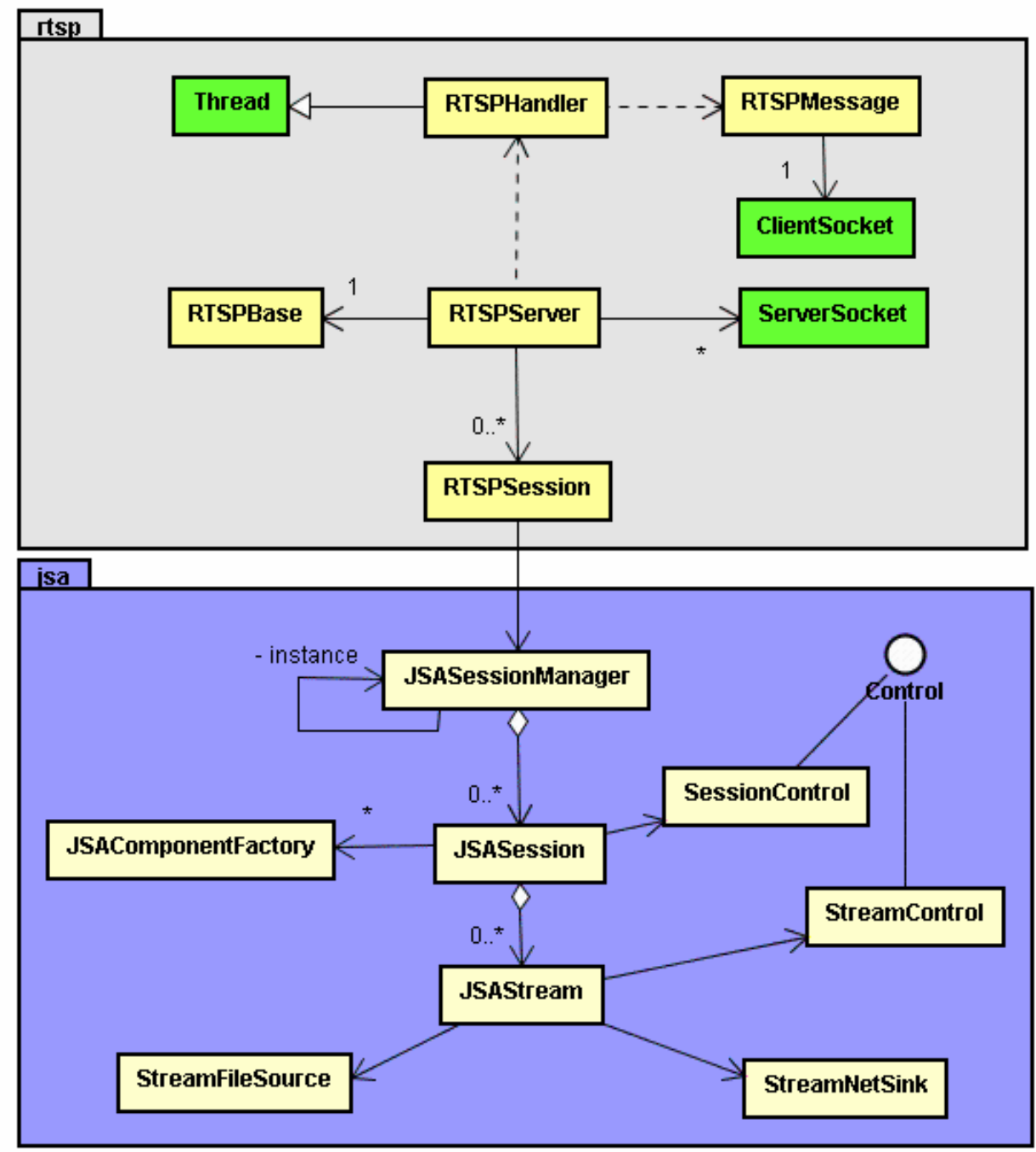

Figura 10 - Diagrama de classes do Servidor RTSP

O pacote "jsa" representa os componentes da API JSA, onde a classe JSASessionManager representa um fachada que gerencia a criação e execução das sessões (JSASession) de transmissão multimídia (através de uma classe SessionControl para cada sessão). Casa sessão pode conter um ou mais processos (pipeline) de transmissão de mídia, que no servidor RTSP é visto como um conjunto de elementos que realizam tarefas e são organizados em seqüência, seguindo o modelo de componentes da API JSA. Na Figura 10 são exibidos 4 (quatro) elementos principais: (i) JsaComponentFactory, StreamFileSource, (iii) StreamNetSink e (iv) JSAStream. O primeiro fornece uma classe para criar objetos StreamFileSource, StreamNetSink e JSAStream, implementado o padrão de projeto "Abstract Factory" [GAMMA95] O segundo implementa o componente que é 
responsável pela leitura da(s) fonte(s) multimídia (representado por um arquivo de áudio e/ou vídeo ou um dispositivo de captura) realizando o processamento de acordo com os atributos da(s) mídia(s). O terceiro tem a função de empacotar o conteúdo da(s) fonte(s) multimídia de acordo com o tipo de codificação da(s) mídia(s) e protocolo de transporte específico (por exemplo, UDP ou RTP). O último realiza a conexão entre os dois últimos, agregando e expondo o controle do processo de transmissão para a JSASession (especificamente, através de uma classe StreamControl). Outros elementos de mais baixo nível de controle da API JSA (por exemplo, portas) que são detalhados na seção 2.4 também estão presentes na implementação do servidor RTSP, mas não foram citados para simplificar a descrição.

Na versão apresentada nesta seção, o servidor RTSP dá suporte a transmissão de vídeo nos formatos H.263 ou MPEG-1 através de RTP, não oferecendo suporte a nenhum mecanismo de configuração ou controle adaptativo. Nas próximas seções nós apresentaremos a inclusão de uma camada de adaptação de forma a possibilitar mudanças na configuração da transmissão de acordo com a monitoração das sessões de transmissões e ambiente de execução.

\subsection{Visão Geral da Camada}

Uma visão geral da Camada de Adaptação proposta é exibida na Figura 11, a qual é constituída por um Módulo de Configuração, um Módulo de Adaptação e um Módulo de Monitoração. A Camada de Adaptação é apresentada como uma camada funcional que está sobre uma Camada de Transmissão, que representa componentes que permitem realizar sessões de transmissão de fluxos de mídias, implementando entre outras funcionalidades, acesso a protocolos de transporte e rede (por exemplo, UDP e IP). Implementação de serviços como configuração das sessões de transmissão, monitoração de Qualidade de Serviço para cada sessão, monitoração do ambiente de execução e adaptação das sessões de transmissão de acordo com os parâmetros definidos em políticas de monitoração e adaptação pré-definidas, são exemplos de funcionalidades disponibilizadas pela Camada de Adaptação à Camada de Aplicação, que pode ser representada por uma aplicação multimídia em rede (por exemplo, um servidor de vídeo sob demanda) ou um usuário responsável pela definição das políticas. 


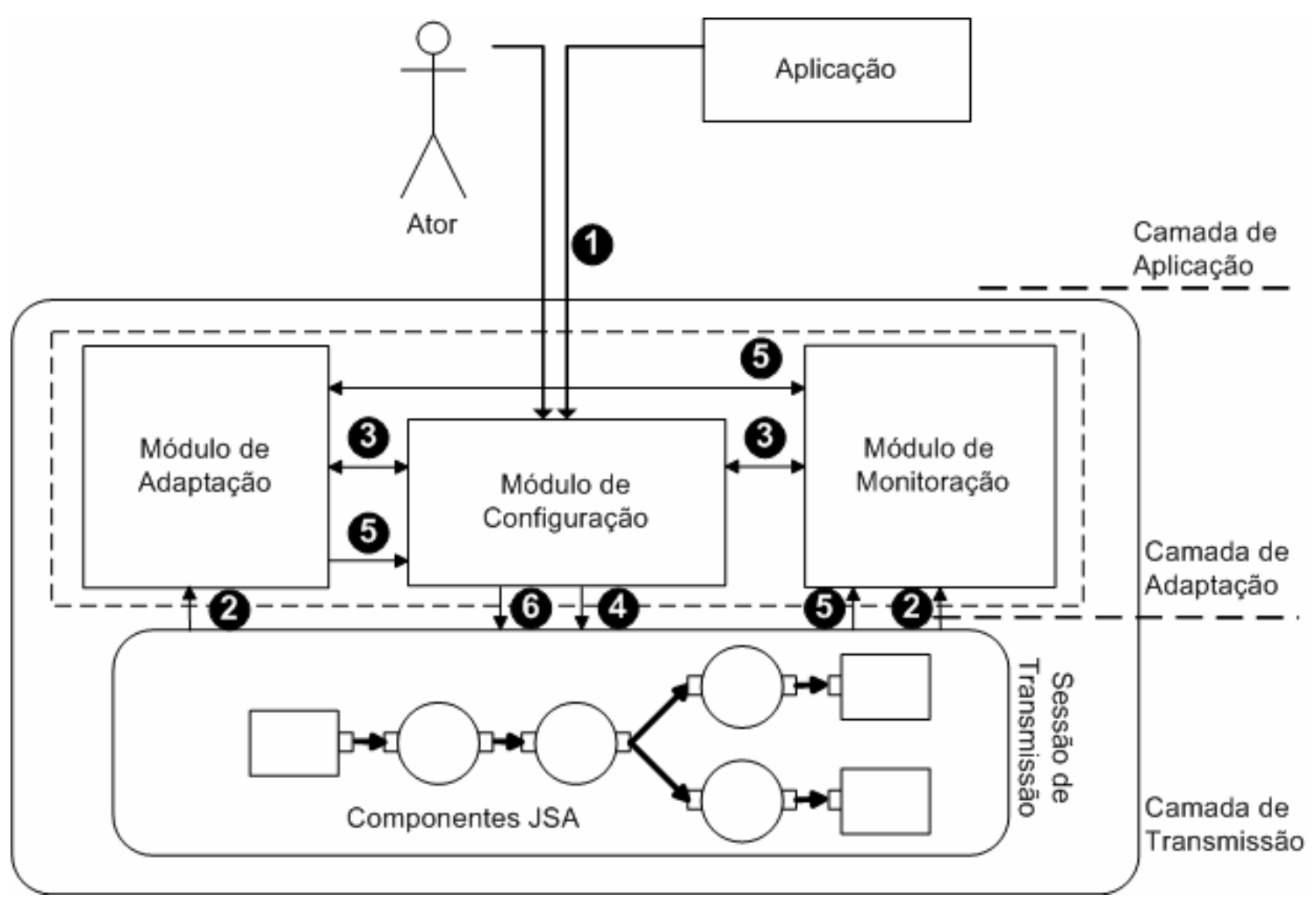

Figura 11 - Visão Geral da Camada de Adaptação

A Figura 11 ilustra o ciclo básico de funcionamento da camada de adaptação, através de um conjunto de 6 passos. No passo (1) ocorre a especificação de atributos e valores de configurações de inicialização para as políticas de adaptação e monitoração pela aplicação. No passo (2), elementos da camada de transmissão são interceptados pelos módulos de adaptação e monitoração da camada de adaptação com o intuito de realizar a configuração inicial dos seus componentes e da própria camada de transmissão (passos 3 e 4). O passo (3) envolve a configuração dos componentes da camada de adaptação (por exemplo, monitoração) para permitir mudanças durante a execução (configuração dinâmica). A configuração inicial das sessões de transmissão é realizada no passo (4), ele envolve desde a definição da política de concorrência a ser usada por todas as sessões até a instanciação de componentes específicos (por exemplo, componentes para transmissão UDP de arquivo no formato MPEG-2 TS). O passo 5 define a monitoração e geração de eventos das sessões de transmissão e do ambiente de execução. Finalmente, o passo (6) determina a execução de configurações adaptativas nas sessões de transmissão, de acordo com eventos recebidos da monitoração e políticas adaptativas definidas no módulo de configuração. 


\subsubsection{Módulo de Configuração}

Este módulo da Camada de Adaptação executa a configuração inicial dos componentes para cada sessão de transmissão instanciada de acordo com parâmetros passados pela aplicação ou desenvolvedor e chamadas interceptadas no Módulo de Adaptação. Além disso, ele é responsável pela disponibilização de dados para mudanças dinâmicas, ou simplesmente, políticas de adaptação, de acordo com mudanças reportadas pelo Módulo de Monitoração. Isto significa que numa situação que é representada pelos mesmos eventos gerados pelo Módulo de Monitoração podem implicar em comportamentos distintos em momentos diferentes de acordo com os dados fornecidos por este módulo para o Módulo de Adaptação.

\subsubsection{Módulo de Monitoração}

Este módulo representa elementos genéricos que devem implementar funcionalidades de monitoração no ambiente de execução da camada de adaptação. No contexto deste trabalho, no Módulo de Monitoração foram especificados dois tipos de monitores: o monitor de sessões de transmissão e o monitor do sistema (ambiente de execução). A partir dos dados passados pelo Módulo de Configuração, o monitor de sessão passa a observar eventos relacionados com as sessões em execução, reportando parâmetros de desempenho associado ao protocolo de transporte empregado por cada sessão individualmente. Já o monitor do sistema é responsável pelo recolhimento de estatísticas de utilização do sistema computacional onde as sessões de transmissão estão sendo executadas. Dessa forma, os dois monitores em conjunto, através da geração de eventos, poderão indicar a ocorrência de violações de políticas para o gerente de adaptação e que foram inicialmente definidas pelo Módulo de Configuração.

\subsubsection{Módulo de Adaptação}

Este módulo possibilita a implementação do requisito de adaptabilidade de forma não intrusiva das sessões de transmissão, que pode ser entendido, no domínio desse trabalho, como o processo ou mecanismo no qual as sessões de transmissão tornam-se capazes de ajustar-se às mudanças constantes nas condições da rede e do seu ambiente de execução. Dessa forma, esse módulo, em conjunto com o Módulo de Configuração e Monitoração, torna as aplicações 
multimídia em rede adaptativas perante variações dinâmicas no desempenho da rede e do seu ambiente de execução. Isso significa que as sessões de transmissão devem tolerar flutuações, obviamente até um limite estipulado, de operação da rede ou do sistema, ajustando seu funcionamento ao que lhe é oferecido. Assim, podemos considerar que não existem protocolos de reserva de recursos, nem contrato de QoS com a rede ou o ambiente de execução.

Mecanismos de adaptação possuem um conjunto de políticas de adaptação. Na camada proposta, uma política de adaptação pode ser entendida como um conjunto de estratégias que tentarão assegurar à Camada de Aplicação que essa terá pelo menos um nível aceitável de execução da tarefa requisitada. Nesse caso, a regra de adaptação consiste em realizar ações corretivas baseadas nas condições verificadas e nos requisitos e configurações especificadas pela Camada de Aplicação e que podem mudar de forma dinâmica.

Como já citado no capítulo 3, mecanismos de adaptação podem utilizar três abordagens diferentes de acordo com sua localização: (i) baseado no transmissor, (ii) baseado no receptor ou (iii) baseado na rede. $\mathrm{Na}$ Camada de Adaptação proposta implementamos apenas a primeira abordagem, situada no lado transmissor. Onde o Módulo de Adaptação controla a instanciação inicial e finalização dos componentes que representam uma sessão de transmissão num servidor. Adicionalmente, este módulo define estratégias de comportamento e/ou arranjo durante a execução dos componentes das sessões e que pode mudar a qualquer momento para se adequar de forma satisfatória às mudanças reportadas pelo Módulo de Monitoração. Além disso, o Módulo de Adaptação se comunica com o Módulo de Configuração de forma a obter os dados para adaptação de forma de dinâmica (políticas de adaptação) e delegar a execução da reconfiguração adequada. A seção seguinte descreve em mais detalhes o funcionamento da arquitetura proposta e na seção 4.4 é descrita sua implementação com Java e AspectJ

\subsection{Funcionamento da Camada}

Nesta seção é explicado resumidamente o funcionamento dinâmico dos módulos constituintes da Camada de Adaptação e a sua relação com as outras camadas. Ao invés de representar objetos, cada caixa do diagrama (Figura 12 e Figura 13) de sequiência representa 
uma coleção de objetos, que corresponde a um determinado módulo das camadas (Figura 11).

Tal modelo foi baseado no trabalho realizado em [DANTAS04a].

Através da Figura 12, ilustramos um cenário onde é realizada uma configuração estática na sessão de transmissão iniciada e também nos elementos responsáveis pela monitoração da mesma:

- A aplicação inicia a execução e requisita a abertura de uma Sessão de Transmissão;

- $\quad$ O Módulo de Adaptação intercepta o(s) ponto(s) de execução (através da implementação do conceito de pontos de junção de POA) da criação da sessão onde uma configuração inicial deve ser realizada;

- $\quad$ O Módulo de Adaptação verifica o estado atual do ambiente de operação (por exemplo, carga atual do sistema ou número de sessões abertas) e realiza uma consulta ao Módulo de Configuração e decide que configuração inicial deve ser realizada,

- $\quad$ No Módulo de Configuração, através de classes auxiliares, é implementada a aplicação da configuração inicial da sessão (por exemplo, estratégia de concorrência e parâmetros iniciais de componentes para transmissão de mídia).

- $\quad$ O Módulo de Monitoração intercepta então o término do processo de criação da sessão e inicia um processo de monitoração individual para a sessão criada, realizando uma consulta ao Módulo de Configuração para verificar e decidir que política de monitoração que deve ser realizada (por exemplo, parâmetros de uma monitoração RTCP). 


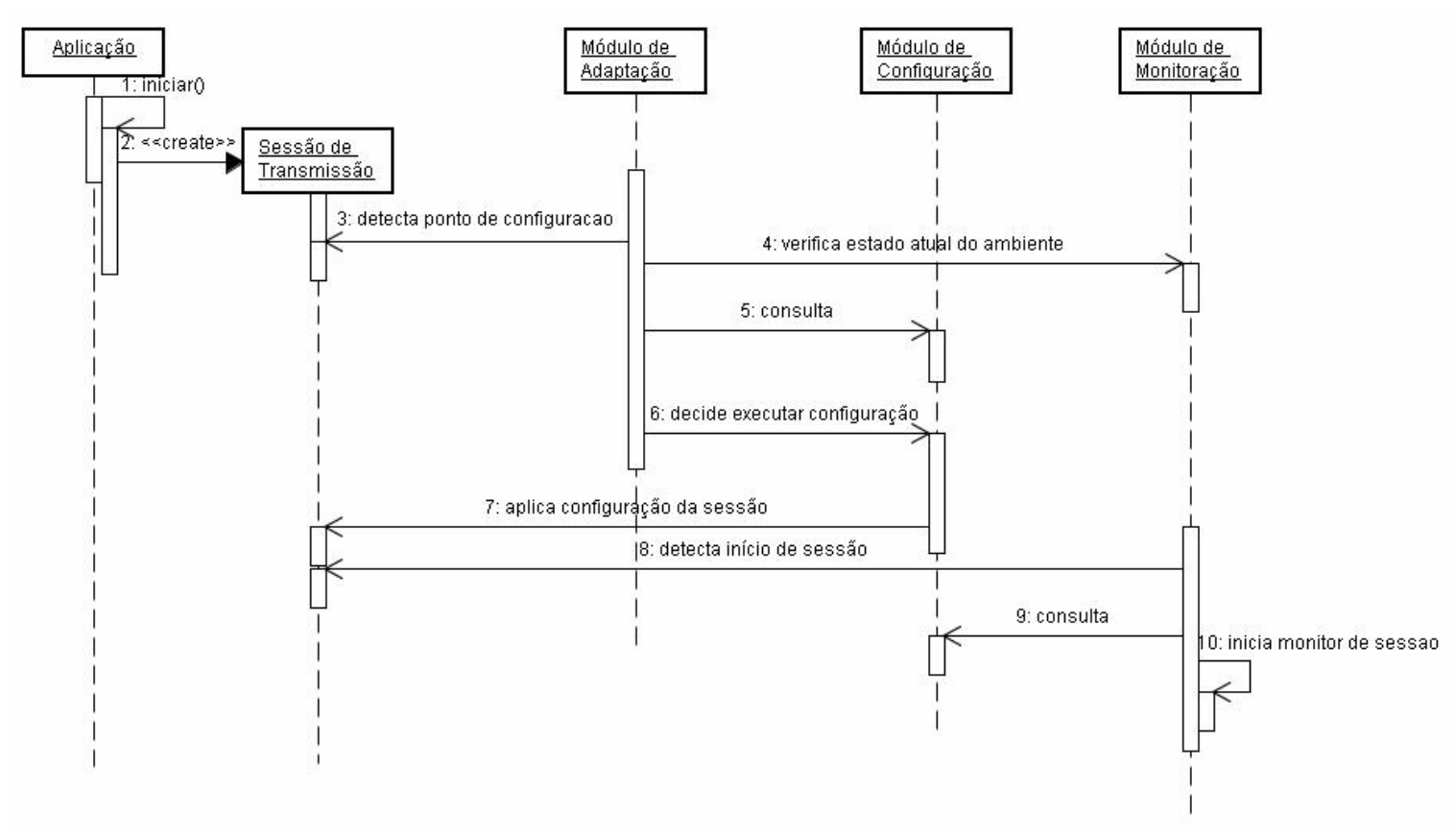

Figura 12 - Cenário de configuração estática da Camada de Adaptação.

A Figura 13 exibe outro cenário de uso, onde os elementos da Camada de Adaptação interagem entre si quando um evento é disparado pelo Módulo de Monitoração e habilita a execução de uma configuração dinâmica através da consulta das políticas de adaptação. A seguir a descrição do diagrama de seqüência:

- $\quad$ A aplicação já iniciou a sessão de transmissão e a monitoração da mesma (ver cenário da Figura 12)

- Quando um evento pré-configurado é gerado pelo Módulo de Monitoração, o Módulo de Adaptação é notificado.

- $\quad$ O Módulo de Adaptação consulta o Módulo de Configuração de forma a obter acesso a informações dinâmicas sobre como a adaptação deve ser executada;

- $\quad$ O Módulo de Adaptação decide onde e como a configuração deve ser realizada e delega para o Módulo de Configuração (classes auxiliares) mudar o comportamento da Sessão de Transmissão de acordo com informações interceptadas e armazenadas pelos aspectos e políticas de adaptação pré-configuradas. 


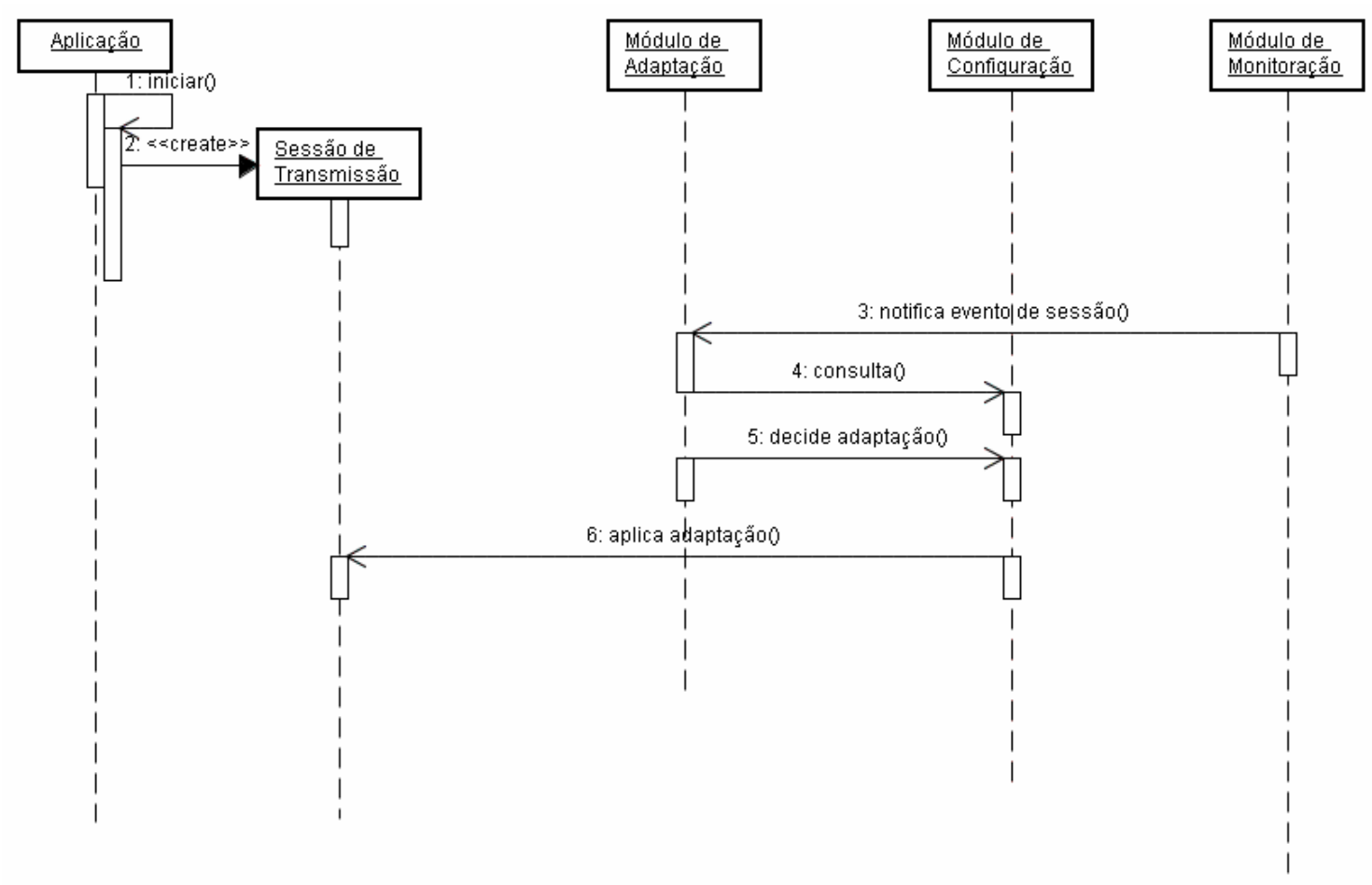

Figura 13 - Cenário de configuração dinâmica da Camada de Adaptação

\subsection{Implementação}

Para validar a especificação da camada de adaptação proposta neste trabalho (ver seção anterior), utilizamos para representar uma camada de Aplicação e Transmissão a aplicação apresentada na seção 4.1 .

Como já apresentado, a aplicação do servidor RTSP não possui nenhum suporte a adaptabilidade. Nesta seção descrevemos como incorporamos funcionalidades de adaptação através da construção de uma camada utilizando programação orientada a aspectos. Através da utilização de aspectos, é possível separar os interesses que implementam os requisitos de adaptabilidade, que podem ser vistos como a capacidade de definição e combinação de diversas estratégias de configuração no servidor RTSP, permitindo mudanças tanto estáticas quanto dinâmicas a variações no seu ambiente de execução. No desenvolvimento da camada de adaptação, o foco principal está nas estratégias dos processos de transmissão de fluxos multimídia, com o objetivo de permitir uma melhor flexibilidade na configuração dos seus 
elementos, bem como disponibilizar a melhor a qualidade de serviço que o ambiente de execução pode oferecer.

As principais classes e aspectos são apresentados na Figura 14, que é um diagrama UML que utiliza o estereótipo <<aspect>> para identificar aspectos. O estereótipo $<<$ affect $>>$ também é empregado em alguns relacionamentos de dependência para representar classes cujo comportamento é monitorado ou alterado por um aspecto. Já o estereótipo $<<$ uses $>>$ identifica classes que são utilizadas apenas como classes auxiliares por um aspecto. Nos tópicos seguintes, apresentamos os aspectos desenvolvidos em cada módulo da camada de adaptação, ressaltando os detalhes de implementação importantes dos mesmos.
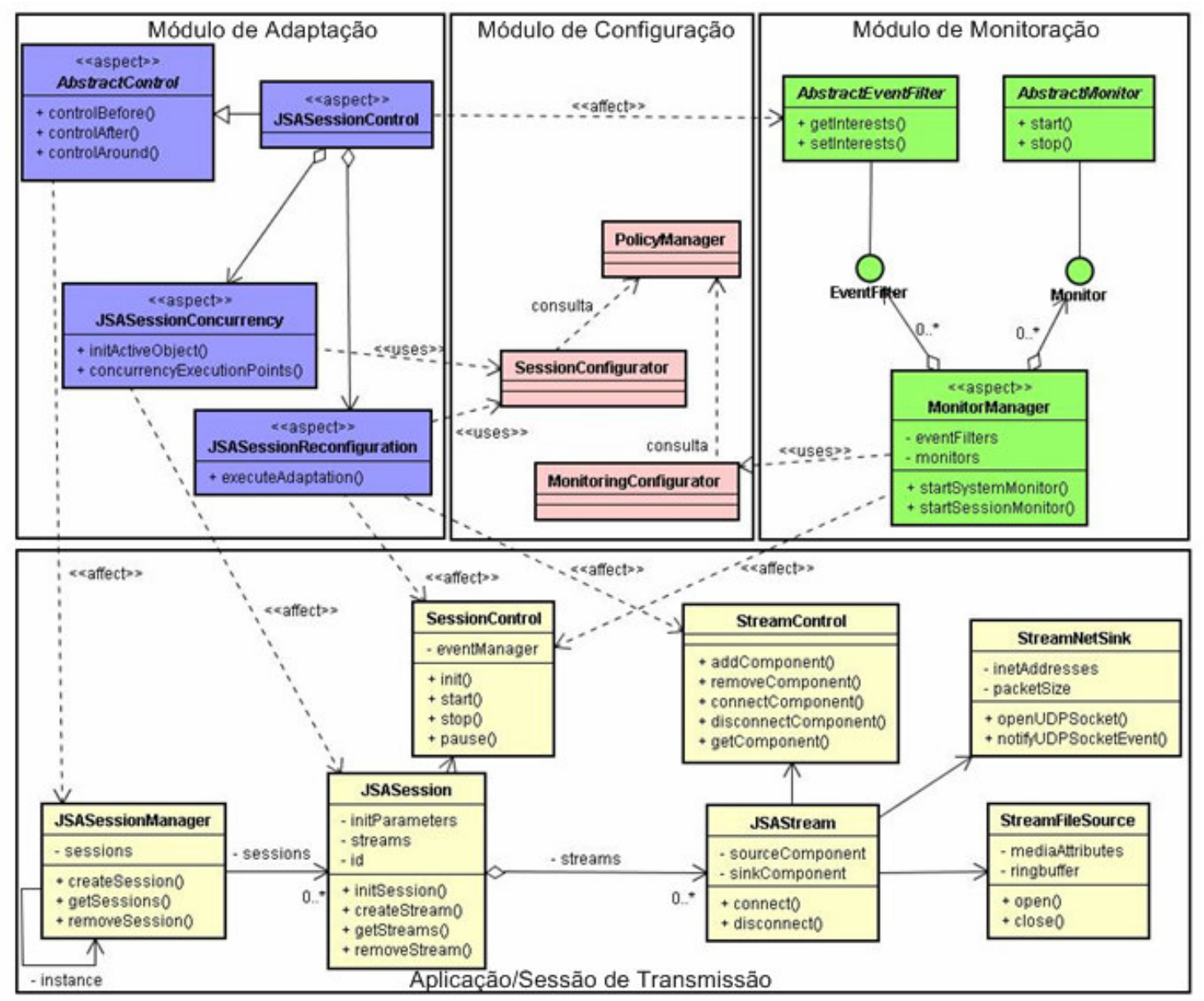

Figura 14 - Projeto detalhado da camada de adaptação no servidor RTSP 


\subsubsection{Módulo de adaptação}

Os aspectos deste módulo têm a função de suportar controle no comportamento de elementos que compõem um processo de transmissão de fluxo de mídia (representados por classes e interfaces da API JSA), representando o interesse de adaptação da camada proposta. Isto é realizado através da configuração inicial na instanciação dos elementos e reconfiguração durante sua execução.

O principal aspecto desse módulo é o AbstractControl, que define os principais pontos de junção (por exemplo, execução de um método) de JSASessionManager e define advices e métodos que podem realizar controle antes, durante, no lugar ou depois da execução desses pontos. O AbstractControl é a implementação do idioma Abstract Pointcut [HANENBERG03], no qual usamos um aspecto abstrato para definir o comportamento comum (advices) dependendo de um pointcut abstrato. A partir desse aspecto abstrato, diferentes aspectos concretos podem ser implementados, os quais concretizam o pointcut abstrato. Isso permite a reutilização do AbstractControl por qualquer aplicação multimídia em rede que utilize a API JSA (no caso, através da classe JSASessionManager) para realizar transmissão de fluxos multimídia. Abaixo exibimos parcialmente o código-fonte de AbstractControl, com a definição de um pointcut para criação de sessões e 3 (três) advices que são executados quando o pointcut é atingido.

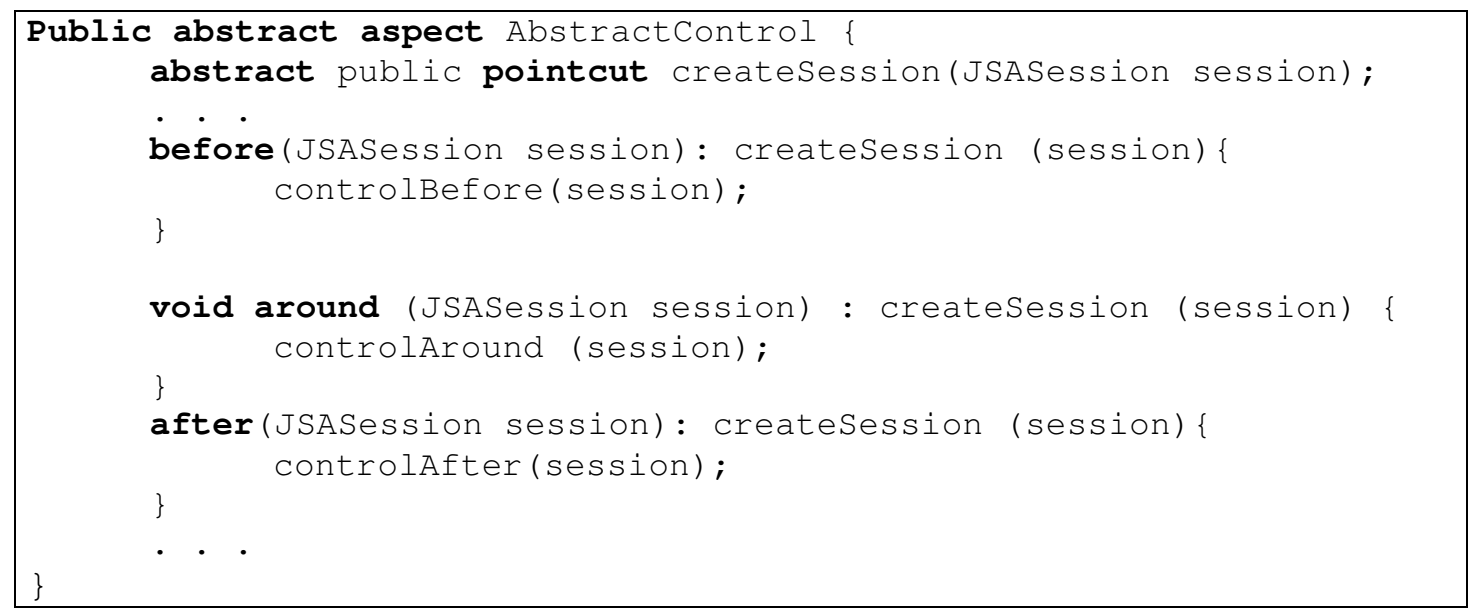


Para a implementação do nosso sistema, foi desenvolvido o aspecto JSASessionControl, que estende o AbstractControl realizando a implementação de controle específica, através da realização da estratégica de configuração estática das sessões de transmissão, isto é, inicialização e composição dos elementos de um processo de transmissão de fluxo de multimídia da API JSA. Adicionalmente, o aspecto JSASessionControl agrega os aspectos JSASessionConcurrency e JSASessionReconfiguration (Figura 14) e os associa dinamicamente, durante a inicialização de uma sessão, aos respectivos componentes funcionais que eles afetam. No trecho do código-fonte abaixo é ilustrado, como o JSASessionControl captura uma instância de uma sessão (JSASession) de transmissão após a sua criação, através dos pontos de junção execution e target, que identificam, respectivamente, a execução do método createSession e objeto alvo da própria instancia do JSASessionManager. O advice after invoca o método controlAfter, depois do pointcut createSession, que recebe a referência para a sessão criada e a armazena para possibilitar mudanças de propriedades sobre o objeto no próprio método (por exemplo, configuração inicial) ou posteriormente (configuração dinâmica). A interação entre o aspecto JSASessionControl e os elementos da JSA é exibida na Figura 14.

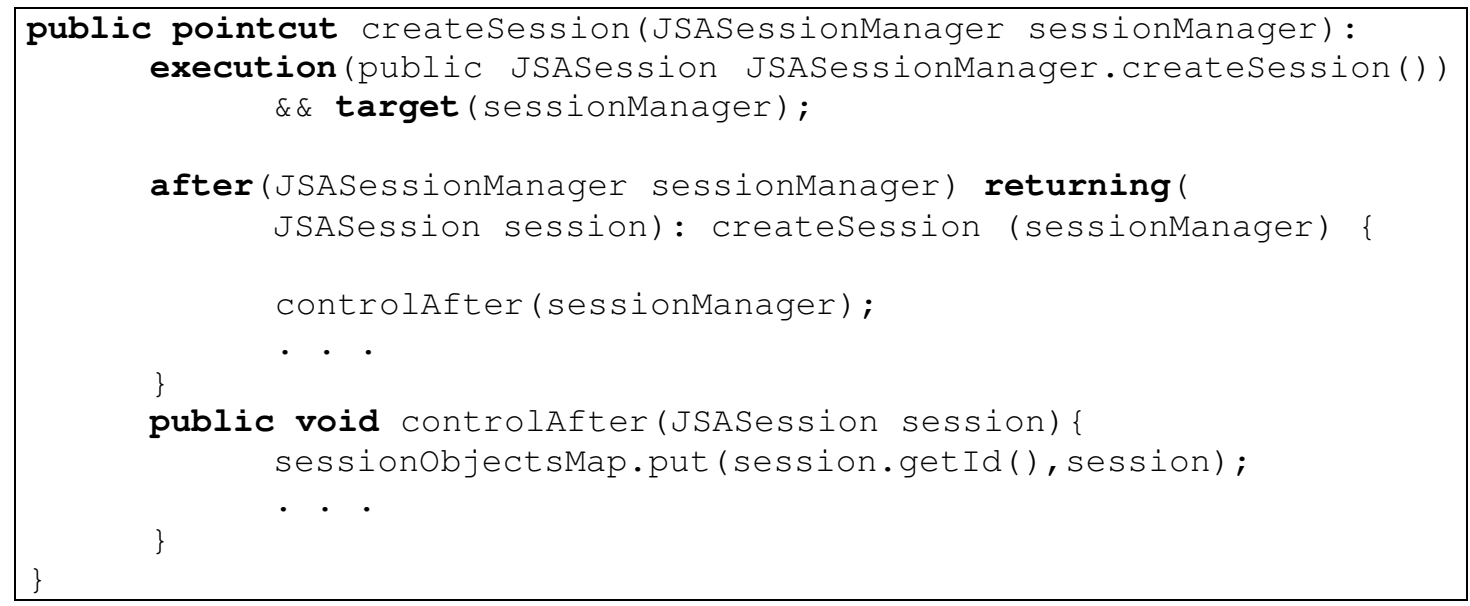

O aspecto JSASessionConcurrency define qual (ou quais) componente/classe será afetado pela estratégia de concorrência, qual estratégia será instanciada e quando ela será ativada. Desta forma, oferece uma implementação para a definição de uma estratégia de concorrência para gerência (criação, destruição e monitoramento) de threads, que permite que o 
método que inicia uma sessão de transmissão seja executado em uma thread de controle separada. Na versão do nosso sistema, estão implementadas duas estratégias que podem ser configuradas para execução concorrentemente das sessões: (i) ThreadPerRequestStrategy - manipula cada pedido de abertura de sessão numa thread separada; e (ii) ThreadPoolStrategy - durante a inicialização do sistema é ativado um conjunto prédefinido de threads (um pool), as quais obtêm pedidos de início de sessão numa fila e os processam, limitando o número total de threads possíveis no servidor. Este projeto do interesse de concorrência é uma adaptação do padrão de projeto Active Object [LAVENDER96] para programação orientada a aspecto e detalhes podem ser consultados em [KULESZA04]. A parte do código-fonte a seguir expõe um trecho de código do aspecto JSASessionConcurrency que inicia, através do método initActiveobject (), o objeto (Activeobject) responsável pelo controle e configuração (escolha de estratégia de concorrência) de execução das threads na instanciação do servidor RTSP (linhas 1 a 6). Também é ilustrado a definição de um pointcut para capturar a chamada do método initSession da classe JSASession que está no pacote br.usp.larc.gtgv.rtsp (linhas 8 a 11) e a declaração de um advice around que substituirá a execução de initSession, para adicionar JSASession (representando por object) numa lista de threads que serão executados pelo Activeobject (linhas 8 a 15). Além disso, é exibido como o aspecto JSASessionConcurrency, através de declarações intertipos (intertype), modifica a classe JSASession para implementar a interface Runnable e ter um novo método run que executará o método initSession ( 1 inhas 18 a 22). De forma resumida, o código-fonte ilustra como o aspecto alterou a JSASession para ser executado como uma thread (particularmente, o trecho de código do método initsession original) e controlado por suas estratégias de concorrência É importante lembrar que todos as classes auxiliares, que são utilizadas pelo aspecto JSASessionConcurrency fazem parte do Módulo de Configuração.

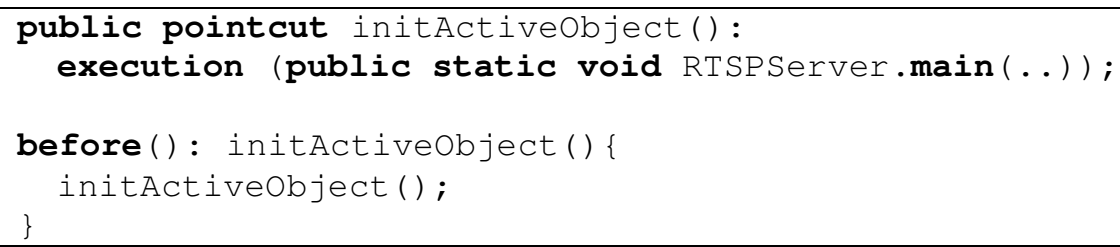




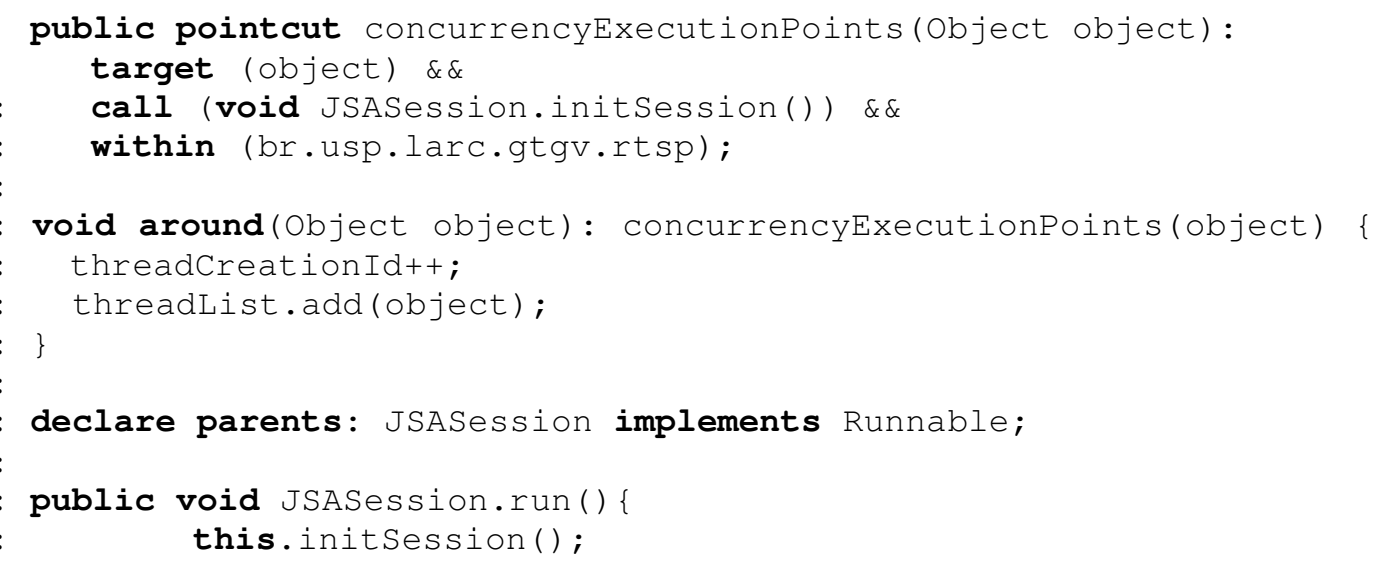

Por fim, o aspecto JSASessionReconfiguration é responsável pela implementação das estratégias de controle dinâmicas dos processos de transmissão de fluxos de mídias, baseado em variações de estados mantidos pelo Módulo de Monitoração. Um processo (pipeline) de transmissão de fluxos de mídia no servidor RTSP é visto como um conjunto de elementos que realizam tarefas e são organizados em seqüência, seguindo o modelo de componentes da API JSA. Na camada de adaptação os processos podem ter sua configuração dinâmica realizada através de três operações básicas (1) modificação das propriedades dos componentes principais (2) inserção ou remoção de componentes do processo de transmissão de mídia; e (3) e modificação das conexões entre componentes. Essas três operações devem ser realizadas através das interfaces de controle da sessão (SessionControl) e fluxos de mídias (StreamControl). Operações de configuração dinâmica complexas devem ser divididas em um conjunto de operações básicas que devem ser executadas numa ordem apropriada.

Como ilustrado na Figura 14 e detalhado no código-fonte abaixo, o aspecto JSASessionControl implementa interfaces (SessionEventFilterListener e SystemEventFilterListener) para receber notificações sobre mudanças de estados das sessões de transmissão multimídia e ambiente de execução (por exemplo, o estado de carga do sistema ou atributos de qualidade de serviço da transmissão) gerados pelo módulo de monitoração através do envio de eventos. Para implementação das estratégias de controle dinâmico, esses eventos são então despachados para o aspecto 
aspecto, já que em AspectJ aspectos são implementados na configuração padrão como objetos singleton [GAMMA95].

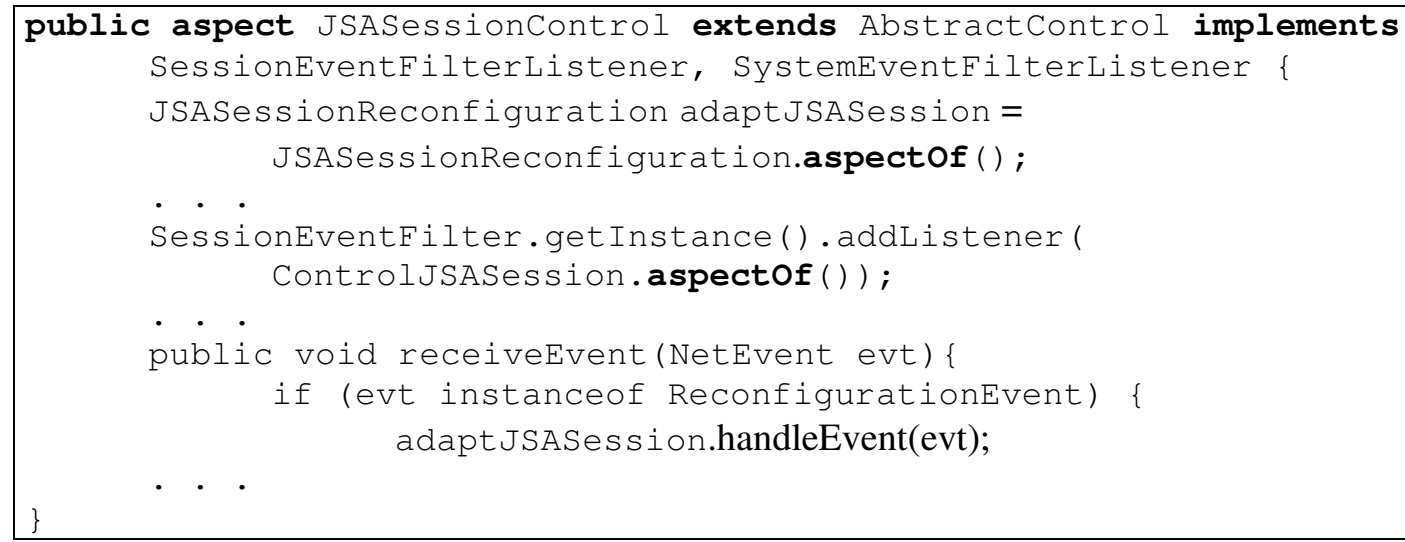

A partir dessa observação de eventos, o aspecto JSASessionReconfiguration decide que ação de reconfiguração realizar e delega a implementação (através da invocação de algum método) para a classe auxiliar SessionConfigurator do Módulo de Configuração, que aplica a política de adaptação de acordo com informações cadastradas em algum repositório e acessadas através do PolicyManager, no contexto de uma sessão e/ou processo de transmissão de fluxo de mídia. No código-fonte abaixo ilustramos um exemplo de um método de reconfiguração implementado na classe auxiliar SessionConfigurator. Onde temos a representação do acesso as políticas de adaptação entre a linha 3 e linha 6 e implementação da reconfiguração da taxa de transmissão de um fluxo de mídia (JSAStream) das linhas 8 a 18. Notem que para ter acesso a componentes de um processo de transmissão, apenas é necessário usar a instancia de JSASession armazenada numa estrutura de dados (sessionobject sMap) do aspecto JSASessionControl na criação da sessão e um identificador do fluxo que será alterado. Os identificadores sessionId e streamId são repassados pelo evento (NetEvent) gerados no Módulo de Monitoração.

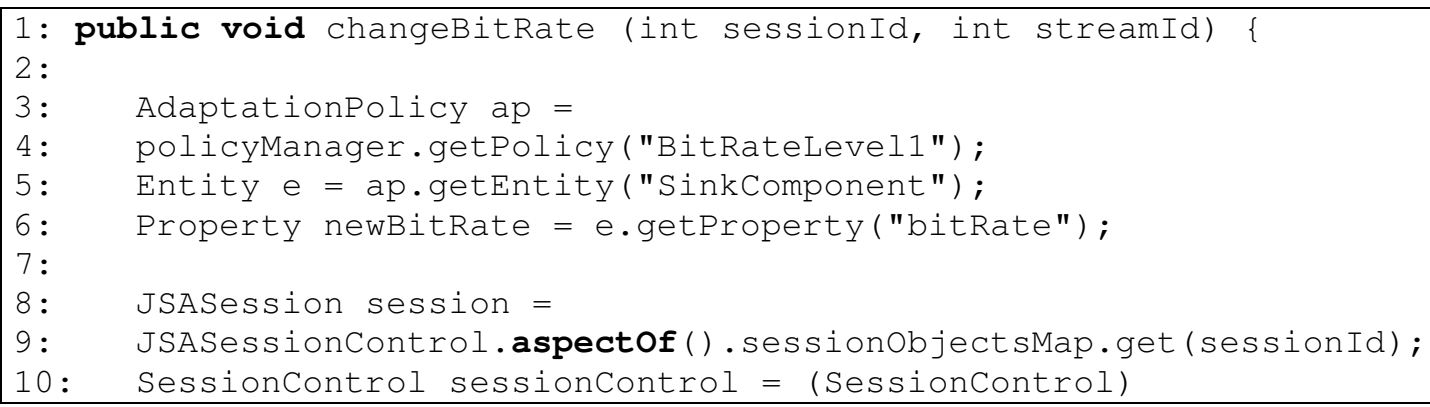




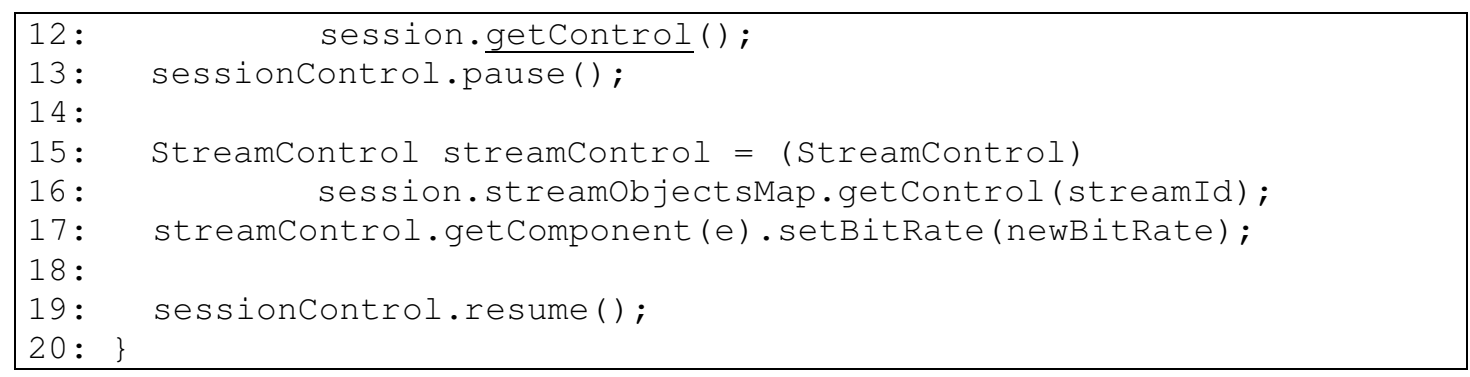

\subsubsection{Módulo de monitoração}

Este módulo da Camada de Adaptação contém elementos relacionados ao monitoramento do estado das sessões de transmissão multimídia e do ambiente de operação do servidor RTSP. Na Figura 14 é exibido o aspecto MonitorManager com coleções de EventFilter e Monitor e a comunicação (através do estereótipo <<affect $>>$ ) do JSASessionControl com o Módulo de Monitoração através da implementação de Listeners (ver padrão Observer em [GAMMA95]) da classe abstrata AbstractEventFilter.

Na figura abaixo é exibido em mais detalhes a implementação de um monitor de sistema (SytemMonitor) e um monitor de sessão (SessionMonitor) e componentes (SessionEventFilter e SystemEventFilter) usados para gerar eventos tais como servidor e/ou rede ocupada, através do consumo de informações dos monitores. O objetivo é permitir que as estratégias de adaptação sejam disparadas dinamicamente de acordo com informações recolhidas pelos monitores e regras definidas nos filtros de eventos, que alteram o estado do sistema ou da sessão. 


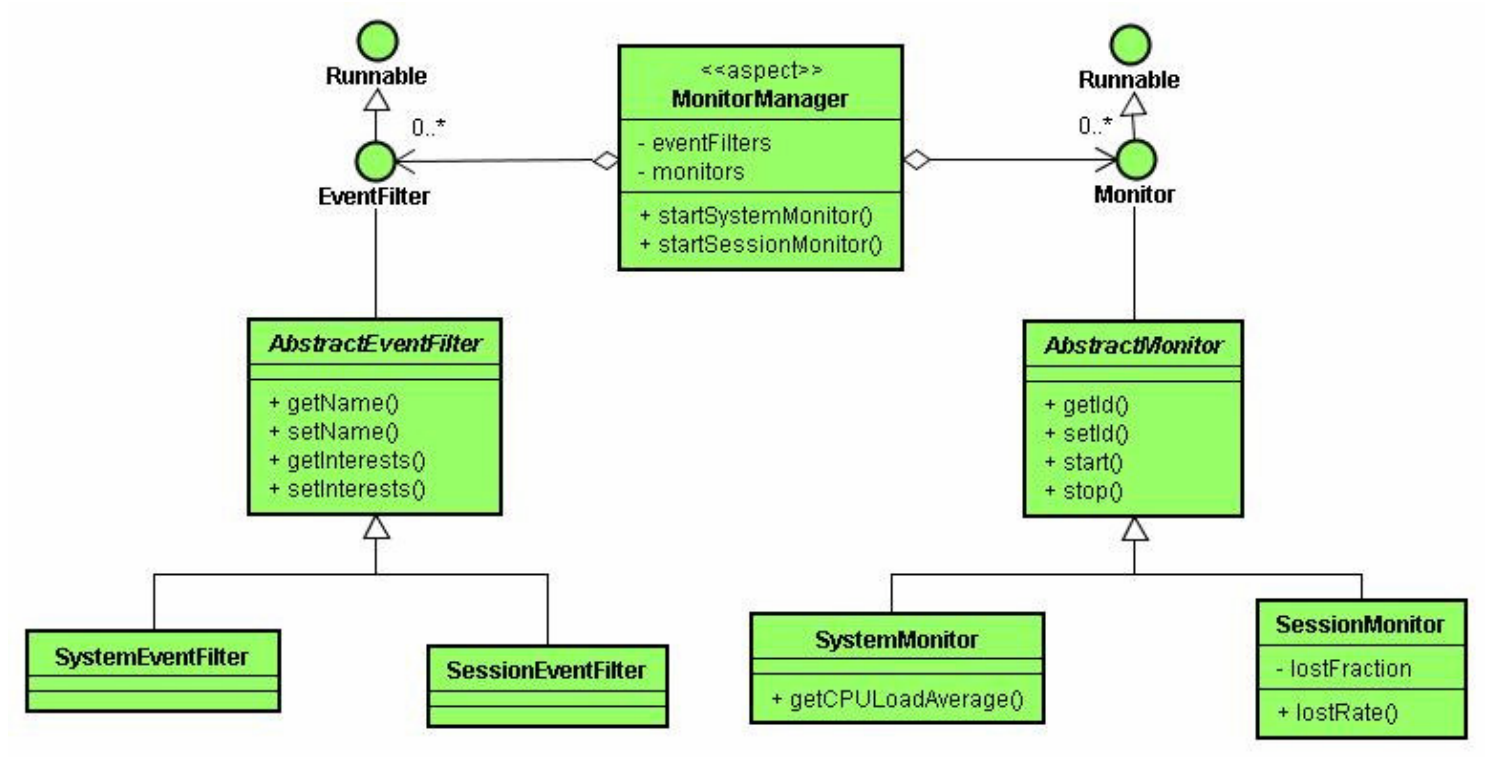

Figura 15 - Detalhamento do Módulo de Monitoração

$\mathrm{O}$ aspecto MonitorManager realiza a configuração do monitoramento e mantém o estado da configuração dos monitores através de informações sobre a quantidade, tipos e nomes de monitores e as associações com geradores de eventos. Tais informações podem ser configuradas na inicialização do servidor ou alteradas durante sua execução, através de consulta ou atualização dos dados do Módulo de Configuração, e são úteis para determinar possíveis mecanismos/políticas de monitoração que o servidor poderá instanciar, assim como para definir uma configuração inicial. Adicionalmente, são configurados no MonitorManager pontos específicos do código do servidor RTSP que atualizam informações dos monitores. Esses pontos são definidos por pontos de junção e cláusulas advice no aspecto MonitorManager.

Apesar da Figura 14 exibir que o aspecto MonitorManager afeta apenas o componente de controle da classe JSASession tratando do interesse de configuração do monitoramento das sessões, o aspecto MonitorManager também trata do interesse de monitoramento do sistema computacional no qual o servidor RTCP está em execução. O código-fonte a seguir ilustra um trecho do MonitorManager que define dois pointcuts. O primeiro define que a inicialização do monitor do sistema deve acontecer na execução do método main da classe RTSPServer, ou seja, na criação do servidor RTSP. O segundo (sessionMonitoringPoints) é responsável pela configuração e início de execução do monitoramento das sessões de transmissão de fluxos 
de mídia no momento após (advice after) a instanciação do componente de controle de uma sessão (execução do construtor de ControlSession).

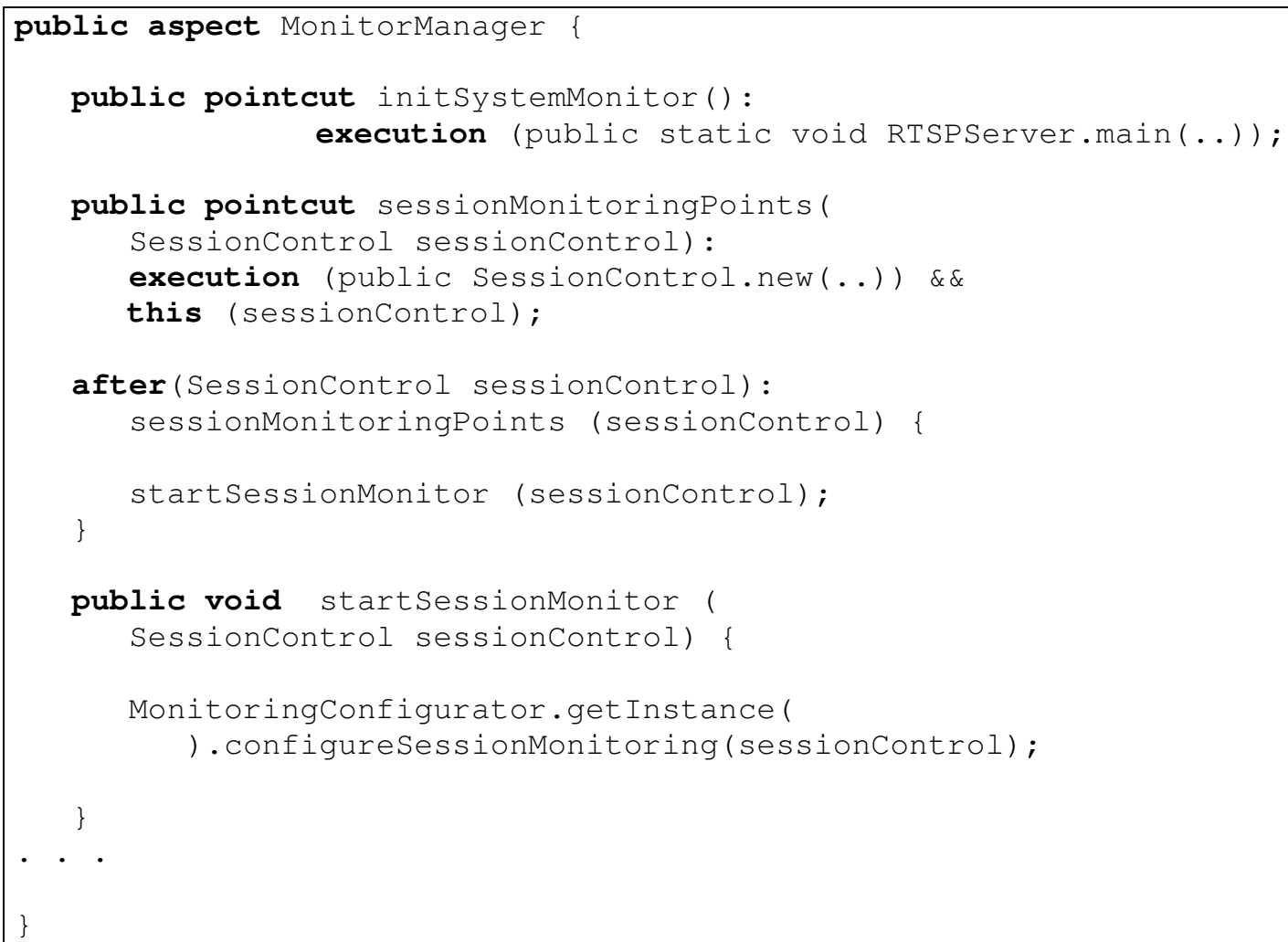

\subsubsection{Módulo de configuração}

Neste módulo estão presentes classes auxiliares (SessionConfigurator e MonitoringConfigurator) que realizam alguma ação de acordo com pontos selecionados por aspectos nos módulo de adaptação e monitoração. O isolamento dos outros módulos é para prover reusabilidade, já que vários aspectos poderão usar essas classes. Sua implementação apenas com orientação a objeto é intencional e tem o objetivo de permitir que desenvolvedores desse módulo não precisem obrigatoriamente conhecer a linguagem de programação orientadas a aspectos AspectJ. Isto permite que o desenvolvedor dos aspectos ou arquiteto de software precise apenas especificar as interfaces para as classes auxiliares e assim, a partir dessas especificações, permitir a construção das classes e invocação dos seus métodos pelos aspectos desenvolvidos nos módulos de adaptação e monitoração. 
Além disso, este módulo possui componentes que são responsáveis pelo acesso a repositórios que provêem as informações sobre as políticas de adaptação e monitoração (PolicyManager) que podem ser realizadas pela camada de adaptação. Desta forma, mudanças dinâmicas na definição dessas políticas podem ser realizadas sem necessidade de expressar essas modificações diretamente no código da camada de adaptação, mas através de metadados. É importante observar, que apesar de estarmos usando uma abordagem simplificada para a definição dos metadados (arquivos no formato de texto), pois não é o foco do nosso trabalho, é possível implementar um mecanismo que permita que as políticas e configurações possam ser definidas de uma forma mais apropriada com uso de XML, modelos para definição de políticas , por exemplo PCIM (Policy Core Information Model) [RFC3460], e metamodelos (modelos que descrevem modelos) para configurações dos objetos [YODER01]. Isto permitiria um comportamento ainda mais dinâmico e flexível para a camada de adaptação. Abaixo segue um trecho do código-fonte da classe auxiliar MonitoringConfigurator, onde o método configureSessionMonitoring faz uso do objeto policyManager (instância da classe PolicyManager) para realizar a configuração inicial da monitoração das sessões e é chamado pelo aspecto MonitorManager (ver seção anterior).

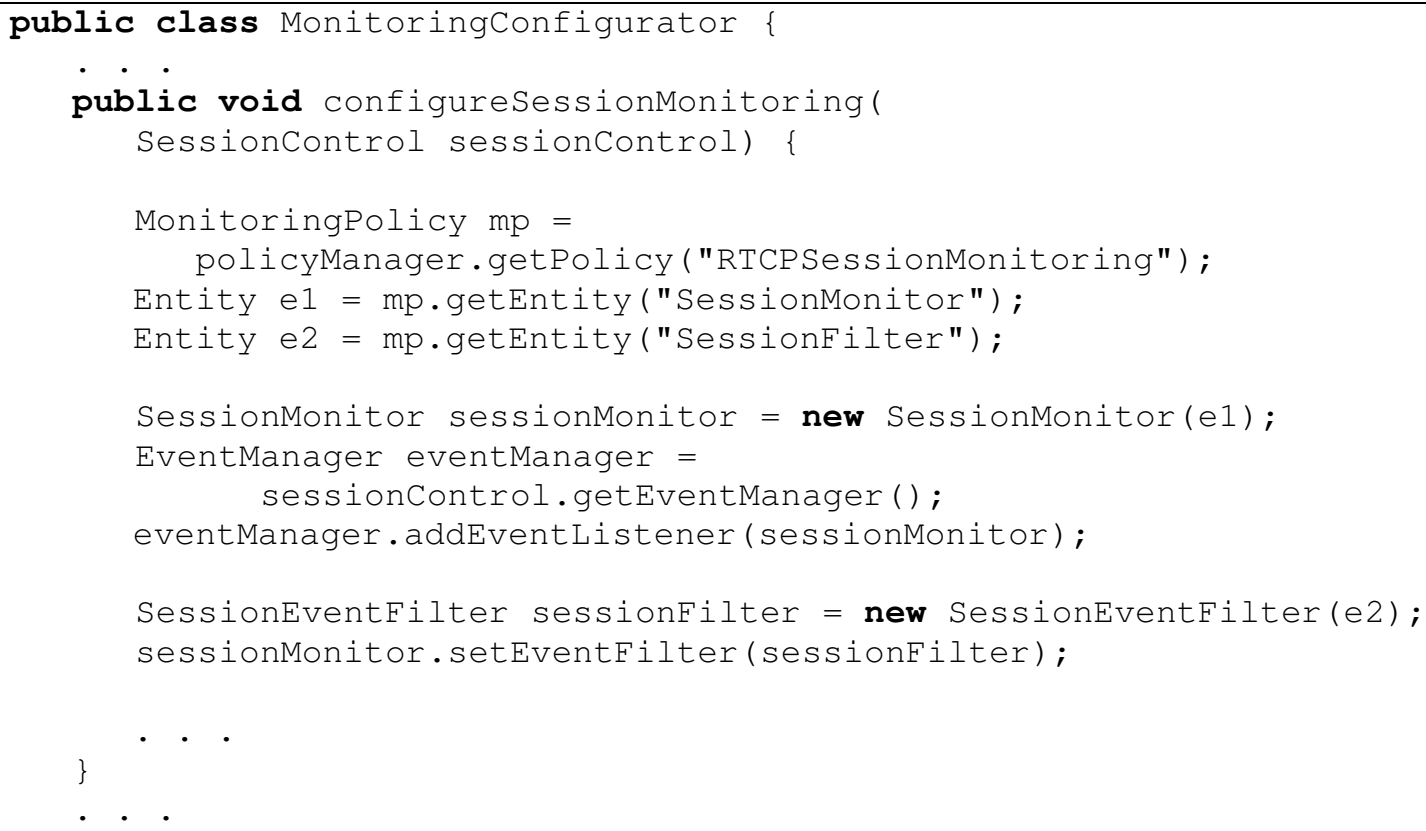




\subsection{Cenário de Validação}

Como itens do cenário de validação e para realizar os experimentos necessários foram desenvolvidos dois mecanismos de monitoração: ambiente de execução e sessão de transmissão. O primeiro coleta estatísticas globais da utilização dos recursos do sistema computacional onde foi executado o Servidor RTSP e a camada de adaptação e deve permanecer ativo durante todo o tempo de vida da aplicação. O segundo responsável pela monitoração de tráfego para cada sessão RTP criada pela aplicação, através do uso do protocolo RTCP.

\subsubsection{Mecanismo para monitoração do ambiente de execução}

A monitoração do ambiente de execução proposta neste trabalho procura levantar de forma simples a informação da carga do sistema computacional que é responsável pela execução da aplicação multimídia em rede que utiliza a camada de adaptação. De acordo com, [BRANCO04] a informação da carga de um sistema computacional é geralmente definida em termos de índices de carga, que corresponde a uma métrica empregada para quantificar a carga de trabalho submetida ao sistema. Para obter essa métrica, diversos recursos do sistema podem ser analisados e os de maior relevância são: CPU, memória, disco e interfaces de rede, que podem gerar índices de carga tais como: tamanho da fila da CPU, utilização de CPU, tempo de processamento, quantidade de memória disponível, taxa de leitura e escrita num disco, quantidade de dados transmitidos e recebidos por segundo em cada interface de rede e funções híbridas que utilizam combinações dos índices mencionados.

Para camada de adaptação proposta neste trabalho, utilizamos como índice de carga de trabalho do ambiente de execução apenas a utilização da CPU, uma vez que a determinação de um modelo para adoção de índices de cargas e medição de desempenho mais elaborado não é o foco do nosso trabalho. Um modelo mais complexo para utilização de índices de cargas pode ser encontrado em [BRANCO04].

Como nosso servidor está sendo executado num sistema Linux, o módulo de monitoração, através da implementação do SystemMonitor, realiza uma chamada para o comando nativo "vmstat" que examina o sistema e relata estatísticas das atividades da CPU de 
acordo com intervalos de tempo definidos nas políticas de monitoração do módulo de configuração. A cada nova estatística gerada (nesse caso, utilização da CPU atual) a classe SystemEventFilter verifica se deve ser gerado um evento de mudança de estado da carga de trabalho do sistema. Baseado em outros trabalhos da literatura, foram especificadas as seguintes condições para nosso o ambiente de execução: (i) ocioso, valor muito pequeno de ou inexistência; (ii) sobrecarregado, condição em que o servidor deve evitar atendimento a novas requisições de sessões de transmissão, e até mesmo considerar a possibilidade de migração de sessões de transmissão atuais (por exemplo, através de comandos REDIRECT do RTSP), de modo a aliviar a carga no sistema; e (iii) execução normal, com a disponibilidade para aceitar o atendimento de novas requisições. As seguintes regras foram definidas e implementadas no SystemEventFilter para determinar a geração de eventos e, consequentemente, mudança de estado da carga do ambiente de execução, onde $T U_{\text {atual }}$ equivale ao valor gerado pelo SystemMonitor para o índice de carga utilização de CPU no último instante:

$$
\begin{aligned}
& \operatorname{Se}\left(T U_{\text {atual }} \geq 60 \%\right) \rightarrow \text { sobrecarregado } \\
& \operatorname{Se}\left(60 \%<T U_{\text {atual }}<5 \%\right) \rightarrow \text { execução normal } \\
& \operatorname{Se}\left(T U_{\text {atual }} \leq 5 \%\right) \rightarrow \text { ocioso }
\end{aligned}
$$

Equação 1 - Algoritmo para computar o estado de carga do ambiente de execução baseado no índice de carga utilização de CPU

Entretanto, para evitar a geração de eventos de mudança de estado de carga do ambiente de execução em instantes curtos em que há pico ou ociosidade de execução de tarefas, o SystemEventFilter apenas notifica o Módulo de Adaptação após ocorrerem 3 (três) ocorrências consecutivas do mesmo estado de carga.

\subsubsection{Mecanismo para monitoração das sessões}

O mecanismo de monitoração de sessões é baseado na arquitetura de um transmissor unicast de fluxos de multimídia e utiliza o protocolo RTCP. Basicamente, é constituído por um módulo que é responsável por analisar informações que são enviadas periodicamente (através de 
Receiver Reports RTCP) pelo receptor para o transmissor (servidor), que indica parâmetros de qualidade de serviço da transmissão.

Neste trabalho, somente a taxa de perda de pacotes é empregada para identificar congestionamento na rede. Adotamos um algoritmo apresentado em [BUSSE96], [LUNARDI01] e [BOURAS05] que calcula a taxa de perda, permite suavizar estatísticas e evitar oscilações de QoS. A implementação do algoritmo consiste na extração das informações dos receiver blocks de pacotes RTCP que contém a fração de pacotes perdidos e que vai alimentar a fórmula apresentada na Equação 2:

$$
T P^{\text {atual }}=\alpha * T P^{\text {anterior }}+(1-\alpha) * T P^{\text {rede }}
$$

Onde,

$T P^{\text {atual }}=$ Valor atual para a taxa de perdas.

$T P^{\text {anterior }}=$ Valor anterior (coletado) para taxa de perdas, onde no início da transmissão $T P^{\text {anterior }}=0$

$T P^{\text {rede }}=$ Valor de taxa de perdas enviado pelo cliente através de RTCP.

$\alpha=$ fator de suavização que determinará que peso tem a taxa de perdas anterior e

$0 \leq \alpha \leq 1$

\section{Equação 2 - Fórmula para cálculo da taxa de perda de pacotes}

Cada sessão é monitorada individual e constantemente pelo algoritmo que verifica a condição de cada transmissão de acordo com a fração de pacotes perdidos, obtida através do uso do protocolo RTCP. Como ilustrado na Equação 2 o estado anterior da rede sempre é levado em conta a cada novo cálculo da taxa de perdas de modo a evitar a geração de eventos de adaptação não necessários em períodos curtos de pico da rede. $\mathrm{O}$ valor de $\alpha$ adotado para aplicação na equação foi 0,5 e foi baseado nos trabalhos já citados.

O módulo que recebe os pacotes do monitor da sessão (que implementa RTCP) realiza então a estimativa das condições da rede para computar o estado da rede seguindo as seguintes regras: (i) Rede congestionada: quando a rede está na condição de congestionada a taxa de perdas de pacotes é alta e a qualidade da transmissão dos fluxos multimídia é baixa. (ii) Rede 
carregada: quando a rede está carregada a qualidade da transmissão dos fluxos multimídia é boa. (iii) Rede não carregada: quando a rede está na condição de não carregada não existe perda de pacotes ou a taxa de perdas é muito pequena. Particularmente, para a taxa de perdas são definidos dois valores limites (limiares): $T P_{\text {congestionada }}$ : taxa de perdas para rede congestionada e $T P_{n \tilde{a} o-c a r r e g a d a}$ : taxa de perdas para rede não carregada, que controlam as mudanças de acordo com as condições da rede e seguem o seguinte algoritmo:

$$
\begin{aligned}
& \text { Se }\left(T P^{\text {atual }} \geq T P_{\text {congestionada }}\right) \rightarrow \text { rede congestionada } \\
& \operatorname{Se}\left(T P_{n \tilde{o} o-c a r r e g a d a}<T P^{\text {atual }}<T P_{\text {congestionada }}\right) \rightarrow \text { rede carregada } \\
& \operatorname{Se}\left(T P^{\text {atual }} \leq T P_{n \tilde{a} o-\text { carregada }}\right) \rightarrow \text { rede não carregada }
\end{aligned}
$$

\section{Equação 3 - Algoritmo para computar o estado da rede baseado na taxa de perdas de pacote}

Os valores utilizados para os experimentos foram $T P_{\text {congestionada }}=1 \%$ e $T P_{\text {ñ̃o-carregada }}=$ $0,5 \%$, ou seja, até $0,5 \%$ estado da rede não carregada; de $0,5 \%$ a $1 \%$, rede carregada; de $1 \%$ em diante rede congestionada.

\subsubsection{Políticas de Adaptação}

No contexto do cenário de validação, as políticas de adaptação foram definidas para modificar o comportamento de uma sessão de transmissão de fluxo multimídia para que esta funcione da melhor maneira possível de acordo com as condições do ambiente de execução e desempenho que a rede pode oferecer. Para desta forma, assegurar à aplicação que esta terá pelo menos um nível mínimo de QoS. Isso em conformidade com as políticas de adaptação especificadas no módulo de configuração. Esses valores servem como regras para que algumas medidas corretivas sejam realizadas. A seguir, é apresentado o mecanismo de adaptação escolhido para implementação.

\subsubsection{Mudança da taxa de transmissão com mudança de codificação}

Partindo de experimentos realizados em [LUNARDI01] podemos garantir que uma diminuição na taxa de transmissão, através de adaptação de parâmetros de codificação de áudio 
e vídeo, pode melhorar substancialmente a qualidade de uma sessão multimídia que encontra problemas de congestionamento da rede (normalmente, representados por atraso e perda de pacotes). Por exemplo, com a inserção de módulos de filtragem de colorido para preto e branco ou mudança nos algoritmos de compressão utilizados, o fluxo de mídia pode ser adaptado para as condições da rede e/ou do ambiente de execução. Contudo, esse processo de adaptação também introduz problemas de qualidade relacionados ao tempo de processamento e complexidade na mudança de configuração de um processo de transmissão multimídia, que normalmente é composto por uma coleção de componentes de software que implementam algum tratamento de conteúdo multimídia (veja a Figura 16 com um exemplo de uma sessão multimídia com dois processos de transmissão de mídias concorrentes ). Assim, quando existem requisitos de mudança de um processo por outro, a adaptação de sessão de transmissão multimídia requer um longo e complicado procedimento para desabilitar um processo e construir um substituto.

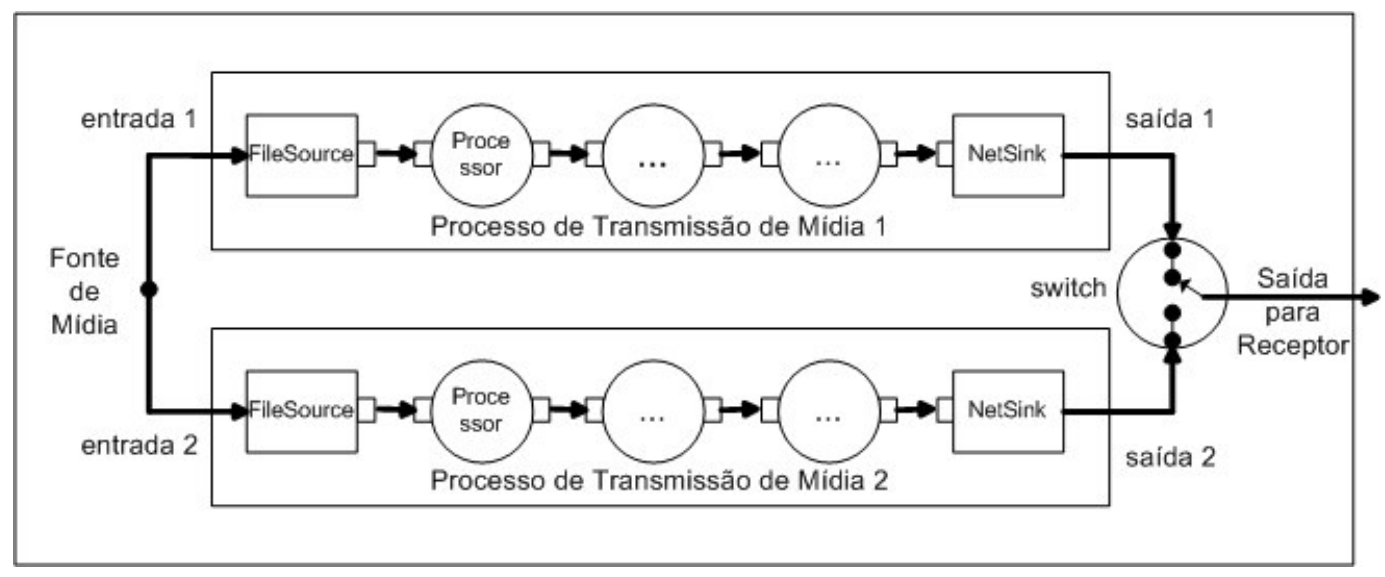

Figura 16 - Exemplo de Processos de Transmissão de Mídias Paralelos

A ação de substituição de processos de transmissão de mídia é fortemente influenciada por dois tipos de atrasos presentes em todo elemento que compõe o processo: (i) atraso de configuração e (ii) atraso intrínseco. O atraso de configuração é caracterizado pelo tempo necessário para cada elemento do processo realizar a inicialização da sua estrutura interna, alocar recursos para execução e estar pronto para operação. O atraso intrínseco é definido como o tempo adicional (posterior ao atraso de configuração), necessário para um elemento já configurado dado uma entrada, produzir uma saída particular. Unidos, esses dois parâmetros 
podem introduzir níveis adicionais de perdas de dados e extensos atrasos na qualidade de transmissão durante a adaptação de uma sessão.

No desenvolvimento das estratégias adaptativas da camada de adaptação proposta neste trabalho, nos baseamos em [CARLSON02] para desenvolver dois mecanismos: (i) modo seqüencial e (ii) modo transparente, que permitem substituir em tempo de execução o processo de transmissão multimídia da sessão, particularmente, com o objetivo de alterar o tipo de codificação utilizado.

No modo seqüencial, o processo atual de transmissão é finalizado antes da construção do novo processo. Durante esse intervalo, ocorrem interrupções no fluxo de saída da transmissão e também alguns dados podem ser perdidos. Na Figura 17 é exibido resumidamente como ocorre o procedimento de adaptação da transmissão nesse modo. A Fonte de Mídia (por exemplo, uma câmera de vídeo) produz amostras de mídias numa dada taxa constante, que são enviadas para o Processo de Transmissão de Mídia $1\left(C_{1}\right)$. $C_{1}$ é constituído de vários componentes para realizar o processamento da mídia e permitir sua transmissão para a rede. $\mathrm{O}$ componente FileSource é responsável pela leitura e armazenamento em buffer das amostras geradas pela Fonte de Mídia. Codificador e Filtro realizam algum processamento sobre a mídia (por exemplo, codificação num formato de compressão e classificação de quadros, respectivamente). O NetSink é responsável pelo encapsulamento dos quadros gerados por Codificador e Filtro em pacotes de protocolos de transporte de tempo real e abertura de socket para transmissão da mídia para o receptor (por exemplo, com a utilização de RTP e UDP). A Requisição de Adaptação é enviada pela Camada de Adaptação, que através de métodos da Sessão de Transmissão realizará a nova configuração solicitada. Num primeiro momento, a Sessão de Transmissão, na Preparação de Adaptação (a), recebe comandos e parâmetros de configuração da Camada de Adaptação. Em seguida, a Sessão de Transmissão inicia a Fase de Destruição (b) dos componentes de $C_{1}$ e depois inicia a Fase de Configuração (c), que cria os componentes do novo Processo de Transmissão de Mídia $C_{2}$. Com $C_{2}$ instanciado e configurado, o procedimento é finalizado com a fase de Finalização de Adaptação (d) e 
recomeça a transmissão do fluxo de mídia. Como ilustrado na Figura 17, devido o tempo gasto para finalizar $C_{1}$ e tempo de atraso de configuração e intrínseco de $C_{2}$, vários quadros de mídias são perdidos, pois mesmo com a utilização de um buffer, em determinado momento o componente FileSource não conseguirá mais armazenar as amostras geradas pela Fonte de Mídia e descarta quadros.
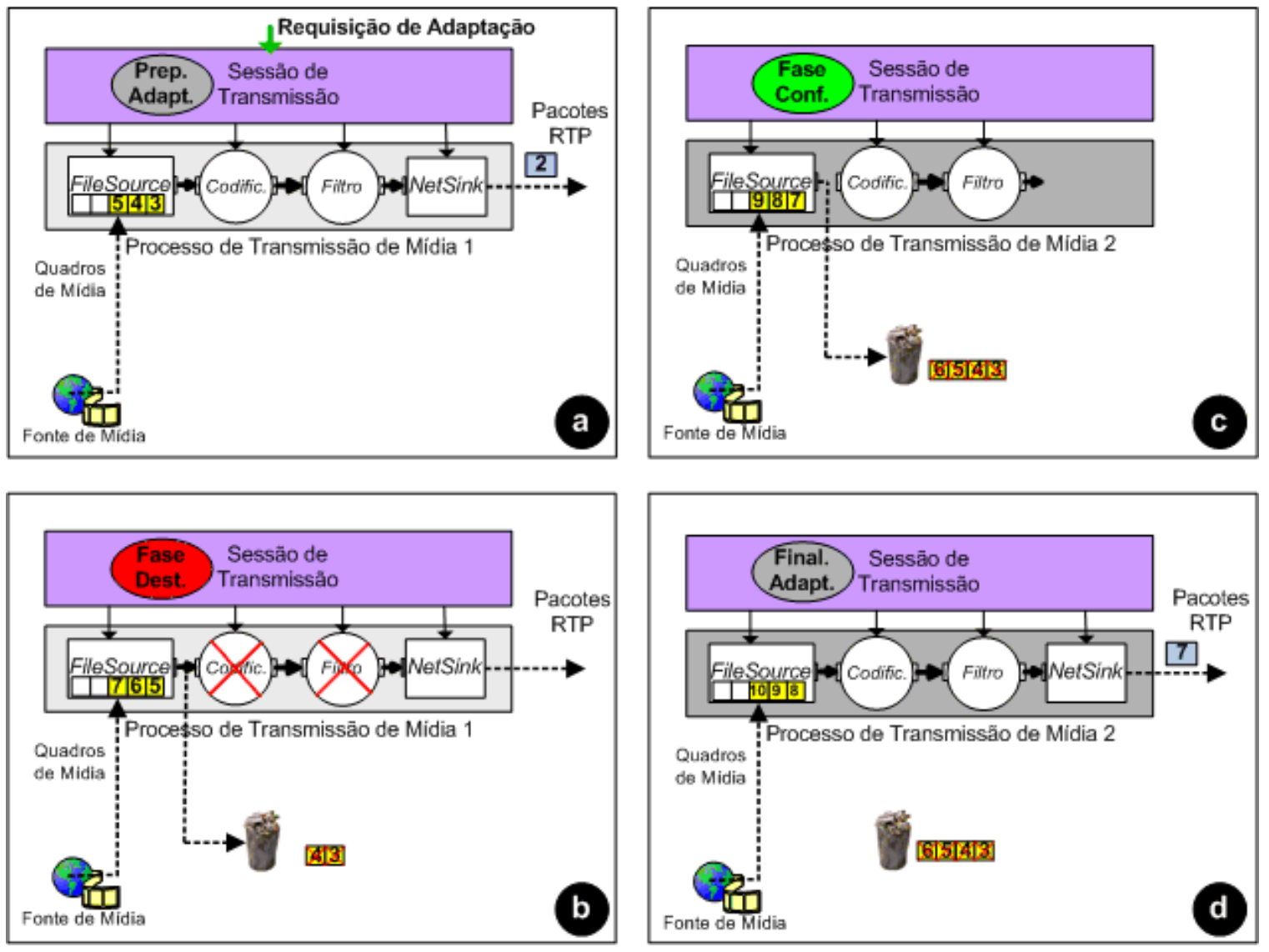

Figura 17 - Modo Sequencial de Adaptação de Processo de Transmissão de Fluxos de Mídias

No modo transparente, a situação muda completamente, através do emprego de um mecanismo mais sofisticado que procura antes da destruição de processo, inicializar o novo processo em paralelo e só interromper a operação do primeiro, depois da sincronização do segundo. Dessa forma, como é visto na Figura 18, durante Fase de Configuração (b) o Processo de Transmissão de Mídias 1 ( $C_{1}$ ) não é interrompido, até que $C_{2}$ esteja pronto para operação. A etapa de Finalização de Adaptação (c e d) é responsável pela finalização de $C_{1}$ e ao mesmo tempo pela mudança da saída de Filesource de $C_{1}$ para $C_{2}$. Assim como no modo seqüencial, antes de realizar essa mudança, deve ser verificado qual é quadro atual que está 
sendo transmitido e só finalizar o procedimento depois de todos os pacotes desse quadro serem transmitidos. A diferença é que no modo transparente nenhum quadro é perdido, já que C1 só deve parar quando $C_{2}$ já está estiver pronto para transmitir o quadro seguinte ao último transmitido por $C_{1}$.
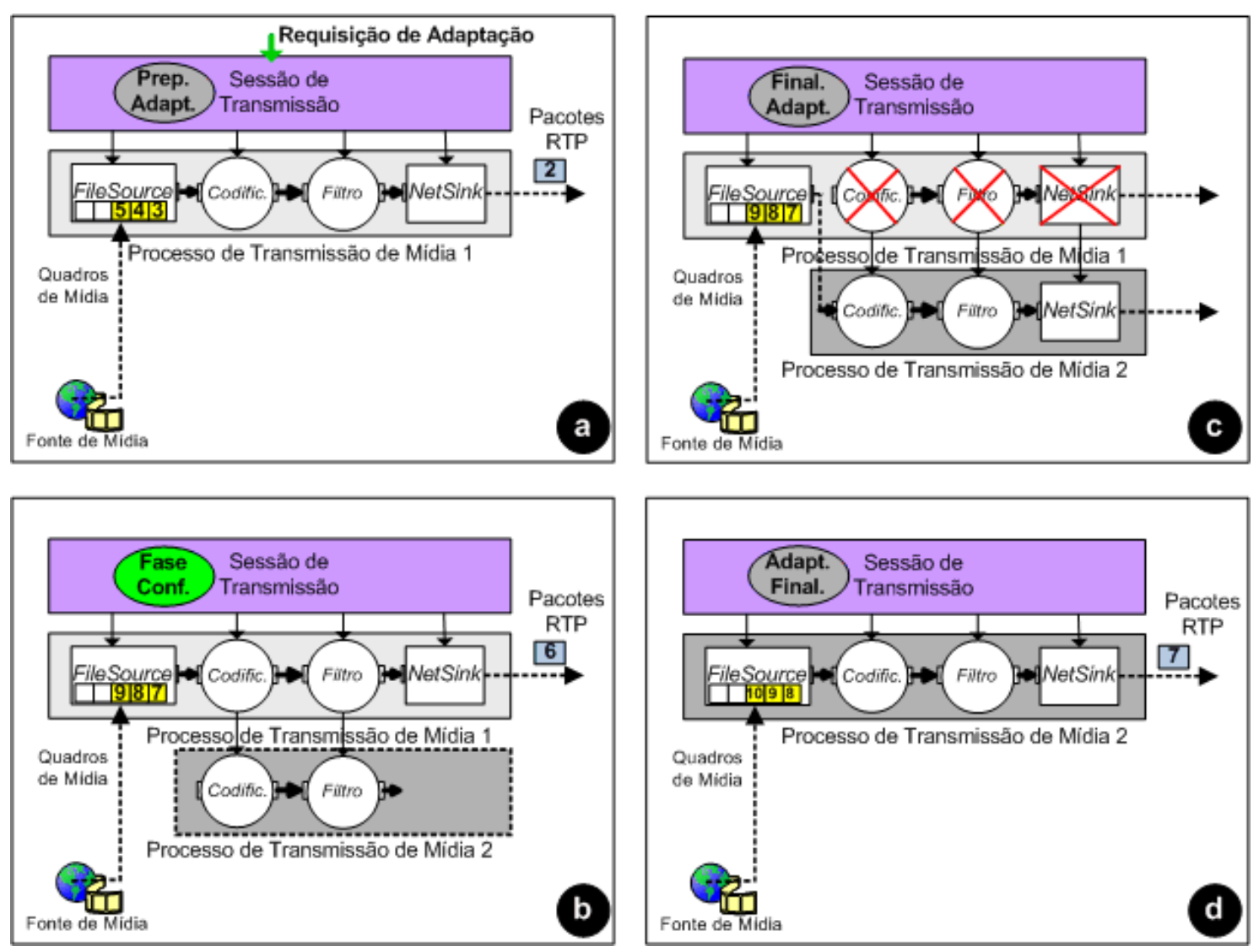

Figura 18 - Modo Transparente de Adaptação de Processo de Transmissão de Fluxos de Mídias

Nos dois modos é considerado que a Fonte de Mídia produz amostras de mídias numa dada taxa constante $f\left[\frac{1}{s}\right]$, que são enviadas para o Processo de Transmissão de Mídia $1\left(C_{1}\right)$ como quadros de mídias sincronizados de duração $\Delta t=\frac{1}{f}$. O atraso intrínseco $C_{1}$ é denotado por $\delta_{1}$ e representa o tempo necessário para $C_{1}$ processar internamente uma entrada da amostra da Fonte de Mídia e produzir uma saída que será transmitida pela rede. De forma análoga, o atraso intrínseco de $C_{2}$ é representado por $\delta_{2}$. Já o tempo necessário para destruir todos os 
componentes de $C_{1}$ é denotado por $\phi_{1}$. O novo elemento que irá substituir o primeiro, o Processo de Transmissão de Mídia $2\left(C_{2}\right)$, será construído com tempo denotado por $\sigma_{2}$.

Para analisar o desempenho e verificar formalmente uma comparação entre os dois modos de adaptação apresentamos abaixo as equações mais importantes utilizadas e extraídas do modelo analítico [SCHRADER04]. Para maiores detalhes, o apêndice A pode ser consultado. Para o modo seqüencial, temos:

$$
\begin{aligned}
& t_{\lambda}=\left\lceil\frac{\delta_{1}+\phi_{1}+\sigma_{2}}{\Delta t}\right\rceil \cdot \Delta t \\
& \lambda=\left\lceil\frac{\delta_{1}+\phi_{1}+\sigma_{2}}{\Delta t}\right\rceil \\
& t_{\gamma}=t_{\lambda}+\left(\delta_{2}-\delta_{1}\right)
\end{aligned}
$$

E para o modo transparente:

$$
\begin{aligned}
& t_{\lambda}=0 \\
& \lambda=0 \\
& t_{\gamma}=\delta_{2}-\delta_{1}
\end{aligned}
$$

Onde,

$\Delta t=$ intervalo de tempo em que cada quadro individualmente é gerado.

$t_{\lambda}=$ atraso total gasto pela adaptação no chaveamento entre $C_{1}$ e $C_{2}$

$\lambda=$ número de quadros não processados durante $t_{\lambda}$

$t_{\gamma}=$ tempo durante a adaptação em que não são transmitidos quadros

$\delta_{1}$ e $\delta_{2}=$ atraso intrínsecos de $C_{1}$ e $C_{2}$, respectivamente

$\phi_{1}=$ tempo de destruição de $C_{1}$

$\sigma_{2}=$ tempo de configuração de $C_{2}$

As equações acima, exibem como o modo de transmissão transparente possibilita uma adaptação sem maiores perdas para a qualidade de transmissão. Uma vez que nenhum quadro é 
perdido e o tempo de interrupção apenas acontecerá se o atraso intrínseco de $C_{2}$ for maior que $C_{1}$. Entretanto, uma vez que a instanciação $C_{2}$ acontece concorrentemente com a execução atual de $C_{1}$, fica claro que a implementação do modo transparente consome mais recursos computacionais do sistema transmissor, podendo inclusive, dependendo da carga no sistema, prejudicar a execução de outros processos de transmissão existentes no servidor. Dessa forma, para a escolha entre a aplicação do modo seqüencial e transparente na política de adaptação também deve ser considerada a carga atual do sistema.

\subsection{Resultados Experimentais}

A implementação de funcionalidades de adaptação normalmente considera o uso de um conjunto de políticas de adaptação. Neste trabalho, uma política de adaptação pode ser entendida como o emprego dos mecanismos de adaptação para alterar o comportamento de um processo de transmissão de uma sessão do servidor RTSP de acordo com informações dos mecanismos de monitoração (a política é aplicada de acordo com os estados definidos pela monitoração). A tabela abaixo detalha as regras utilizadas nas políticas de adaptação dos experimentos de validação do servidor RTSP adaptativo.

Tabela 4 - Políticas de Adaptação do servidor RTSP

\begin{tabular}{|l|l|l|}
\hline \multicolumn{1}{|c|}{ Política } & \multicolumn{1}{|c|}{ Condição } & \multicolumn{1}{c|}{ Procedimento } \\
\hline $\mathbf{1}$ & $\begin{array}{l}\text { TPatual = carregada OU não } \\
\text { carregada }\end{array}$ & Continuar monitoração \\
\hline $\mathbf{2}$ & $\begin{array}{l}\text { TPatual = congestionada E } \\
\text { TUatual = normal OU ocioso }\end{array}$ & $\begin{array}{l}\text { Aplicar mecanismo de adaptação } \\
\text { transparente de forma a diminuir } \\
\text { taxa de transmissão da sessão }\end{array}$ \\
\hline $\mathbf{3}$ & $\begin{array}{l}\text { TPatual = congestionada E } \\
\text { TUatual = sobrecarregado }\end{array}$ & $\begin{array}{l}\text { Aplicar mecanismo de adaptação } \\
\text { seqüencial de forma a diminuir } \\
\text { taxa de transmissão da sessão }\end{array}$ \\
\hline $\mathbf{4}$ & $\begin{array}{l}\text { TPatual = não carregada E } \\
\text { TPanterior }=\text { congestionada E } \\
\text { TUatual = normal OU ocioso }\end{array}$ & $\begin{array}{l}\text { Aplicar mecanismo de adaptação } \\
\text { transparente de forma a } \\
\text { aumentar taxa de transmissão da } \\
\text { sessão }\end{array}$ \\
\hline
\end{tabular}




\begin{tabular}{|l|l|l|}
\hline $\mathbf{5}$ & $\begin{array}{l}\text { TPatual = não carregada E } \\
\text { TPanterior = congestionada E } \\
\text { TUatual = sobrecarregado }\end{array}$ & $\begin{array}{l}\text { Aplicar mecanismo de adaptação } \\
\text { seqüencial de forma a aumentar } \\
\text { taxa de transmissão da sessão }\end{array}$ \\
\hline
\end{tabular}

Os experimentos foram através da conexão de dois computadores (fabricante Dell, modelo Optiplex GX620) pessoais numa rede local de 100MBps. A aplicação de validação escolhida para utilizar a camada de adaptação foi uma transmissão no servidor RTSP, através do RTP sobre UDP, de um arquivo de vídeo de 49 segundos, inicialmente transmitido no formato MPEG-1 (resolução 352x240, 30 quadros por segundo e taxa de codificação $1500 \mathrm{KBps}$ ), e posteriormente modificado para o formato H.263 (resolução $352 \times 240,30$ quadros por segundo,taxa de 630KBps). Utilizamos o comando "tc" para introduzir limitação de banda na saída da interface de rede do servidor e simular uma taxa de perda maior que $1 \%$ e possibilitar uma mudança imediata do estado da rede. Também foram executados algoritmos na máquina onde estava sendo executado o servidor para que a carga de utilização da CPU ultrapassasse $60 \%$.

Os gráficos apresentados abaixo ilustram o funcionamento do servidor sem ativação de nenhum mecanismo de adaptação (os mecanismos estavam propositalmente desativados), utilização da abordagem seqüencial e abordagem transparente, respectivamente. As estatísticas dos pacotes RTCP (fração de pacotes perdidos) foram recebidas num intervalo de 5 segundos e o programa para simular perda de pacotes foi iniciado depois de 7 segundos do início da transmissão do vídeo. O experimento da Figura 19 não realiza nenhuma adaptação (conseqüentemente, a taxa de erros sempre é alta) e foi possível inclusive observar a interrupção inúmeras vezes na exibição da mídia no lado do cliente. Já para os experimentos das Figura 20 e Figura 21, pôde-se claramente observar que devido ao fator perdas ser elevado as políticas de adaptação foram aplicadas (tempo 10s) e resultaram em uma modificação significativa de largura de banda utilizada pela aplicação e, consequentemente, na queda significativa da taxa de erros e possibilidade de visualização da mídia, mesmo com a rede carregada ou congestionada.

\footnotetext{
${ }^{6}$ Comando da ferramenta Netem (Network Emulator): http://developer.osdl.org/shemminger/netem/
} 
Porém, podemos notar que a adaptação seqüencial acarretou numa maior taxa de erros nos instantes posteriores ao processo de mudança do tipo de codificação utilizado, acarretando inclusive na interrupção da transmissão no instante da adaptação (tempo 11s da Figura 20) Entretanto, apesar de não exibido aqui, sua aplicação exige menos recursos computacionais do sistema.

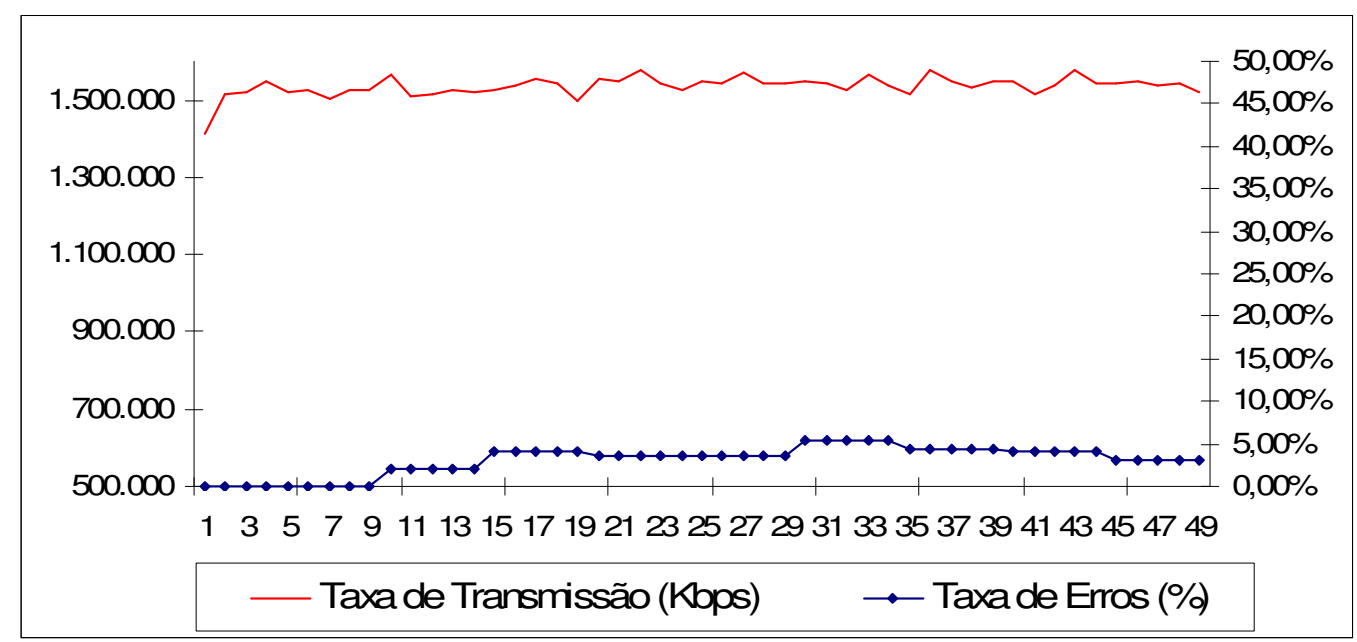

Figura 19 - Transmissão com simulação de taxa de perdas e sem adaptação

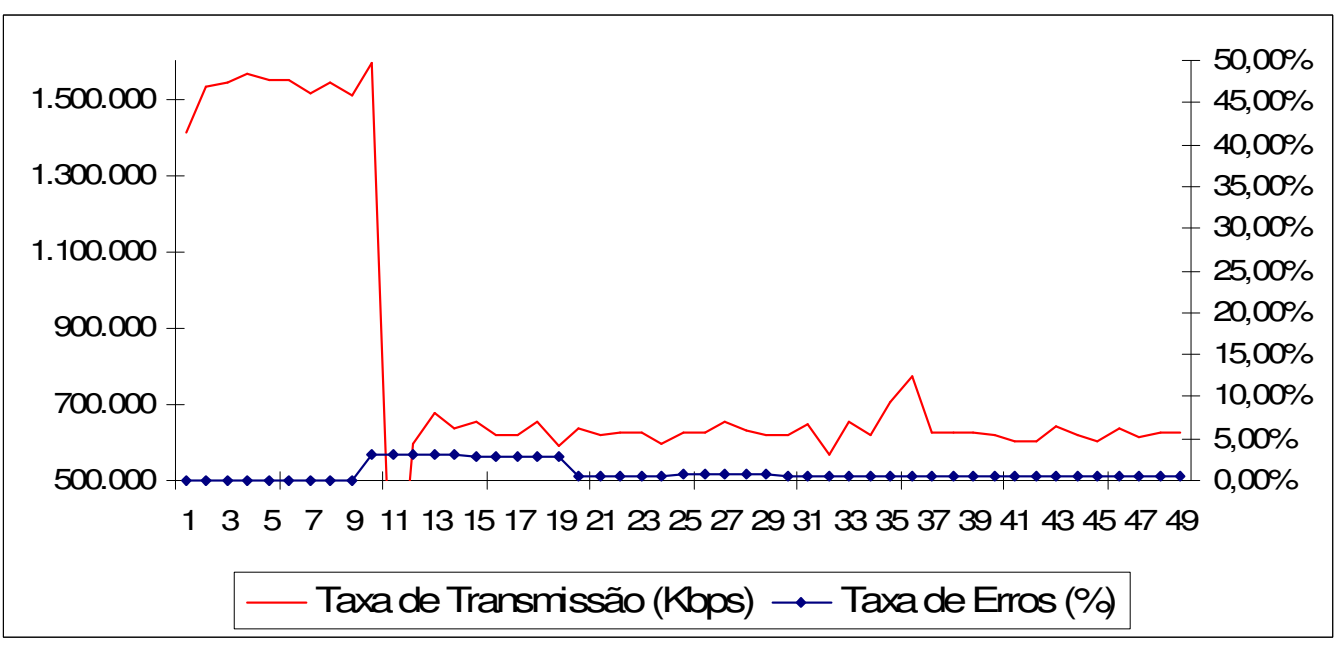

Figura 20 - Transmissão com simulação de taxa de perdas e adaptação sequencial 


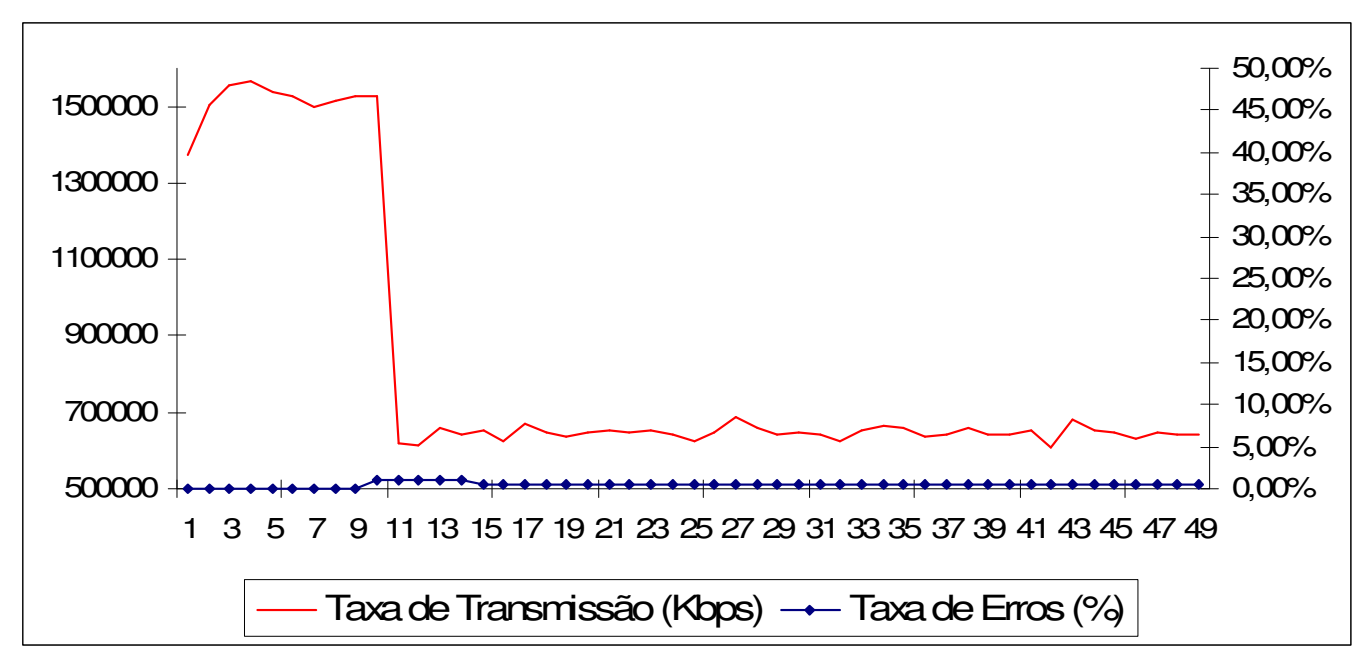

Figura 21 - Transmissão com simulação de taxa de perdas e adaptação transparente

\subsection{Trabalhos Relacionados}

Atualmente, na comunidade científica das áreas de redes de comunicação, sistemas distribuídos, sistema multimídia, engenharia de software e afins, é possível encontrar diversas abordagens que tratam o desenvolvimento de aplicações multimídia em rede com técnicas de software adaptativo. Devido à grande quantidade de propostas existentes, procuramos apresentar nesta seção apenas aquelas que têm mais proximidade com nossa proposta, apontando as principais semelhanças e diferenças.

\subsubsection{Uma Camada de Suporte à QoS para Aplicações Multimídia}

\section{na Internet}

Em [LUNARDI01] foi apresentada uma camada de adaptação de QoS para incorporar QoS em aplicações multimídia em rede, visando melhorar a qualidade dessas aplicações no cenário de operação da Internet atual. A camada possui funções de monitoração de QoS através de pacotes de controle RTCP e adaptação de QoS através da aplicação de políticas adaptativas. Como resultado, uma API baseada no Java Media Framework (JMF) [SUN_JMF] foi desenvolvida. A API oferece funções para evitar a degradação das mídias em cenários sem reserva de recursos como a Internet. A principal diferença desse trabalho em relação a nossa proposta, é que implementamos nossa camada de adaptação com POA, o que permitiu uma modularização das funcionalidades que realizam a adaptação através da separação de interesses 
transversais. Na camada proposta todo o código relacionado a adaptação encontra-se entrelaçado e espalhado pelo código da aplicação, dificultando o entendimento e manutenção adaptativa. O esquema de adaptação é baseado no servidor e no receptor.

\subsubsection{DynaVideo - Um Serviço de Distribuição de Vídeo baseado em Configuração Dinâmica}

Em [LEITE01] é apresentado um serviço de distribuição de vídeo denominado DynaVideo (Dynamic Video Distribution Service). A arquitetura do serviço foi projetada para suportar distribuição de vídeo independente de formato de codificação e interação com diversos tipos de clientes. Alem disso, o DynaVideo tem a capacidade de configurar dinamicamente a distribuição de servidores de vídeo intermediários para atender a uma determinada demanda. O DynaVideo utiliza o conceito de configuração dinâmica em componentes $\mathrm{C}++$ através da implementação direta no código dos mesmos, entretanto, não suporta adaptações de uma transmissão já iniciada. Nossa proposta, além de não tratar replicação do servidor de transmissão (aplicação com sessões de transmissão de fluxos de mídias) e adaptações localizadas em elementos da rede (refletores), procura usar a orientação a aspectos para separar a capacidade de configuração dinâmica do código dos componentes que implementam os requisitos de transmissão de fluxos de mídias.

\subsubsection{APSL - Adaptation Proxy Specification Language}

Um grupo de pesquisa do INRIA (Institut National de Recherche en Informatique et Automatique) está estudando adaptação em aplicação multimídia utilizando tecnologias baseadas em componentes e considerando vários mecanismos de adaptação [HAGIMONT03, HAGIMONT04a, HAGIMONT04b, HAGIMONT04c, HAGIMONT05]. Dentre as principais contribuições, podemos citar a proposta de um framework para possibilitar adaptações baseadas na rede em aplicações de transmissões de fluxos contínuos. O framework utiliza uma linguagem declarativa baseada em XML, Adaptation Proxy Specification Language (APSL), que funciona como um protocolo meta-objeto que permite realizar serviços de adaptação sobre processos de transmissão de mídia equivalentes ao desenvolvidos na camada de adaptação proposta por este 
trabalho. As principais diferenças em relação a nossa proposta estão: (i) na localização do código de adaptação; (ii) utilização de técnicas de desenvolvimento de software adaptativo distintas (mas com objetivos equivalentes); e (iii) uso do modelo de componentes DirectShow ${ }^{7} /$ COM [PESCE03], tornando a solução dependente de tecnologias e plataformas de execução, uma desvantagem no ambiente heterogêneo da Internet. A arquitetura de nossa camada de adaptação embora tenha sido implementada e validada em AspectJ poderia ser facilmente implementada em outras linguagens orientadas a aspectos, tais como, AspectC++.

\subsubsection{Multimedia synchronization based on AOP}

Este artigo [FURFARO03] apresenta o desenvolvimento de um mecanismo para sincronização de recepção de fluxos de mídia baseado programação orientada a aspectos com AspecJ. No trabalho também é utilizada a API Java Media Framework e foi implementado um aspecto (QoSFilter) que fica responsável pela interceptação dos pacotes de fluxos multimídia que chegam para sessões de recepção RTP. Através do tratamento dos pacotes com buffers, o QoSFilter pode realizar operações de sincronização sobre os pacotes com o objetivo de melhorar a parâmetros de QoS (por exemplo, atraso e variação de atraso) na recepção da mídia.

\subsubsection{ARE - Adaptative Runtime Enviroment}

Esta proposta apresentada em [KHAN05], também utiliza programação orientada a aspectos, mas ao invés de se limitar apenas a adaptação da sessão de recepção RTP, ela propõe um ambiente de execução adaptativo inovador, Adaptative Runtime Enviroment (ARE) que permite a inclusão e remoção de aspectos que realizam controle de QoS de forma automática e sem intervenção humana de acordo com a geração de eventos de monitoração do ambiente de operação e que implementam políticas de adaptação definidas no momento do projeto do ARE. Além de possuir a capacidade de introdução de aspectos em tempo de execução, essa proposta se diferencia da camada de adaptação proposta no nosso trabalho por endereçar a execução e

\footnotetext{
${ }^{7}$ Solução da Microsoft ${ }^{\mathrm{TM}}$ para programação de aplicações multimídia.
} 
escopo de atuação do ARE apenas para dispositivos com recursos escassos. (por exemplo, celulares).

\subsubsection{Adaptative QoS Mechanism for Multimedia Applications in}

\section{Heterogeneous Environment}

Este trabalho [DESAI01] apresentou implementações de mecanismos de adaptação que usam as abordagens baseadas em servidores e clientes e que são configurados através de políticas, estando muito próximo do trabalho apresentado na seção 4.6 .1 e apresentando os mesmos problemas em relação a separação de interesse das funcionalidades de adaptação. Adicionalmente, as técnicas de adaptação foram implementadas para cenários de sessões multicast.

\subsubsection{Structuring Adaptive Applications using AspectJ}

Este trabalho de mestrado [DANTAS04a] endereça o estudo de boas práticas para a estruturação de aplicações adaptativas utilizando AspectJ através da implementação de requisitos de adaptabilidade no domínio de aplicações para dispositivos com recursos limitados. Foram realizadas comparações com uma outra solução que utilizava apenas padrões de projeto puramente orientados a objeto para provar as vantagens de POA na implementação interesses transversais de forma modular. Adicionalmente, foi proposto um padrão arquitetural para auxiliar no desenvolvimento de aplicações adaptativas utilizando aspectos que foi chamado de Adaptability Aspects e uma integração da abordagem de aspectos para o estilo arquitetural "Adaptive Object-Models". Apesar desse trabalho não tratar mecanismos de adaptação na transmissão ou recepção de conteúdo multimídia, nos baseamos na estrutura proposta do padrão arquitetural, ressaltando que foram realizadas alterações no módulo responsável pela monitoração. 


\subsection{Resumo comparativo com trabalhos relacionados}

A Tabela 5 exibe um resumo comparativo das propostas descritas na seção anterior seguindo três critérios: localização da adaptação, técnica de projeto de software e tecnologias empregadas e tipo de mecanismos de monitoração suportados.

Tabela 5 - Resumo comparativo dos trabalhos relacionados

\begin{tabular}{|c|c|c|c|}
\hline & $\begin{array}{l}\text { Localização de } \\
\text { Adaptação }\end{array}$ & $\begin{array}{l}\text { Técnica de projeto de } \\
\text { software e tecnologias }\end{array}$ & $\begin{array}{l}\text { Mecanismos de } \\
\text { Monitoração }\end{array}$ \\
\hline LUNARDI & Servidor e Receptor & $\begin{array}{l}\text { Orientação a Objeto e } \\
\text { JMF }\end{array}$ & RTCP \\
\hline DynaVideo & Servidor e Rede & $\begin{array}{l}\text { Software Baseado em } \\
\text { Componentes e C++ }\end{array}$ & $\begin{array}{l}\text { Monitoração do Status } \\
\text { dos servidores da rede. }\end{array}$ \\
\hline APSL & Rede & $\begin{array}{l}\text { Arquitetura Reflexiva } \\
\text { com Protocolo Meta } \\
\text { objeto baseado em } \\
\text { XML } \\
\text { DirectShow/COM }\end{array}$ & $\begin{array}{l}\text { RTCP } \\
\text { Carga do Sistema }\end{array}$ \\
\hline FURFARO & Receptor & $\begin{array}{l}\text { POA com AspectJ e } \\
\text { JMF }\end{array}$ & RTCP \\
\hline ARE & Receptor & $\begin{array}{l}\text { POA com AspectJ e } \\
\text { PROSE e JMF }\end{array}$ & $\begin{array}{l}\text { RTCP } \\
\text { Carga do Sistema }\end{array}$ \\
\hline DESAI & Servidor e Rede & $\begin{array}{l}\text { Orientação a Objeto } \\
\text { com JMF }\end{array}$ & RTCP \\
\hline DANTAS & $\begin{array}{l}\text { Receptor, mas não } \\
\text { trata explicitamente } \\
\text { adaptação na recepção } \\
\text { de fluxos multimídia. }\end{array}$ & POA com AspectJ & $\begin{array}{l}\text { Não define nenhum } \\
\text { mecanismo específico. }\end{array}$ \\
\hline $\begin{array}{l}\text { Proposta de } \\
\text { Trabalho }\end{array}$ & Servidor & $\begin{array}{l}\text { POA com AspectJ e } \\
\text { JSA }\end{array}$ & $\begin{array}{l}\text { RTCP } \\
\text { Carga do Sistema } \\
\text { Estado do Servidor }\end{array}$ \\
\hline
\end{tabular}




\section{Capítulo 5}

\section{Conclusão}

Como discutido ao longo do texto, o desenvolvimento de software adaptativo compreende uma atividade complexa e, dependendo do tipo de técnicas de projeto de software utilizada, pode adicionar problemas de manutenibilidade.

Através do estudo de aplicações multimídia em rede, seus requisitos e trabalhos relacionados, pudemos observar que a implementação do requisito de adaptabilidade (como por exemplo, configuração e provimento de qualidade de serviço) é um interesse transversal e afeta várias partes dos requisitos funcionais básicos de uma aplicação e que pode conduzir ao entrelaçamento e espalhamento do seu código (code tangling e scatteging), dificultando a manutenção adaptativa. Nesse contexto, a estruturação de um programa através de programação orientada a aspecto mostrou-se como um recurso para minimizar esse problema permitindo:

- $\quad$ Separação do interesse de adaptabilidade de outros interesses, de forma a possibilitar reuso e facilidade de manutenção;

- Acoplar, desacoplar, ativar e desativar (do inglês, plug in e plug out, respectivamente) facilmente as funcionalidades de adaptabilidade, uma vez que a forma de monitorar o ambiente e o comportamento gerado por essa monitoração é bastante variável;

- $\quad$ facilidade de manutenção das funcionalidades da aplicação-base de forma independente da funcionalidade de adaptação;

- $\quad$ Possibilidade de mudanças nas políticas de monitoração e adaptação sem afetar de forma significativa a estrutura geral da aplicação-base.

\subsection{Contribuições do Trabalho}

As principais contribuição desse trabalho são a definição da arquitetura e implementação de uma camada de adaptação que possibilita a inclusão de funcionalidades de adaptação em aplicações multimídia em rede de forma modularizada e não intrusiva utilizando 
técnicas de projeto de software orientado a aspectos. Particularmente, foi utilizada a linguagem de programação AspectJ, que permitiu a captura de pontos de execução da aplicação multimídia em rede que representam locais em devem ser realizadas configurações e obtidos dados de monitoração, além do isolamento dos elementos que permitem realizar mudanças na estrutura do software e funcionalidades de forma adaptativa.

A validação da proposta foi realizada através da inclusão de mecanismos de monitoração e estratégias de configuração estática e dinâmica num servidor RTSP que utiliza a API JSA para implementar as sessões de transmissões multimídia. É importante, também lembrar, que o emprego do modelo de componentes da API JSA e uso de suas interfaces de controle também permitem um isolamento das tecnologias e protocolos utilizados para realizar os processos de transmissão de fluxos mídia.

\subsection{Trabalhos Futuros}

Indubitavelmente, uma quantidade razoável de atividades futuras devem ser realizadas para elaborar melhores soluções para os problemas tratados por este trabalho, entre os pontos complementares que podem ser tratados, destacam-se:

- Realização de experimentos e implementações adicionais para observar melhor o comportamento e desempenho da camada de adaptação e permitir utilizar técnicas de codificações de áudio ou vídeo mais recentes ou diferentes compiladores para aspectos;

- $\quad$ Análise aprofundada do desempenho das políticas de adaptação implementadas com orientação a aspectos em contraposição a implementação orientada a objeto;

- Investigação e proposta de modelo mais avançado para definição de políticas de adaptação e monitoração;

- Investigação de abordagens de adaptação distribuída (baseadas também no receptor e rede), que possibilite implementar a camada de adaptação proposta nesse trabalho em múltiplos elementos da rede. 
- $\quad$ Aprimoramento do modelo de componentes da JSA, principalmente, na melhor definição de interfaces de controle para gerenciamento de sessões e eventos, uma vez que a especificação da API ainda está em andamento e não trata bem essas funcionalidades;

- $\quad$ Implementação de um modelo de configuração de componentes da API JSA mais flexível e baseado em XML e XSD.

- Disponibilização de frameworks e bibliotecas orientadas a aspectos [KULESZA06] que possam ser reusados durante a implementação de aplicações multimídia adaptativas. 


\section{Referências Bibliográficas}

Segue abaixo as publicações referenciadas no trabalho e que são importantes para entendimento mais detalhado dos conceitos, definições e tecnologias utilizadas na proposta do trabalho.

[AGHA02] AGHA, G., Adaptive Middleware, Communications of the ACM, Vol. 45, No. 6, jun., 2002, p. 31-32.

[ASPECTJ05] The AspectJ Team. The AspectJ ${ }^{T M}$ Programming Guide. Disponível em: <http:/www.eclipse.org/aspectj>, Acesso em: 01 de jan. de 2006.

[ATMFORUM96] ATM Fórum, Audiovisual Multimedia Services: Video on Demand Specification 1. af-saa-0049.000, jan., 1996.

[BARROS05] BARROS, F. A. do R., LOQUeS, O., CORRADI, A. M. C. e SZTAJNBERG, A. Especificação e Suporte de Requisitos Não-funcionais para Serviços de Nivel Alto. In XXIII Simpósio Brasileiro de Redes de Computadores (Minicurso), Fortaleza, mai., 2005, p. 223-284.

[BLACK02] BLACK, A., HUANG, J., KOSTER, R., WALPOLE, J. e PU, C. Infopipes: an Abstraction for Multimedia Streaming. In ACM Multimedia Systems Journal. 2002.

[BLAKE98] BLAKE, S., et al. An Architecture for Differentiated Services, RFC 2475, Internet Engineering Task Force. dez., 1998.

[BOURAS05] BOURAS, C. e GKAMAS, A. Performance of Adaptive Multimedia Transmission The case of Unicast Technique. In 5th International Network Conference (INC 2005), jul., 2005, p. 121-128.

[BRADEN97] BRADEN B., ZHANG, L., BERSON, S., HERZOG, S. e JAMIN, S. Resource ReSerVation Protocol (RSVP), RFC 2205, Internet Engineering Task Force, out. 1997.

[BRANCO04] BRANCO, K.R.L.J. Índices de carga e desempenho em ambientes paralelos/distribuídos - modelagem e métricas. São Carlos: Instituto de Ciências Matemáticas e de Computação, Universidade de São Paulo (USP), 2002. 260p. Tese de Doutorado em Ciências da Computação. 
[BRAY04] BRAY, T. PAOLI, J., SPERBERG-MCQUEEN, C. M., YERGEAU, F. e MALER, E. Extensible markup language (XML) 1.0 (Third Edition), W3C recommendation, Technical report, W3C, 2004.

[BUSCHMANN96] BUSCHMANN, F., MEUNIER, R., ROHNERT H., SOMMERLAD, P. e Stal M.. A System of Patterns: Pattern-Oriented Software Architecture. John Wiley\& Sons, 1996.

[BUSSE96] BUSSE, I., DEFFNER, B. e SCHULZRINNE, H. Dynamic QoS Control of Multimedia Applications based on RTP, In Computer Communications, [s.l.], vol 19, jan., 1996, p. 49-58.

[CARLSON02] CARLSON, D. e SCHRADER, A. Seamless Media Adaptation with Simultaneous Processing. In Proceedings of the ACM Conference on Multimedia, dez., 2002.

[CHAVES04] CHAVES, R. A. Aspectos e MDA. Criando modelos executáveis baseados em aspectos. Florianópolis: Universidade Federal de Santa Catarina (UFSC), 2004, 87p. Dissertação de Mestrado em Ciência da Computação.

[CLARK90] CLARK, D. e TENNENHOUSE, D. Architectural Considerations for a New Generation of Protocols, In SIGCOMM Symposium on Communications Architectures and Protocols, IEEE Computer Communications Review, vol. 20, set. 1990, p. 200-208.

[CROWCROFT99] CROWCROFT, J., HANDLEY, M. e WAKEMAN, I. Internetworking Multimedia, Morgan Kaufmann Publishers, 1999.

[CZARNECKI00] CZARNECKI, K. e EISENECKER, U. Generative Programming, Addison-Wesley, 2000, p. 123-162.

[DANTAS03] DANTAS, A., BORBA, P. Adaptability Aspects An Architectural Pattern for Structuring Adaptive Applications with Aspects, In Proceedings of the SugarloafPlop 2003, Brasil, ago., 2003.

[DANTAS04a] DANTAS, A. Structuring Adaptive Applications Using AspectJ. Recife: Centro de Informática, Universidade Federal de Pernambuco (UFPE), 2004. 120 p. Dissertação de Mestrado em Ciência da Computação. .

[DANTAS04b] DANTAS, A., YODER, J. W., BORBA, P. e JOHNSON, R. Using Aspects to Make Adaptive Object-Models Adaptable. In Workshop Position Paper, European Conference on Object Oriented Programming, Noruega, jun., 2004.

[DESAI01] DESAI, A. N. e A., PARASHAR, M. Multimedia Content Adaptation for QoS Management over Heterogeneous Networks. International Conference on Internet Computing (IC2001), Nevada, USA, jun., 2001. 
[DIJKSTRA76] DIJKSTRA, E. W. A Discipline of Programming. Prentice-Hall, Englewood Cliffs, Nova Jersey, 1976.

[DIJKSTRA82] DIJKSTRA, E. W. Selected Writings on Computing: A Personal Perspective. Springer-Verlag, 1982. ISBN 0387906525. junho de 2006.

[ECLIPSE] Eclipse.org. Disponível em: <http://www.eclipse.org> Acesso em: 01 de

[FINEBERG03] FINEBERG, V. QoS support in MPLS networks, MPLS Forum, White Paper, mai., 2003.

[FLUCKIGER95] FLUCKIGER, F. Understanding Networked Multimedia Applications and Technology. Prentice Hall, 1995.

[FURFARO03] FURFARO, A., NIGRO, L. e PUPO, F. Multimedia synchronization based on aspect oriented programming. Microprocessors and Microsystems, 2003, p. 47-56.

[GAMMA95] GAMMA, E., HELM, R., JOHNSON, R. e VLISSIDES, J. Design Patterns: Elements of Reusable Object-Oriented Software. Addison-Wesley Publishing, 1995.

[GHEZZI91] GHEZZI, C., JAZAYERI, M. e MANDRIOLI, D. Fundamentals of Software Engineering. Prentice-Hall, Englewood Cliffs, Nova Jersey, 1991.

[GÖBEL04] GÖBEL S., POHL C., RÖTTGER S. e ZSCHALER S. The COMQUAD Component Model-Enabling Dynamic Selection of Implementations by Weaving Non-functional Aspects. In Karl Lieberherr, editor, 3rd International Conference on Aspect-Oriented Software Development (AOSD'04), ACM Press., Lancaster, UK, 22-26 mar., 2004, p. 74-82.

[GOSLING00] GOSLING, J., JOY, B.M STEELE, G., BRACHA, G. The Java Language Specification. Addison-Wesley, second edition, 2000

[GROSS98] GROSS, T. e BOLLIGER, J. A Framework-Based Approach to the Development of Network-Aware Applications, In IEEE Transactions on Software Engineering, vol. 24, no 5, mai., 1998, p. 376-389

[HAGIMONT03] ATALLAH, S. B., LAYAÏDA O, DE-PALMA, N., e HAGIMONT, D. Dynamic Configuration of Multimedia Applications. In Proceedings of the 6th IFIP/IEEE International Conference on Management of Multimedia Networks and Services, MMNS'03. Irlanda, set., 2003. 
[HAGIMONT04a] LAYAÏDA O., ATALLAH, S. B., e HAGIMONT, D. A Framework for Dynamically Configurable and Reconfigurable Network-based Media Adaptations. In Journal Of Internet Technology, Special Issue on Real Time Adaptive Media Delivery over the Internet, vol. 5, n. 4, 2004.

[HAGIMONT04b] LAYAÏDA, O., ATALLAH, S. B., e HAGIMONT, D. Adaptive Media Streaming Using Self-reconfigurable Proxies. In Proc. 7th IEEE International Conference on High Speed Networks and Multimedia Communications (HSNMC'04), Toulouse, França,, jun., 2004.

[HAGIMONT04c] LAYAÏDA O., ATALLAH, S. B., e HAGIMONT, D. Reconfiguration-based QoS Management in Multimedia Streaming Applications. In Proc.30th IEEE/Euromicro Conference, Track on Multimedia and Communications: Challenges in Distributed Multimedia Systems, Rennes, França, ago., 2004.

[HAGIMONT05] LAYAÏDA O. e HAGIMONT, D. PLASMA: A Component-based Framework for Building Self-Adaptive Applications. In Proc. SPIE/IS\&T Symposium On Electronic Imaging, Conference on Embedded Multimedia Processing and Communications, San Jose, Califórnia, jan., 2005. Sons Inc., 1994.

[HALL94] HALL, C. L. Technical Foundations of Client/Server Systems. John Wiley \&

[HANENBERG03] HANENBERG, S. e SCHMIDMEIER. Idioms for Building Software Frameworks in AspectJ. In $2^{\text {nd }}$ AOSD Workshop on Aspects, Components, and Patterns for Infrastructure Software(ACP4IS), Boston, mar., 2003

[JBOSS_AOP] JBoss Aspect-Oriented Programming Framework, Disponível em: $<$ http://www.jboss.org/products/aop>, Acesso em: 01 de junho de 2006.

[KARR01] KARR, D. A., RODRIGUES, C, LOYALL, J. P e SCHANTZ, R. E. Controlling Quality-of-Service in a Distributed Video Application by an Adaptive Middleware Framework. In Proceedings of ACM Multimedia 2001, Ottawa, Ontario, Canada. set., 2000.

[KEPHART03] KEPHART, J. O. e CHESS, D. M. The Vision of Autonomic Computing. IEEE Computer Magazine, jan., 2003.

[KHANVILKAR04] KHANVILKAR, S., BASHIR, F., SCHONFELD, D. e KHOKHAR A. Multimedia Networks and Communication. The Electrical Engineering handbook (ed. by Wai Chen), out., 2004.

[KHAN05] KHAN M. A., FISCHER, S. A Reflective Runtime Environment for Dynamic Adaptation of Streaming Media on Resource Constrained Devices. In Proceedings of the 38th Annual Hawaii International Conference on System Sciences (HICSS 2005), 2005. 
[KICZALES97] KICZALES, G., et al. Aspect-Oriented Programming. In Proceedings of the 11th European Conference on Object-Oriented Programming, LNCS (1241), SpringerVerlag, , Finlandia, 1997, p. 220-242

[KICZALES01a] KICZALES, G., et al; Getting Started with AspectJ. Communication of the ACM, 44 (10), out., 2001, p. 59-65.

[KICZALES01b] KICZALES, G., HUGUNIN, E., KERSTEN, J., PALM, M., J. e GRISWOLD, W. An Overview of AspectJ. In Proceedings of ECOOP 2001, pp. 327-353, jun., 2001.

[KINSNER02] KINSNER, W. Compression and its metrics for multimedia. In Proceedings of First IEEE International Conference on Cognitive Informatics, 2002, p. 107-121

[KON02] KON, F., COSTA, F., BLAIR, G. e CAMPBELL, R. H. "The Case for Reflective Middleware". Communications of The ACM, jun., 2002. p. 33-38.

[KOZAMERNIK02] KOZAMERNIK, F., Media Streaming over the Internet - an overview of delivery technologies. EBU Technical Review, n.292, Out, 2002.

[KULESZAa] KULESZA, U. e SILVA, D. Reengineering of the JAWS Web Server Design using Aspect-Oriented Programming. In Proceedings of the Workshop on Aspects and Dimensions of Concerns, ECOOP'2000, Cannes, França, jun., 2000.

[KULESZAb] KULESZA, U. Técnicas de Orientação a Objetos para Projeto de Sistemas Adaptáveis. São Paulo: Instituto de Matemática e Estatística, Universidade de São Paulo (USP), 2000. 184 p. Dissertação de Mestrado em Ciência da Computação.

[KULESZA04] KULESZA, U., GARCIA, A., LUCENA, C., STAA, A. V. Integrating Generative and Aspect-Oriented Technologies. In Simpósio Brasileiro de Engenheira de Software (SBES'2004), Brasília, Brasil, out., 2004, p. 130-146.

[KULESZA06] KULESZA, U., ALVES, V., GARCIA, A., LUCENA, C., BORBA, P. Improving Extensibility of Object-Oriented Frameworks with Aspect-Oriented Programming, In: Proceedings of 9th International Conference on Software Reuse (ICSR'2006), Springer Verlag, LNCS 4039, Itália, jun., 2006, p. 231-245

[KUROSE03] KUROSE, J. F. e ROSS, K. W. Redes de Computadores e a Internet: Uma nova abordagem. 1. ed. - São Paulo: Addison Wesley, 2003.

[LAVENDER96] R. LAVENDER, D. SCHMIDT. Active Object:an Object Behavioral Pattern for Concurrent Programming. In Pattern Languages of Program Design, AddisonWesley, 1996. 
[LEITE01] LEITE L. E., LEMOS G. e BATISTA T., DynaVideo - Um Serviço de Distribuição de Vídeo baseado em Configuração Dinâmica, In XIX Simpósio Brasileiro de Redes de Computadores (SBRC2001), Florianópolis, SC, mai., 2001. p. 838-852.

[LEON-GARCIA00] LEON-GARCIA, A. e WIDJAJA, I., Communication Networks: Fundamental Concepts and Key Architectures, McGraw-Hill, 2000.

[LIEBERHERR95] LIEBERHERR, K. Workshop on Adaptable and Adaptive Software. In Addendum to the Proceedings OOPSLA'95, p. 149-154. ACM Press, 1995

[LIENTZ78] LIENTZ, B. P., SWANSON, E. B. e TOMPKINS, G. E. Characteristics of Application Software Maintenance. Communications of the ACM, 1978, p. 21(6)466-471.

[LOUGHRAN05] LOUGHRAN N., PARLAVANTZAS, N., PINTO, M., SÁNCHEZ, P., WEBSTER, M. e COLYER. A. Survey of Aspect-Oriented Middleware. AOSD-Europe Project Deliverable No: AOSD-Europe-ULANC-10, jun., 2005.

[LUNARDI01] LUNARDI, S. C., Uma Camada de Suporte a Qualidade de Serviço para Aplicações Multimídia na Internet. Porto Alegre: Pontifícia Universidade Católica do Rio Grande do Sul (PUC-RS), 2001. 110 p. Dissertação de Mestrado em Ciência da Computação.

[LYYTINEN02] LYYTINEN, K. e YOO, Y. Issues and challenges in ubiquitous computing. Communications of the ACM, 2002, p. 45(12)62-65

[MA02] MA, H. e SHIN, K. G., Multicast Video-on-Demand Services. In ACM Computer Communication Review, vol. 32, no. 1, jan., 2002.

[MAES87] MAES, P. Concepts and Experiments in Computational Reflection. In Proc. ACM Conf. Object-Oriented Programming Systems, Languages, and Applications (OOPSLA), ACM Press, 1987, p. 147-155.

[MARGI00] MARGI, C. B. Um mecanismo para distribuição segura de vídeo MPEG. São Paulo: Escola Politécnica, Universidade de São Paulo (USP), 2000. 126 p. Dissertação de Mestrado em Engenharia Elétrica.

[MCKINLEY04] MCKINLEY, P. K., SADJADI S. M., KASTEN, E. P. e CHENG, B. H. C. A Taxonomy of Compositional Adaptation. Technical Report MSU-CSE-04-17, Department of Computer Science and Engineering, Michigan State University, East Lansing, Michigan, 2004.

[MPEG] The MPEG HomePage, Disponível em: $<$ http://www.chiariglione.org/mpeg>.Acesso em: 01 de jan. de 2006. 
[MPEG94] INTERNATIONAL ORGANIZATION FOR STANDARDIZATION. Coding of Moving Pictures and Associated Audio (ISO/IEC), MPEG-2 Video, 1994, ISO/IEC IS $13818-2$.

[MPEG00] INTERNATIONAL ORGANIZATION FOR STANDARDIZATION. Coding of Moving Pictures and Associated Audio (ISO/IEC), MPEG-2 Systems, 2000, ISO/IEC 13818-1.

[PARNAS72] PARNAS, D. L. On the Criteria To Be Used in Decomposing Systems into Modules. Communications of the ACM, vol. 15, 1972, p. 1053-1058.

[PERKINS03] PERKINS, C., RTP: Audio and Video for the Internet, Addison Wesley, 2003. ISBN 0-672-32249-8

[PEYMAN99] OREIZY, P. e GORLICK, M. M. An Architecture-Based Approach to Self-Adaptive Software. IEEE Intelligent Systems, mai., 1999, p. 14(3)54-62.

[PESCE03] PESCE, M. D. (2003). Programming Microsoft DirectShow for Digital Video and Television. Microsoft Press, 2003, ISBN 0-7356-1821-6.

[PIVETA01] PIVETA, E. Um Modelo de Suporte a Programação Orientada a Aspectos. Florianópolis: Universidade Federal de Santa Catarina (UFSC), 2001. Dissertação de Mestrado em Ciência da Computação.

[RFC2068] FIELDING, R. e GETTYS, J., MOGUL, J., NIELSEN, H. e BERNERSLEE, T., Hypertext transfer protocol - HTTP/1.1, RFC2068, IETF, jan., 1997.

[RFC2326] SCHULZRINNE, H., RAO, A. e LANPHIER, R., Real Time Streaming Protocol (RTSP), RFC2326, IETF, abr. 1998.

[RFC3060] MOORE, B., et al. Policy Core Information Model -- Version 1 Specification. RFC 3060, IETF, fev. 2001.

[RFC3460] MOORE, B., et al. Policy Core Information Model Extensions Extensions, RFC 3460, IETF, jan. 2003.

[RFC3550] SCHULZRINNE, H., CASNER, S., FREDERICK, R. e JACOBSON, V., RTP: A Transport Protocol for Real-Time Applications, RFC 3550, IETF, jul., 2003.

[RFC3551] SCHULZRINNE, H. e CASNER, S. RTP Profile for Audio and Video Conference with Minimal Control. RFC 3551, IETF jul., 2003. 
[RFC2327] HANDLEY, M. e V. JACOBSON, SDP: Session description protocol, RFC 2327, IETF, abr.,1998.

[RODRIGUEZ02] MOURA, A. L., URURAHY, C., CERQUEIRA, R., e RODRIGUEZ, N. Dynamic Support for Distributed Auto-adaptive Applications. In Workshop on Aspect Oriented Programming for Distributed Computing, Vienna, jul. 2002, p. 451-458.

[SCHRADER04] SCHRADER, A. e CARLSON D. Mechanism for transmission of time-synchronous data. US 2004/008626 A1, jan., 2004.

[SCHMIDT01] SCHMIDT, D., STAL, M., ROHNERT, H. e BUSCHMANN, F., Pattern-Oriented Software Architecture, vol. 2. John Wiley, 2001.

[SILVA03] SILVA, F. J. S., ENDLER, M. Endler, KON, F. Developing Adaptive Distributed Applications a Framework Overview and Experimental Results. In International Symposium on Distributed Objects and Applications, Proceedings of the 5th International Symposium on Distributed Objects and Applications. Heidelberg : LNCS - Springer-Verlag, v. 2888, 2003. p. 1275-1291

[SILVEIRA00] SILVEIRA, R. M. Técnica para ajuste dos coeficientes de quantização da compressão MPEG em tempo-real. São Paulo: Escola Politécnica, Universidade de São Paulo (USP), 2000. 119 p. Tese de Doutorado em Engenharia Elétrica.

[SMETENA04] SMETANA, G. M. M. A., Um sistema de conferência centralizada com controle de posse da palavra para educação à distância. São Paulo: Escola Politécnica, Universidade de São Paulo (USP), 2004. 285 p. Dissertação de Mestrado em Engenharia Elétrica.

[STAEHLI04] STAEHLI, R., ELIASSEN, F. e AMUNDSEN, S., Designing Adaptive Middleware for Reuse, In Middleware 2004 Companion, 3rd Workshop on Reflective and Adaptive Middleware, out., 2004.

[STALLINGS02] STALLINGS, W., High-Speed Networks and Internets Performance and Quality of Service, Prentice-Hall, 2002.

[STEINMETZ95] STEINMETZ, R. e NAHRSTEDT, K., Multimedia: "Computing, communications and applications. Prentice Hall, 1995.

[SUN_JCP] Java Community Process. Disponível em: <http://www.jcp.org> Acesso em: 01 de junho de 2006.

[SUN_JMF] Sun Microsystems. Java Media Framework. Disponível em $<$ http://java.sun.com/products/java-media/jmf/ > . Acesso em: 01 de junho de 2006. 
[SUN_JNI] Sun Microsystems. Java Native Interface. Disponível em: $<$ http://java.sun.com/j2se/1.4.2/docs/guide/jni/>. Acesso em: 01 de junho de 2006.

[SUN_JSAa] Sun Microsystems. Java Stream Assembly API Programmer's Guide. 2004. Disponível em: <http://www.jcp.org/> Acesso em: 01 de junho de 2006.

[SUN_JSAb] Sun Microsystems. Using Java Stream Assembly API (JSR158) in TV Services, JavaOne, 2003.

[SUN_J2SE] Sun Microsystems, Java 2 Platform Standard Edition. Disponível em: $<$ http://java.sun.com/javase/> Acesso em: 01 de junho de 2006.

[SZYPERSKI02] SZYPERSKI C., Component Software: Beyond Object-Oriented Programming, $2^{\mathrm{a}}$ edição, Addison-Wesley, 2002.

[TANEMBAUM_03] TANEMBAUM, A.S., Computer Networks. 4th ed., Prentice Hall PTR, 2003.

[TARR99] TARR, P., et al. N Degrees of Separation: Multi-Dimensional Separation of Concerns. Proceedings of the 21st International Conference on Software Engineering, ACM Press, Los Angeles, EUA, pp. 107-119, 1999.

[TEKINER97] TEKINERDOGAN, B. e AKSIT, M. Adaptability in Object-Oriented Software Development. ECOOP'96 Workshop Report, in M. Muhlhauser (ed), Special issues in Object-Oriented Programming, Dpunkt, Heiderlberg, 1997.

[TRIPATHI02] TRIPATHI, A., Challenges Designing Next-Generation Middleware Systems. Communications of the ACM, jun., 2002. p. 45(6):39-42.

[VANDALORE00] VANDALORE, B., FENG, W., JAIN, R. e FAHMY, S. A Survey of Application Layer Techniques for Adaptive Streaming of Multimedia. Journal of Real Time Systems (Special Issue on Adaptive Multimedia). jan., 2000.

[VENKATASUBRAMANIAN02] VENKATASUBRAMANIAN, N., Safe 'Composability' of Middleware Services, Communications of the ACM, Jun., 2002. Vol. 45, No. 6, pp. 49-52.

[VOGEL95] VOGEL, L., KERHERVÉ, B., BOCHMANN, G., GECSE, J. Distributed Multimedia and QoS: A Survey, IEEE Multimedia, 1995. pp. 10-19.

[WANG99] WANG, X. e SCHULZRINNE, H., Comparison of Adaptive Internet Multimedia Applications. IEICE Transactions on Communications, Vol. E82-B, No. 6, jun., 1999, p. 806-818. 
[WEISER93] WEISER, M., Hot Topics: Ubiquitous Computing, IEEE Computer Magazine, out., 1993.

[YODER98] FOOTE, B. e YODER, J. W. Metadata and Active Object-Models. Collected papers from the PLoP '98 and EuroPLoP ' 98 Conference Technical Report, Dept. of Computer Science, Washington University, set. 1998, pp. 98-25.

[YODER01] YODER, J. W., BALAGUER, F. e Ralph JOHNSON, R. Architecture and Design of Adaptive Object-Models. ACM SIGPLAN Notices, 2001. p. 36(12):50-60. 


\section{Apêndice A}

\section{Modelo Analítico para Adaptação de Processos}

\section{de Transmissão de Mídias}

Neste apêndice apresentamos detalhadamente o modelo analítico apresentado em [SCHRADER04] e que se baseamos para implementar um dos mecanismos de adaptação que a camada proposta neste trabalho utiliza no servidor RTSP e em componentes de transmissão JSA.

\section{Abordagem Convencional}

Na abordagem convencional, o processo de transmissão de fluxo inicial é descontruído antes que um novo processo seja construído. Durante este intervalo, alguns dados são perdidos, apresentando um intervalo de vazio no fluxo de saída.

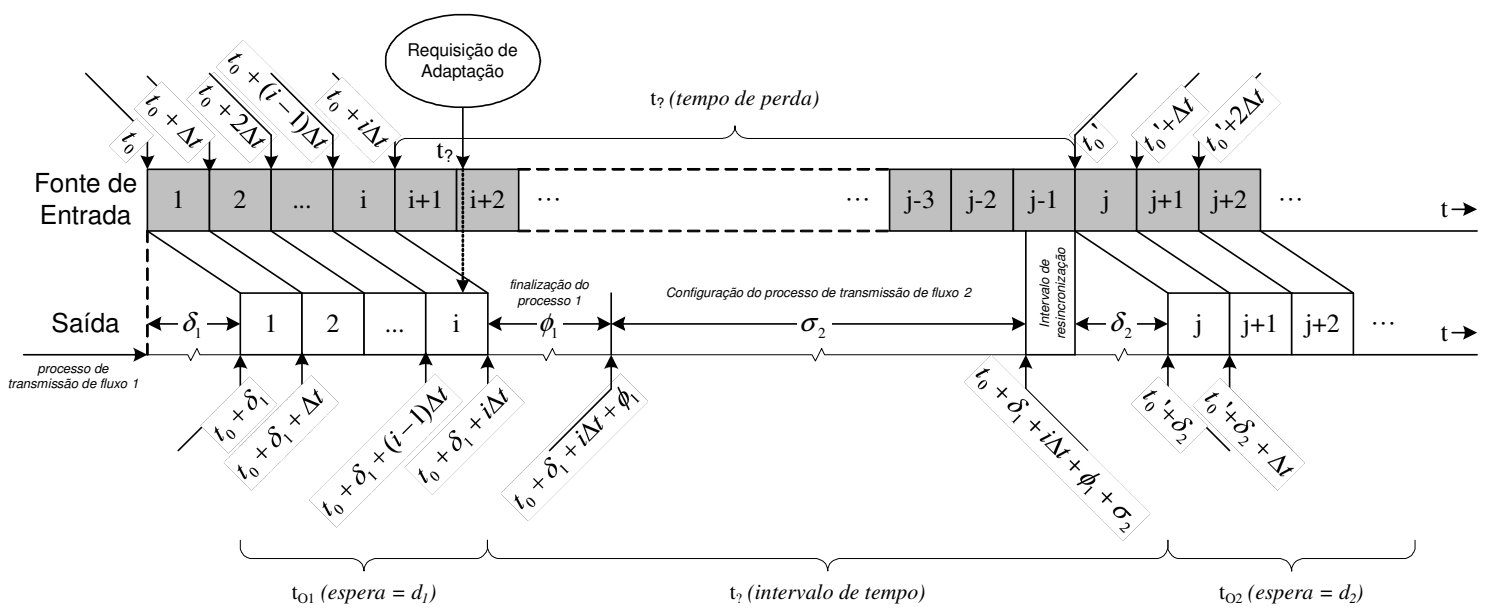

Figura 22 - Adaptação convencional de processos de transmissão de mídia através da construção seqüencial

A Figura 22 mostra como o processo de adaptação de mídias é realizado normalmente. Uma fonte de mídia (por exemplo, uma câmera) gerando quadros de vídeo não codificados a uma taxa de $\mathrm{f}[1 / \mathrm{s}]$ é usada como entrada I no processo de transmissão de fluxo $C_{1}$. Considerando esta entrada como conjunto de quadros sincronizados de comprimento $\Delta_{t}=1 / \mathrm{f}$, 
estes estarão disponíveis para os processos de transmissão de fluxo nos intervalos síncronos de tempo $\left\{t_{0}, t_{0}+\Delta_{t}, t_{0}+2 . \Delta_{t}, \ldots.\right\}$

O tempo necessário para fazer o processamento de um fluxo $C i$ (o qual envolve operações dos codecs, filtros, buffers, empacotamento e desempacotamento e todos os recursos relacionados) é denotado como $\sigma_{\mathrm{i}}$. É assumido que o processo de fluxo de transmissão $C_{1}$ já está configurado no instante de tempo $t_{0}$ e o quadro 1 é o primeiro a ser processado. $\mathrm{O}$ atraso intrínseco do processo de transmissão de fluxo $C i$ é denotado como $\delta i$, que é o tempo necessário para processar uma entrada e criar sua saída. As saídas dos processos de transmissão de fluxo são assim geradas nos instantes de tempo $\left\{t_{0}+\delta_{1}, t_{0}+\delta_{1}+\Delta_{t}, t_{0}+\delta_{1}+2 . \Delta_{t}, \ldots.\right\}$. Na Figura $22 \mathrm{t}_{\mathrm{r}}$ representa o instante de tempo em que uma requisição de adaptação foi realizada, tendo esta ocorrida na saída no quadro de número $i$. Após este instante de tempo, as cadeias de processamento de fluxo são fechadas.

$\phi_{1}$ é denotado como o tempo necessário para liberar todos os recursos. Logo, o processo inicialmente em execução é finalizado em $t_{0}+\delta_{1}+i \cdot \Delta_{t}$. Neste momento é iniciado o processo de construção da nova cadeia de processamento $C_{2}$, a qual demanda $\sigma_{2}$ segundos para ser concluída. Para evitar grandes buffers e atrasos, é assumido que o processamento dos quadros não pode ser realizado mais rápido que em tempo real, isto é, que o processamento de um quadro de entrada só pode ser iniciado após a chegada de um quadro novo completo. Na figura, o próximo quadro disponível após a requisição de adaptação é o quadro de número $j$.

O novo processo de transmissão de fluxo começa a consumir a fonte descomprimida de vídeo no instante de tempo $t^{\prime}{ }_{0}$ e devido ao intervalo de atraso $\delta_{2}$, a primeira saída é disponível no instante $t^{\prime}{ }_{0}+\delta_{2}$. Durante o intervalo de tempo (gap time) $\left[t_{0}+\delta_{1}+i . \Delta_{t}, t^{\prime}{ }_{0}+\delta_{2}\right]$ nenhuma saída é produzida. Este intervalo de tempo é denotado como t $\mathrm{t}_{\gamma} \mathrm{O}$ início da cadeia $C_{2}$ pode ser calculada como:

$$
t_{0}^{\prime}=t_{0}+\left\lceil\frac{\delta_{1}+i \cdot \Delta_{t}+\phi_{1}+\sigma_{2}}{\Delta_{t}}\right\rceil \cdot \Delta_{t}=t_{0}+\left\lceil i+\frac{\delta_{1}+\phi_{1}+\sigma_{2}}{\Delta_{t}}\right\rceil \cdot \Delta_{t}(1)
$$

Com $t^{\prime}{ }_{0}=t_{0}+(j-1) . \Delta_{\mathrm{t}}$, pode ser determinado o primeiro quadro a ser processado pela novo fluxo de processamento: 


$$
j=i+\left\lceil\frac{\delta_{1}+\phi_{1}+\sigma_{2}}{\Delta_{t}}\right\rceil+1
$$

Com $\mathrm{t}_{\lambda}=(j-1) \cdot \Delta_{\mathrm{t}}-i \cdot \Delta_{\mathrm{t}}$, obtém-se o tempo de perda $\mathrm{t}_{\lambda}$ :

$$
t_{\lambda}=\left\lceil\frac{\delta_{1}+\phi_{1}+\sigma_{2}}{\Delta_{t}}\right\rceil \cdot \Delta_{t}(3)
$$

Também pode ser determinado o número de pacotes não processados durante este período de tempo:

$$
\lambda=j-1-i=\left\lceil\frac{\delta_{1}+\phi_{1}+\sigma_{2}}{\Delta_{t}}\right\rceil
$$

O intervalo de tempo $t_{\gamma}$, o qual refere-se ao intervalo no qual nenhuma saída é produzida durante o processo de adaptação pode ser obtido através de:

$$
t_{\lambda}=t_{0}^{\prime}+\delta_{2}-\left(t_{0}+\delta_{1}+i \cdot \Delta_{t}\right)=\left\lceil\frac{\delta_{1}+\phi_{1}+\sigma_{2}}{\Delta_{t}}\right\rceil \cdot \Delta_{t}+\left(\delta_{2}-\delta_{1}\right)
$$

No caso convencional, o tempo $t_{\alpha}$ necessário para atender a requisição de adaptação é exatamente o intervalo de tempo $t_{\gamma}: t_{\alpha}=t_{\gamma}$. Dependendo do tempo de configuração de $C_{2}$ a adaptação não somente será lenta, como também irá resultar na perda de alguns quadros.

\section{Abordagem Transparente}

Esta abordagem melhora significantemente o tempo de adaptação através do uso de processos simultâneos, minimizando atraso e perda apresentados anteriormente pela abordagem 
convencional.

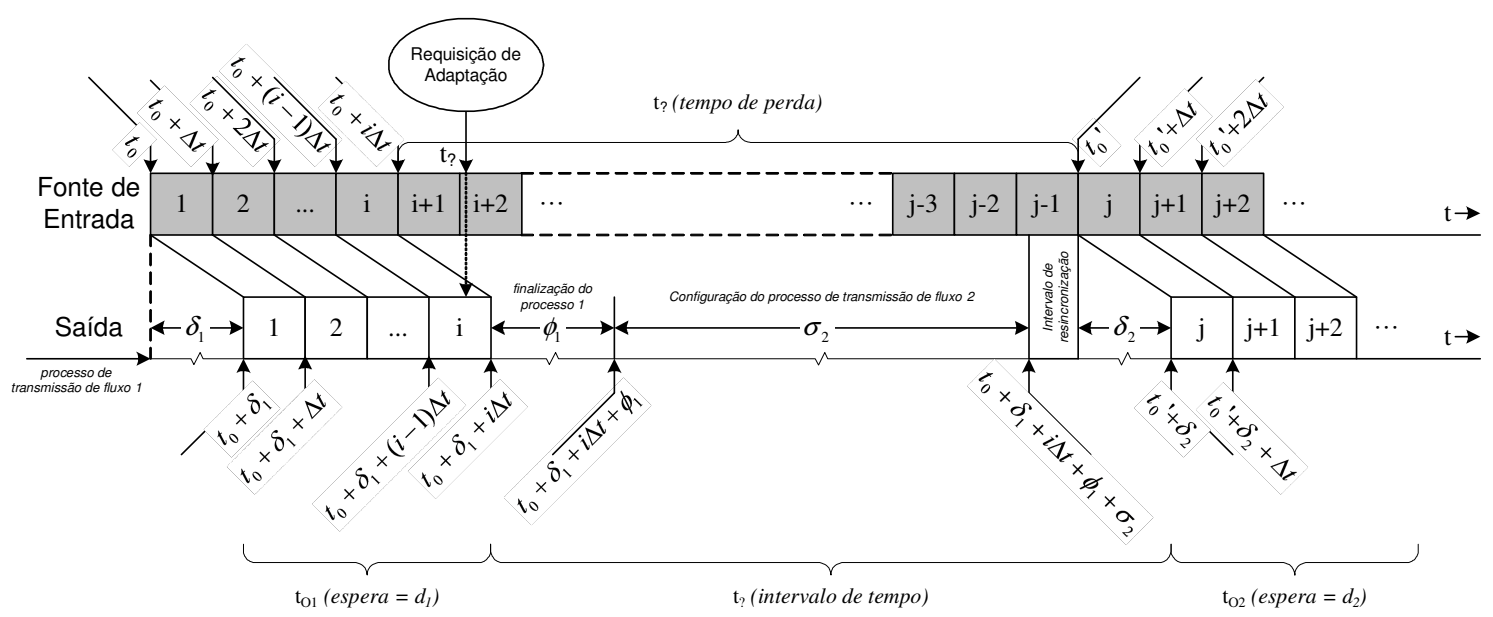

Figura 23 - Adaptação transparente de processos de transmissão de mídia através da construção simultânea

A Figura 23 apresenta esta nova abordagem. No que se refere aos dados de entrada, as mesmas condições apresentadas para a abordagem anterior são consideradas.

Da mesma forma $t_{\mathrm{r}}$ representa o instante de requisição da adaptação. Porém, na nova abordagem, o processo de transmissão de fluxo corrente não é finalizada imediatamente e a configuração do novo processo de transmissão de fluxo $C_{2}$ é realizada em paralelo. Da mesma forma, $\sigma_{2}$ é o tempo em segundos para a configuração de $C_{2}$ e $j$ é o número do primeiro quadro gerado após a requisição de adaptação. O instante de tempo em que este quadro é produzido também é representado por $t^{\prime}{ }_{0}$. Agora, o primeiro quadro processado após a requisição de adaptação passa a ser disponibilizado em $t^{\prime}{ }_{0}+\delta_{2}$.

Uma vez que a configuração do processo de transmissão de fluxo $C_{2}$ é realizada em paralelo, $\mathrm{C}_{1}$ enquanto isso, ainda produz os dados comprimidos (incluindo o quadro $j$-1). Dado que $\mathrm{C}_{2}$ começa a processar a saída a partir do quadro de número $j$, neste modelo, nenhum quadro será perdido. Uma vez que $\phi_{1}=0$ o tempo de início de $\mathrm{C}_{2}$ pode ser calculado como:

$$
t^{\prime}{ }_{0}=t_{0}+\left\lceil\frac{\delta_{1}+i \cdot \Delta_{t}+\sigma_{2}}{\Delta_{t}}\right\rceil \cdot \Delta_{t}=t_{0}+\left\lceil i+\frac{\delta_{1}+\sigma_{2}}{\Delta_{t}}\right\rceil \cdot \Delta_{t}(6)
$$


Com $t^{\prime}{ }_{0}=t_{0}+(j-1) . \Delta_{\mathrm{t}}$, pode ser determinado o primeiro quadro a ser processado pelo novo processo de transmissão de fluxo $\left(C_{2}\right)$ através de:

$$
j=i+\left\lceil\frac{\delta_{1}+\sigma_{2}}{\Delta_{t}}\right\rceil+1(7)
$$

O intervalo de tempo pode ser determinado através de:

$$
t_{\lambda}=t^{\prime}{ }_{0}+\delta_{2}-\left(t_{0}+\delta_{1}+(j-1) \cdot \Delta_{t}\right)=\delta_{2}-\delta_{1}
$$

No caso de $\delta_{2}>\delta_{1}$, será verificado um pequeno intervalo de tempo, o qual pode ser compensado com o uso de buffers. Estes buffers seriam usados de qualquer forma para a compensação de jitter. Este intervalo de tempo é inerente às características do processo e é baseado na diferença de atraso entre os codecs. Se $\delta_{2}<\delta_{1}$, a saída do processo de transmissão de fluxo $C_{2}$ estará disponível antes mesmo da saída do processo de transmissão de fluxo anterior. Neste caso, recai para o algoritmo decidir quando será realizado o chaveamento para os quadros do novo processo de transmissão de fluxo. Uma solução poderia ser realizar o chaveamento no momento em que a saída de $\mathrm{C}_{2}$ gera uma taxa de dados menor. Independentemente, em ambos os casos, nenhum quadro é perdido e por isso:

$$
t_{\lambda}=0, \lambda=0(9)
$$

$\mathrm{Na}$ abordagem transparente, $\mathrm{o}$ tempo de adaptação $\mathrm{t}_{\alpha}$ é também mais curto, podendo ser obtido através de:

$$
t_{\alpha}=t_{0}^{\prime}+\delta_{2}-\left(t_{0}+\delta_{1}+i \cdot \Delta_{t}\right)=t_{0}+\left\lceil i+\frac{\delta_{1}+\sigma_{2}}{\Delta_{t}}\right\rceil \cdot \Delta_{t}+\delta_{2}-t_{0}-\delta_{1}-i \cdot \Delta_{t}=\left\lceil\frac{\delta_{1}+\sigma_{2}}{\Delta_{t}}\right\rceil \cdot \Delta_{t}+\left(\delta_{2}-\delta_{1}\right)
$$

